\title{
Development of $\boldsymbol{N}-\mathrm{F}$ fluorinating agents and their fluorinations: Historical perspective
}

\author{
Teruo Umemoto*, Yuhao Yang and Gerald B. Hammond ${ }^{*}$
}

\author{
Review \\ Address: \\ Department Chemistry, University of Louisville, Lousiville, Kentucky \\ 40292, USA \\ Email: \\ Teruo Umemoto* - teruo.umemoto@louisville.edu; \\ Gerald B. Hammond* - gb.hammond@louisville.edu \\ * Corresponding author \\ Keywords: \\ $\mathrm{N}-\mathrm{F}$ fluorinating agent; fluorination; fluorodiazoniabicyclo[2.2.2]octane \\ salt; fluoropyridinium salt; fluorosulfonimide
}

\author{
Beilstein J. Org. Chem. 2021, 17, 1752-1813. \\ https://doi.org/10.3762/bjoc.17.123 \\ Received: 24 March 2021 \\ Accepted: 06 July 2021 \\ Published: 27 July 2021 \\ This article is part of the thematic issue "Organo-fluorine chemistry V". \\ Guest Editor: D. O'Hagan \\ (C) 2021 Umemoto et al.; licensee Beilstein-Institut. \\ License and terms: see end of document.
}

\begin{abstract}
This review deals with the historical development of all $\mathrm{N}$-F fluorinating agents developed so far. The unique properties of fluorine make fluorinated organic compounds attractive in many research areas and therefore fluorinating agents are important. $N$-F agents have proven useful by virtue of their easy handling. This reagent class includes many types of $N$-F compounds: perfluoro- $N$-fluoropiperidine, $\mathrm{N}$-fluoro-2-pyridone, $\mathrm{N}$-fluoro- $\mathrm{N}$-alkylarenesulfonamides, $\mathrm{N}$-fluoropyridinium salts and derivatives, $\mathrm{N}$-fluoroquinuclidium salts, $N$-fluoro-trifluoromethanesulfonimide, $N$-fluoro-sultams, $N$-fluoro-benzothiazole dioxides, $N$-fluoro-lactams, $N$-fluoro-o-benzenedisulfonimide, $N$-fluoro-benzenesulfonimide, 1-alkyl-4-fluoro-1,4-diazoniabicyclo[2.2.2] octane salts, $N$-fluoropyridinium-2-sulfonate derivatives, 1-fluoro-4-hydroxy-1,4-diazoniabicyclo[2.2.2]octane salts, $N$-fluorodinitroimidazole, $N$-fluoro-trichloro-1,3,5-triazinium salt, $N$-F ethano-Tröger's base derivatives, $N$-fluoro-methanesulfonimide, $N$-fluoro- $N$-arylarenesulfonamides, bis $N$-F salts such as $N, N^{\prime}$-difluorobipyridinium salts and $N, N$ '-difluoro-1,4-diazoniabicyclo[2.2.2] ]octane salts, and their many derivatives and analogs, including chiral $N$-F reagents such as optically active $N$-fluoro-sultam derivatives, $N$-fluoroalkaloid derivatives, DABCO-based $N$-F derivatives, and $N$-F binaphthyldisulfonimides. The synthesis and reactions of these reagents are described chronologically and the review also discusses the relative fluorination power of each reagent and their mechanisms chronicling developments from a historical perspective.
\end{abstract}

\section{Introduction}

Fluorinated organic compounds occupy an important position in pharmaceuticals [1], agrochemicals [2], and materials [3]. Especially, in the first two areas, the presence of fluorine has attracted attention during the last decades. Nowadays, a considerable number of medicines [4,5] and agrochemicals [6] contain at least one fluorine atom in their structures. The fluorine atom has unique properties such as the highest electronegativity, extremely low polarization, strong $\mathrm{C}-\mathrm{F}$ bonds, and the smallest size after a hydrogen atom [7]. Thus, introduction of fluorine into selective positions of a bioactive compound can produce 
remarkable changes in efficacy. Fluorine-scan/fluorine editing of a lead molecule is now a routine step in drug discovery [8]. Organofluorine compounds are very rare in nature [9] and therefore without natural compounds, chemical processes are required to generate building blocks. Molecular fluorine $\left(\mathrm{F}_{2}\right)$ is a useful fluorinating reagent, however, unlike $\mathrm{Cl}_{2}$ and $\mathrm{Br}_{2}, \mathrm{~F}_{2}$ is extremely reactive, toxic, and corrosive and its handling requires specialist skills and equipment. Therefore, easy-tohandle and selective fluorinating agents are essential for the wide-spread advancement of organofluorine chemistry to nonspecialist chemists. Alternatives to $\mathrm{F}_{2}$, such as perchloryl fluoride $\left(\mathrm{FClO}_{3}\right)$ [10] and the $O$-F reagents such as $\mathrm{CF}_{3} \mathrm{OF}$ [11], $\mathrm{CF}_{2}(\mathrm{OF})_{2}$ [11], $\mathrm{CsOSO}_{2} \mathrm{OF}$ [12], $\mathrm{CF}_{3} \mathrm{COOF}$ [13], and $\mathrm{CH}_{3} \mathrm{COOF}$ [14] have been used as fluorinating agents for many years. However, these reagents have significant risks for safe handling. Although $\mathrm{XeF}_{2}$ [15] was considered as a safer alternative, it is expensive because of the scarcity of $\mathrm{Xe}$ in nature. The appearance of the safe and easy-to-handle $N$-F fluorinating agents described in this review have brought about a breakthrough in synthetic fluorine chemistry enabling an increasing number of researchers to engage in organofluorine chemistry. Their development has significantly contributed towards the current 'golden age' of fluorine chemistry. The $N$-F fluorinating agents now stand out as particularly useful electrophilic or radical fluorinating agents by virtue of their easy handling, efficiency, and selectivity. These non-hygroscopic nature and stability make them easier to handle than nucleophilic fluoride reagents. Potassium fluoride (KF) and naked fluoride anion salts are extremely sensitive to moisture, while HF seriously attacks human skin. The $N$-F fluorinating agents can be classified into two categories: these are neutral and cationic. This review covers the chronological advancement of these reagents regardless of their classification, as they advanced side by side.

\section{Review}

\section{Historical progress of $N-F$ fluorinating agents}

\section{1-1. Perfluoro- $N$-fluoropiperidine}

The history of the $N$-F compounds acting as fluorine atomtransfer reagents can be traced back to 1964 when Banks and co-worker [16] first reported that perfluoro- $N$-fluoropiperidine (1-1) could fluorinate the sodium salt of 2-nitropropane to form 2-fluoro-2-nitropropane in a $40 \%$ yield (Scheme 1). The reaction with sodium diethyl malonate was also reported to produce the difluoromalonate, but in a very low yield of ca. $5 \%$.

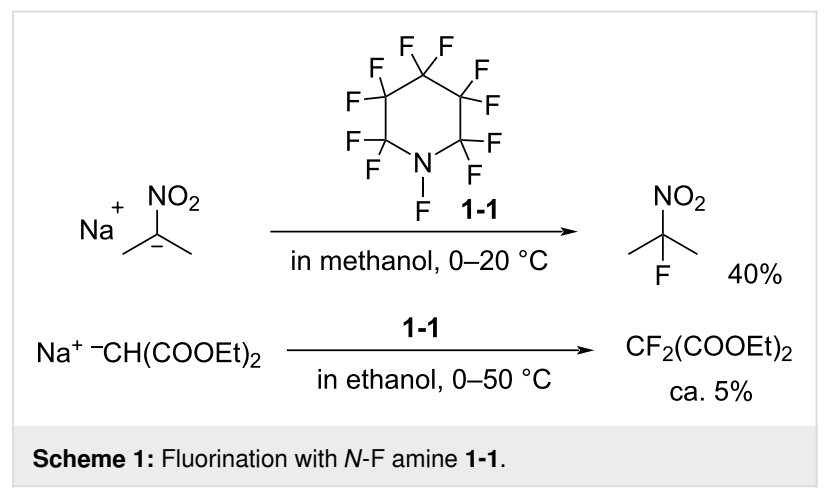

$\mathrm{N}$-F amine 1-1 is very volatile (bp $49.5{ }^{\circ} \mathrm{C}$ ), and could only be prepared in $7.5 \%$ or $13 \%$ yield by electrochemical fluorination of pyridine or 2-fluoropyridine in anhydrous hydrogen fluoride $[17,18]$ (Scheme 2). Not surprisingly, 1-1 did not become a popular reagent.

In 1967, Banks et al. reported reactions of 1-1 with piperidine and triphenylphosphine, -arsine, and -stibine (Scheme 3, entries 1 and 2) [19]. The former reaction gave adduct $\mathbf{1 - 3}$ as a major product and the latter showed good fluorine-transfer to the hetero atoms. In 1972, German et al. reported the reaction with sodium phenoxide, which gave a small amount (5\%) of fluorophenols 1-6 and a larger amount of adduct 1-7 (Scheme 3, entry 3) [20]. These data showed that the fluorinations with 1-1 were suppressed by the formation of perfluoro-3,4,5,6-tetrahydropyridine (1-5), which was reactive to the nucleophilic substrates existing in the reaction mixture.

In 1986, Banks and co-worker reported the preparation of polymeric analogues of perfluoro- $N$-fluoropiperidine (1-1) [21] and then in 1991, Banks et al. reported the improved yields of the reactions of 1-1 with sodium salts of 2-nitropropane, malonate esters, and a keto ester, and phenylmagnesium bromide [22].

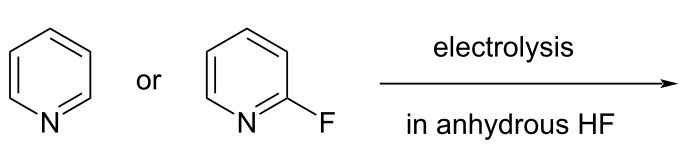

$7.5 \%$, from pyridine $13 \%$, from 2 -fluoropyridine 


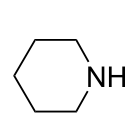

$\mathrm{Ph}_{3} \mathrm{~A}$

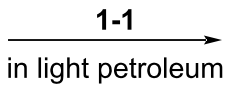

rt

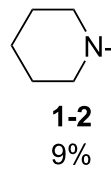

1-1
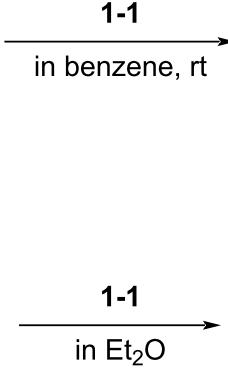

$\mathrm{Ph}_{3} \mathrm{AF}_{2}$

$1-4$

$A=P 84 \%$

$A=$ As $81 \%$

$\mathrm{A}=\mathrm{Sb} 69 \%$

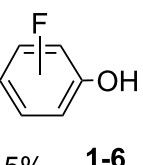

$5 \% \quad 1-6$

$o / p=3.5: 1$<smiles>FC1(F)N=C(N2CCCCC2)C(F)(F)C(F)(F)C1(F)F</smiles>

entry 1

Scheme 3: Reactions of $N-\mathrm{F}$ amine 1-1.

However, the fluorinated products were still accompanied by considerable amounts of byproducts resulting from the reaction of the substrates with $\mathbf{1 - 5}$.

\section{1-2. $N$-Fluoroperfluorosuccinimide and $N$-fluoroper- fluoroglutarimide}

In 1981, Yagupols'kii and co-worker reported the synthesis of $\mathrm{N}$-fluoroperfluorosuccinimide (2-1) and $\mathrm{N}$-fluoroperfluoroglutarimide (2-2) by reaction of precursor imides with $\mathrm{XeF}_{2}$ (Scheme 4) [23]. However, there were no reports on the fluorination capability of these $N$-F compounds. The purpose of this research was to establish if the presence of perfluoroacyl groups was sufficient to stabilize the $\mathrm{Xe}-\mathrm{N}$ bond. Their experiment revealed that the intermediate $\mathrm{F}-\mathrm{Xe}-\mathrm{N}$ compounds were not detected, but $N$-fluoroimides $\mathbf{2 - 1}$ and 2-2 were formed. The stability of these $N$-F compounds was low, since they decomposed to $\mathrm{H}_{2} \mathrm{NCO}\left(\mathrm{CF}_{2}\right)_{n} \mathrm{COOH}$ upon standing with air.<smiles>CC(=O)NC(=O)C(F)(F)F</smiles><smiles>O=C1NC(=O)C(F)(F)C1=O</smiles>

2-1 $n=2: 55-65 \%$ 2-2 $n=3: 50-60 \%$

Scheme 4: Synthesis of N-F perfluoroimides 2-1 and 2-2.

\section{1-3. 1-Fluoro-2-pyridone}

In 1983, Purrington and co-worker synthesized 1-fluoro-2-pyridone (3-1) as a fluorination agent [24]. When 2-(trimethylsiloxy)pyridine was allowed to react with $5 \% \mathrm{~F}_{2}$ diluted with
$\mathrm{N}_{2}$ in a freon solvent at $-78{ }^{\circ} \mathrm{C}, 1$-fluoro-2-pyridone was obtained in $63 \%$ yield (Scheme 5).

$$
\underset{\mathrm{OSiMe}_{3}}{\stackrel{5 \% \mathrm{~F}_{2} \text { in } \mathrm{N}_{2}}{\text { in } \mathrm{CFCl}_{3},-78^{\circ} \mathrm{C}}}
$$

Scheme 5: Synthesis of 1-fluoro-2-pyridone (3-1).

The fluorination efficiency of 3-1 was higher than perfluoro- $N$ fluoropiperidine (1-1) and the yields of reaction with sodium diethyl malonates improved to between 9-39\%; a difluorinated byproduct was obtained when the substituent $\mathrm{R}$ was $\mathrm{H}$ (Scheme 6). Further applications were investigated by the same authors in 1984 [25]. Grignard reagents and enamines could be fluorinated, but in very low yields and unfortunately, this reagent was not so stable.

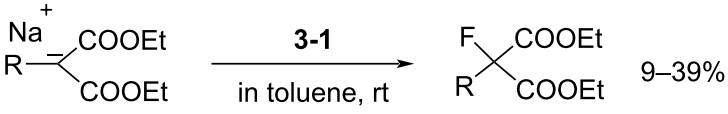

$$
\begin{aligned}
& \mathrm{R}=\mathrm{Ph}, \mathrm{PhCH}_{2}, \mathrm{CH}_{3}, \mathrm{H} \\
& \operatorname{RMgX} \\
& \stackrel{3-1}{\stackrel{\mathrm{Et}}{2} \mathrm{O} / \mathrm{CH}_{2} \mathrm{Cl}_{2}, \mathrm{rt}} \begin{array}{c}
\mathrm{RF} \\
\mathrm{R}=\mathrm{Ph}, \text { cyclohexyl, 2-octyl }
\end{array} \\
& \text { enamines } \underset{\mathrm{CH}_{2} \mathrm{Cl}_{2} \text {, reflux }}{\mathbf{3 - 1}} \alpha \text {-fluoroketones } 11-44 \%
\end{aligned}
$$

Scheme 6: Fluorination with 1-fluoro-2-pyridone (3-1). 
Notably, attempts to prepare $N$-fluorosuccinimide from succinimide, or one of its salts by reaction with fluorine $\left(\mathrm{F}_{2}\right)$, trifluoromethyl hypofluorite, or perchloryl fluoride in a variety of solvents, and at temperatures ranging from $-78{ }^{\circ} \mathrm{C}$ to room temperature, all but failed, as reported in the margin of the paper cited in [24].

\section{1-4. N-Fluoro- $N$-alkylarenesulfonamides}

In 1984, a series of stable $N$-fluoro- $N$-alkylsulfonamides 4-1a-g was reported by Barnette [26]. The treatment of $N$-alkylsulfonamides with very dilute $\mathrm{F}_{2}(1 \%$ or $5 \%)$ in $\mathrm{N}_{2}$ at $-78{ }^{\circ} \mathrm{C}$ afforded the fluorinated products 4-1a-g. As detailed in Figure 1, various kinds of $N$-fluoro- $N$-alkylsulfonamides were synthesized by this method. However, the yields were low except for the case of compound 4-1d. In the cases of secondary and tertiary alkyl groups on the amine side, low yields were obtained and these were attributed to concomitant $\mathrm{N}-\mathrm{S}$-bond cleavage reactions with $F_{2}$. This method, using the dilute $F_{2}$, was inefficient for their production due to long reaction times.

\begin{tabular}{|c|c|c|c|c|c|}
\hline \multicolumn{2}{|c|}{ 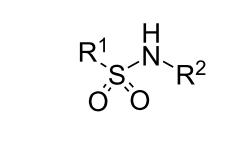 } & \multicolumn{2}{|c|}{$\begin{array}{c}\frac{1 \% \text { or } 5 \% \mathrm{~F}_{2} / \mathrm{N}_{2}}{\mathrm{n}_{\mathrm{CFCl}} / \mathrm{CHCl}_{3} 1: 1} \\
-78{ }^{\circ} \mathrm{C}\end{array}$} & \multicolumn{2}{|c|}{ 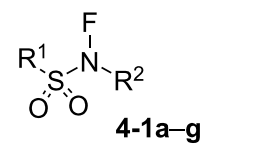 } \\
\hline compound & $\mathrm{R}^{1}$ & & $\mathrm{R}^{2}$ & 2 in $\mathrm{N}_{2}$ & yield(\%) \\
\hline $4-1 a$ & $4-\mathrm{CH}_{3} \mathrm{C}_{6}$ & ${ }_{6} \mathrm{H}_{4-}$ & $\mathrm{CH}_{3^{-}}$ & $1 \%$ & $59 \%$ \\
\hline $4-1 b$ & $4-\mathrm{CH}_{3} \mathrm{C}_{6}$ & ${ }_{6} \mathrm{H}_{4^{-}}$ & $\left(\mathrm{CH}_{3}\right)_{3} \mathrm{C}-$ & $5 \%$ & $14 \%$ \\
\hline $4-1 c$ & $4-\mathrm{CH}_{3} \mathrm{C}_{6}$ & ${ }_{6} \mathrm{H}_{4^{-}}$ & exo-2-norbornyl & $1 \%$ & $47 \%$ \\
\hline $4-1 d$ & $4-\mathrm{CH}_{3} \mathrm{C}_{6}$ & ${ }_{6} \mathrm{H}_{4-}^{-}$ & endo-2-norbornyl & $1 \%$ & $71 \%$ \\
\hline $4-1 e$ & $4-\mathrm{CH}_{3} \mathrm{C}_{6}$ & ${ }_{6} \mathrm{H}_{4^{-}}$ & cyclohexyl & $5 \%$ & $11 \%$ \\
\hline $4-1 f$ & $4-\mathrm{CH}_{3} \mathrm{C}_{6}$ & ${ }_{6} \mathrm{H}_{4^{-}}$ & $\left(\mathrm{CH}_{3}\right)_{3} \mathrm{CCH}_{2^{-}}$ & $5 \%$ & $57 \%$ \\
\hline 4-1g & $\mathrm{CH}_{3} \mathrm{CH}_{2}$ & $\mathrm{CH}_{2} \mathrm{CH}_{2}-$ & $\left(\mathrm{CH}_{3}\right)_{3} \mathrm{CCH}_{2^{-}}$ & $1 \%$ & $50 \%$ \\
\hline
\end{tabular}

Figure 1: Synthesis of $N-\mathrm{F}$ sulfonamides $4-1 \mathbf{a}-\mathrm{g}$

$N$-Fluoro- $N$-alkyl- $p$-toluenesulfonamides $4-1 \mathbf{b}, \mathbf{c}, \mathbf{f}$ proved to be efficient fluorinating agents in the fluorination of carbanions (Scheme 7). The yields of reactions with sodium malonates and Grignard reagents were largely improved to up to $81 \%$ and $50 \%$, respectively. The carbanions of aromatics, ketones, nitroalkanes, amides, etc. could also be reasonably well fluorinated and this study showed great progress. However, although these fluorinating agents were stable and easy-to-handle, their fluorinating power was low. They could fluorinate only reactive carbanions, but not aromatics, olefins, vinyl acetates, trimethylsilyl or alkyl enol ethers, and so on.

Soon after (1986), Schwartz and co-worker reported the stereospecific synthesis of alkenyl fluorides with $\mathrm{N}$-fluoro- $\mathrm{N}$-tertbutylbenzenesulfonamide (4-1h), a compound which is soluble at low temperature [27]. Alkenyllithium reagents, generated in situ, reacted at $-120{ }^{\circ} \mathrm{C}$ with $\mathbf{4 - 1 h}$ in $\mathrm{THF} / \mathrm{Et}_{2} \mathrm{O} /$ pentane to give the desired alkenyl fluorides 4-2 in good yields (Scheme 8). However, reactions that were run above $-120{ }^{\circ} \mathrm{C}$, or in pure ether or THF gave higher yields of the protonated products 4-3.

\section{1-5. $N$-Fluoropyridinium salts and their derivatives}

In 1986, Umemoto et al. reported $N$-fluoropyridinium triflate and its derivatives 5-4 as new stable cationic fluorinating agents. These possessed either electron-donating or -withdrawing substituents on the pyridinium nuclei, and were the first reactive, easy-to-handle fluorinating agents with wide application $[28,29]$. The work continued with additional disclosures until 1991 [30-34]. Before that, reactive fluorinating reagents were difficult to handle because of toxicity, a tendency to explode, instability, and/or hygroscopicity, while easy-tohandle reagents had limited application because of their low reactivity.

Umemoto et al. found that the hygroscopic pyridine $\cdot \mathrm{F}_{2}$ complex 5-2a decomposing vigorously at temperatures above $-2{ }^{\circ} \mathrm{C}$ [35], which was formed by the fluorination of pyridine $(10 \%$ $\mathrm{F}_{2} / \mathrm{N}_{2}$ ) at low temperature in a freon solvent, could undergo straightforward counteranion replacement with a non-nucleophilic anion. Therefore, exchange with salts such as sodium triflate in acetonitrile generated non-hygroscopic $N$-fluoropyridinium triflate salts as highly thermally stable reagents as illustrated in Scheme 9 [28]. Moreover, they found that the fluorination power (reactivity) of these $N$-fluoropyridinium salts could be tuned by the substituents on the pyridinium nuclei.

The transformation of the unstable pyridine $\cdot \mathrm{F}_{2}$ complex to stable $\mathrm{N}$-fluoropyridinium salts could be conducted by direct fluorination $\left(10 \% \mathrm{~F}_{2} / \mathrm{N}_{2}\right)$ of the pyridine in acetonitrile and in the presence of a suitable salt at low temperature (method B in Scheme 10). This one-step process was successfully applied to many other pyridine derivatives (method B in Figure 2).

It was finally shown that the stable $N$-fluoropyridinium salts 5-4 could be synthesized in four different ways using $10 \% \mathrm{~F}_{2} / \mathrm{N}_{2}$ [28,31,33] (Scheme 10): method A (stepwise method) involved the fluorination of a pyridine derivative with $\mathrm{F}_{2} / \mathrm{N}_{2}$, to form a pyridine $\cdot \mathrm{F}_{2}$ complex $\mathbf{5 - 2}$, followed by treatment with a nonnucleophilic anion salt, acid, or silyl derivative. Method B (onestep method) involved the fluorination of a pyridine derivative with $\mathrm{F}_{2} / \mathrm{N}_{2}$ in the presence of a non-nucleophilic anion salt. Method $\mathrm{C}$ involved mixing a pyridine derivative with an acid or its silyl derivative, forming a salt $\mathbf{5 - 5}$, before fluorination. Method D involved mixing a pyridine derivative with a Lewis acid, forming complex 5-6, and then the fluorination with $\mathrm{F}_{2} / \mathrm{N}_{2}$ was carried out. 


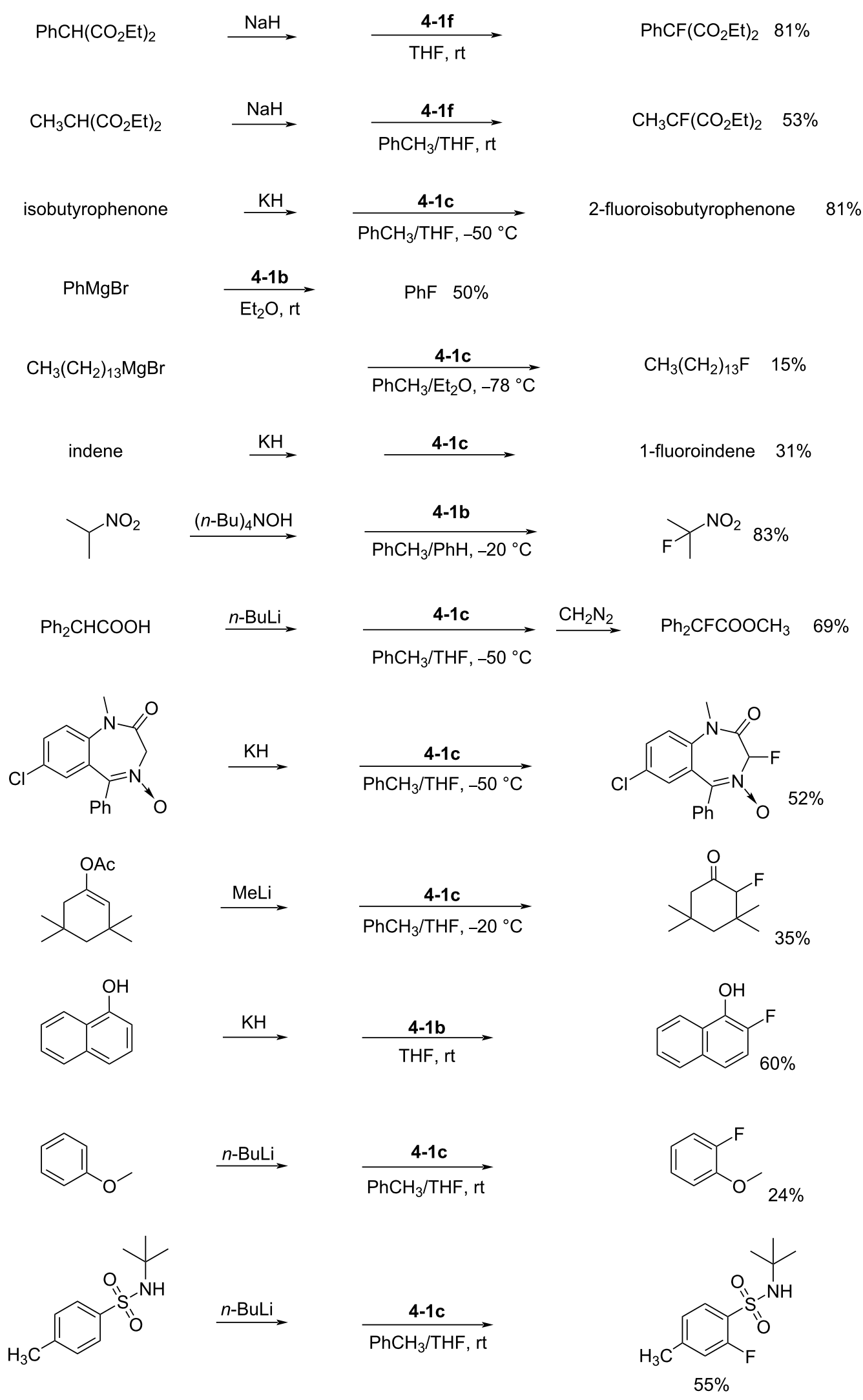




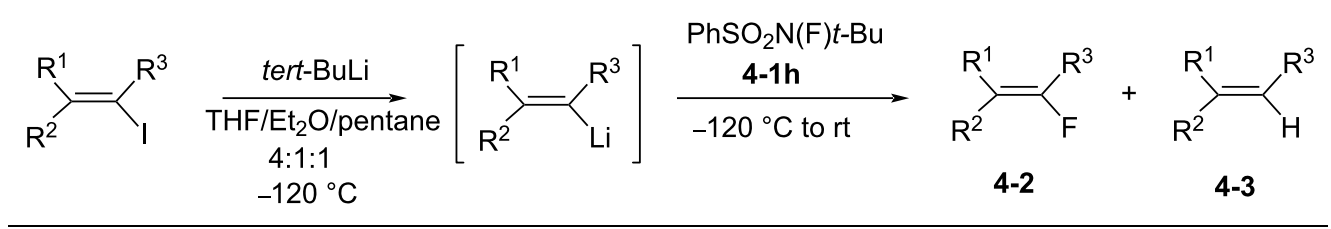

$\overbrace{F} 71 \%(+4-3: 15 \%)$<smiles>F/C=C/c1ccccc1</smiles>

$76 \%(+4-3: 10 \%)$

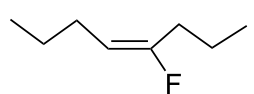

$85 \%(+4-3: 3 \%)$

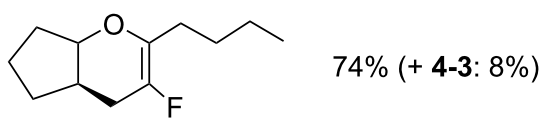<smiles>C[C@]12CCCCC1CCC1C2CC[C@]2(C)C1CC[C@@H]2/C=C/F</smiles>

$80 \%(+4-3: 13 \%)$

Scheme 8: Fluorination of alkenyllithiums with N-F 4-1h.

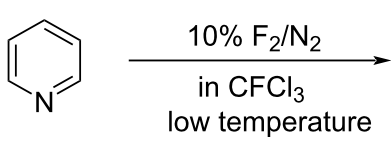

5-1a<smiles>F[n+]1ccccc1</smiles>

5-2a<smiles>CCCCCCCCC</smiles>

5-3a

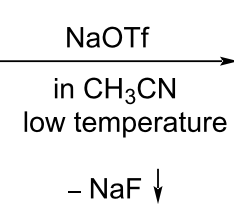

$-\mathrm{NaF} \downarrow$

decomp. vigorously at $>-2{ }^{\circ} \mathrm{C}$ hygroscopic solid<smiles>F[n+]1ccccc1</smiles>

$5-4 a$

highly stable, non-hygroscopic crystals, mp $185-187^{\circ} \mathrm{C}$

Scheme 9: Synthesis of $N$-fluoropyridinium triflate (5-4a).

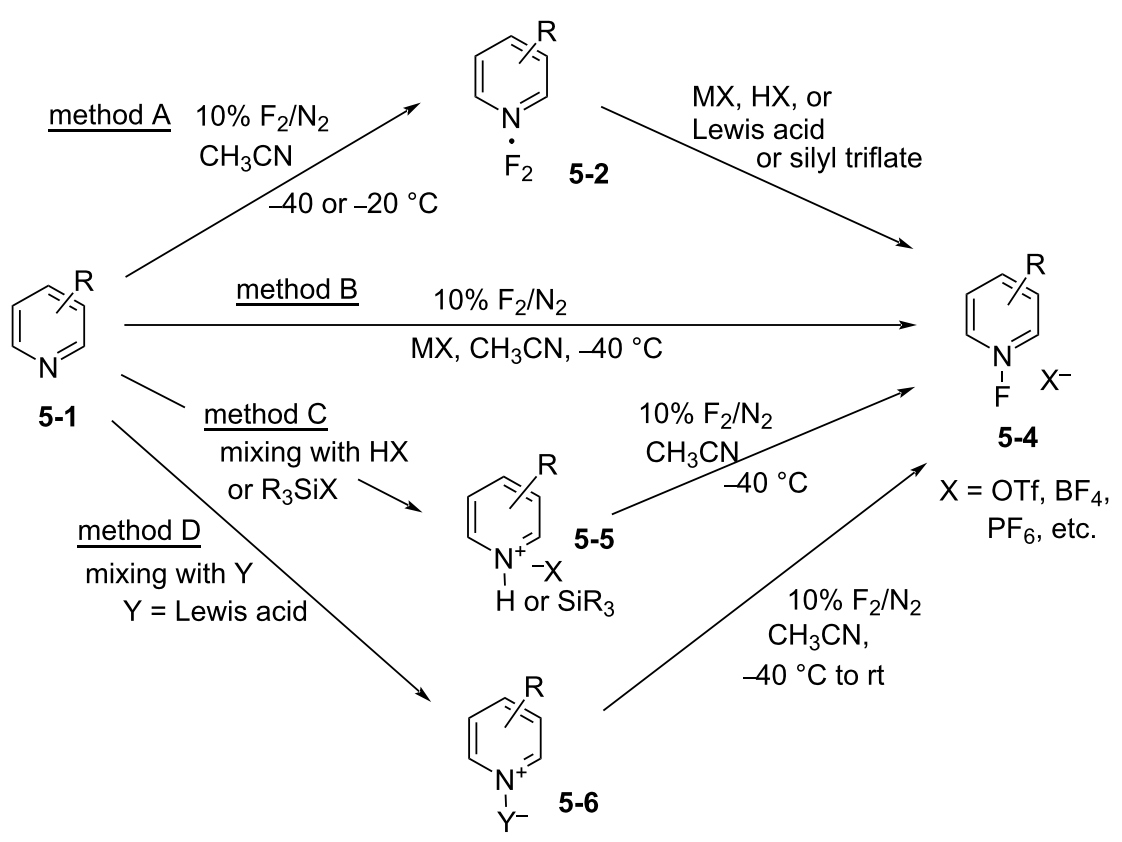

Scheme 10: Synthetic methods for N-F-pyridinium salts. 


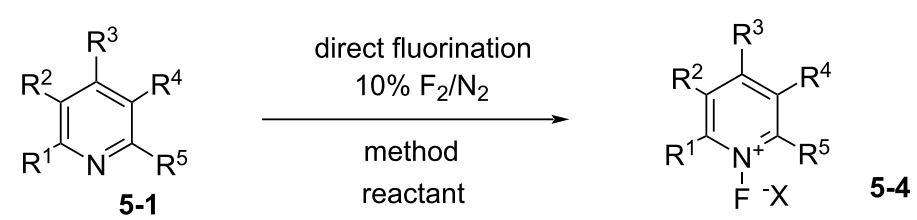

\begin{tabular}{|c|c|c|c|c|c|c|c|c|c|}
\hline compound & $x$ & $\mathrm{R}^{1}$ & $\mathrm{R}^{2}$ & $R^{3}$ & $\mathrm{R}^{4}$ & $\mathrm{R}^{5}$ & method & reactant & yield (\%) \\
\hline $5-4 a$ & OTf & $\mathrm{H}$ & $\mathrm{H}$ & $\mathrm{H}$ & $\mathrm{H}$ & $\mathrm{H}$ & B & $\mathrm{NaOTf}$ & $75 \%$ \\
\hline $4 a$ & OTf & $\mathrm{H}$ & $\mathrm{H}$ & $\mathrm{H}$ & $\mathrm{H}$ & $\mathrm{H}$ & $\mathrm{C}$ & $\mathrm{TfOH}$ & $96 \%{ }^{a}$ \\
\hline $4 b$ & $\mathrm{BF}_{4}$ & $\mathrm{H}$ & $\mathrm{H}$ & $\mathrm{H}$ & $\mathrm{H}$ & $\mathrm{H}$ & B & $\mathrm{NaBF}_{4}$ & $78 \%$ \\
\hline $4 c$ & $\mathrm{PF}_{6}$ & $\mathrm{H}$ & $\mathrm{H}$ & $\mathrm{H}$ & $\mathrm{H}$ & $\mathrm{H}$ & B & $\mathrm{NaPF}_{6}$ & $83 \%$ \\
\hline $4 d$ & $\mathrm{AsF}_{6}$ & $\mathrm{H}$ & $\mathrm{H}$ & $\mathrm{H}$ & $\mathrm{H}$ & $\mathrm{H}$ & B & $\mathrm{NaAsF}_{6}$ & $66 \%$ \\
\hline $4 e$ & $\mathrm{SbF}_{6}$ & $\mathrm{H}$ & $\mathrm{H}$ & $\mathrm{H}$ & $\mathrm{H}$ & $\mathrm{H}$ & B & $\mathrm{LiSbF}_{6}$ & $93 \%$ \\
\hline $4 f$ & ONf & $\mathrm{H}$ & $\mathrm{H}$ & $\mathrm{H}$ & $\mathrm{H}$ & $\mathrm{H}$ & B & $\mathrm{NaONf}$ & $87 \%$ \\
\hline $4 \mathrm{~g}$ & OMs & $\mathrm{H}$ & $\mathrm{H}$ & $\mathrm{H}$ & $\mathrm{H}$ & $\mathrm{H}$ & $C$ & $\mathrm{MsOH}$ & $79 \%$ \\
\hline $4 \mathrm{~h}$ & OTf & $\mathrm{H}$ & $\mathrm{H}$ & $\mathrm{Me}$ & $\mathrm{H}$ & $\mathrm{H}$ & B & $\mathrm{NaOTf}$ & $90 \%$ \\
\hline $4 i$ & OTf & $\mathrm{H}$ & $\mathrm{Me}$ & $\mathrm{H}$ & $\mathrm{Me}$ & $\mathrm{H}$ & $B$ & $\mathrm{NaOTf}$ & $60 \%$ \\
\hline $4 j$ & OTf & $\mathrm{Me}$ & $\mathrm{H}$ & $\mathrm{Me}$ & $\mathrm{H}$ & $\mathrm{Me}$ & B & KOTf & $81 \%$ \\
\hline $4 k$ & $\mathrm{BF}_{4}$ & $\mathrm{Me}$ & $\mathrm{H}$ & $\mathrm{Me}$ & $\mathrm{H}$ & $\mathrm{Me}$ & B & $\mathrm{NaBF}_{4}$ & $70 \%$ \\
\hline 4I & OTf & $\mathrm{CH}_{2} \mathrm{OMe}$ & $\mathrm{H}$ & $\mathrm{H}$ & $\mathrm{H}$ & $\mathrm{CH}_{2} \mathrm{COMe}$ & e $B$ & $\mathrm{NaOTf}$ & $85 \%$ \\
\hline $4 m$ & OTf & $\mathrm{CH}_{2} \mathrm{OMe}$ & $\mathrm{H}$ & $\mathrm{CH}_{2} \mathrm{OMe}$ & $\mathrm{H}$ & $\mathrm{CH}_{2} \mathrm{COMe}$ & e $B$ & $\mathrm{NaOTf}$ & $73 \%$ \\
\hline $4 n$ & OTf & $\mathrm{CH}_{2} \mathrm{OAc}$ & $\mathrm{H}$ & $\mathrm{H}$ & $\mathrm{H}$ & $\mathrm{CH}_{2} \mathrm{OAC}$ & B & $\mathrm{NaOTf}$ & $74 \%$ \\
\hline 40 & OTf & $\mathrm{OMe}$ & $\mathrm{H}$ & $\mathrm{H}$ & $\mathrm{H}$ & $\mathrm{H}$ & B & $\mathrm{NaOTf}$ & $73 \%$ \\
\hline $4 p$ & OTf & $\mathrm{F}$ & $\mathrm{H}$ & $\mathrm{H}$ & $\mathrm{H}$ & $\mathrm{H}$ & B & LiOTf & $23 \%$ \\
\hline $4 q$ & OTf & $\mathrm{Cl}$ & $\mathrm{H}$ & $\mathrm{H}$ & $\mathrm{H}$ & $\mathrm{H}$ & B & $\mathrm{NaOTf}$ & $71 \%$ \\
\hline $4 r$ & OTf & $\mathrm{Cl}$ & $\mathrm{H}$ & $\mathrm{H}$ & $\mathrm{H}$ & $\mathrm{Cl}$ & $\mathrm{C}$ & $\mathrm{TfOH}$ & $62 \%$ \\
\hline $4 \mathrm{~s}$ & $\mathrm{BF}_{4}$ & $\mathrm{Cl}$ & $\mathrm{H}$ & $\mathrm{H}$ & $\mathrm{H}$ & $\mathrm{Cl}$ & D & $\mathrm{BF}_{3} / \mathrm{HF} / \mathrm{H}_{2} \mathrm{O}^{\mathrm{b}}$ & $76 \%$ \\
\hline $4 t$ & OTf & $\mathrm{H}$ & $\mathrm{Cl}$ & $\mathrm{H}$ & $\mathrm{Cl}$ & $\mathrm{H}$ & B & LiOTf & $77 \%$ \\
\hline $4 u$ & $\mathrm{BF}_{4}$ & $\mathrm{H}$ & $\mathrm{Cl}$ & $\mathrm{H}$ & $\mathrm{Cl}$ & $\mathrm{H}$ & $\mathrm{D}$ & $\mathrm{BF}_{3} \mathrm{OEt}_{2}$ & $87 \%$ \\
\hline $4 v$ & OTf & $\mathrm{Cl}$ & $\mathrm{Cl}$ & $\mathrm{Cl}$ & $\mathrm{Cl}$ & $\mathrm{Cl}$ & $\mathrm{C}$ & $\mathrm{TfOH}$ & $85 \%$ \\
\hline $4 w$ & $\mathrm{BF}_{4}$ & $\mathrm{Cl}$ & $\mathrm{Cl}$ & $\mathrm{Cl}$ & $\mathrm{Cl}$ & $\mathrm{Cl}$ & $\mathrm{D}$ & $\mathrm{BF}_{3}$ & $87 \%$ \\
\hline $4 x$ & OTf & $\mathrm{H}$ & $\mathrm{CF}_{3}$ & $\mathrm{H}$ & $\mathrm{CF}_{3}$ & $\mathrm{H}$ & C & $\mathrm{TfOSiMe}_{3}$ & $68 \%$ \\
\hline $4 y$ & OTf & coOMe & $\mathrm{H}$ & $\mathrm{H}$ & $\mathrm{H}$ & COOMe & B & $\mathrm{NaOTf}$ & $72 \%$ \\
\hline $4 z$ & OTf & coOMe & $\mathrm{H}$ & COOMe & $\mathrm{H}$ & COOMe & B & LiOTf & $15 \%$ \\
\hline $4 z a$ & OTf & COMe & $\mathrm{H}$ & $\mathrm{H}$ & $\mathrm{H}$ & $\mathrm{H}$ & B & $\mathrm{NaOTf}$ & $72 \%$ \\
\hline $4 z b$ & $\mathrm{BF}_{4}$ & $\mathrm{CN}$ & $\mathrm{H}$ & $\mathrm{H}$ & $\mathrm{H}$ & $\mathrm{H}$ & B & $\mathrm{LiBF}_{4}$ & $78 \%$ \\
\hline $4 \mathrm{zc}$ & OTf & $\mathrm{H}$ & $\mathrm{H}$ & $\mathrm{CN}$ & $\mathrm{H}$ & $\mathrm{H}$ & B & LiOTf & $84 \%$ \\
\hline $4 z d$ & OTf & $\mathrm{CN}$ & $\mathrm{H}$ & $\mathrm{H}$ & $\mathrm{H}$ & $\mathrm{CN}$ & B & LiOTf & $50 \%$ \\
\hline $4 z e$ & OTf & $\mathrm{H}$ & $\mathrm{H}$ & $\mathrm{NO}_{2}$ & $\mathrm{H}$ & $\mathrm{H}$ & B & LiOTf & $86 \%$ \\
\hline
\end{tabular}

Figure 2: Synthesis of various $N$-fluoropyridinium salts. Note: ${ }^{\text {athis }}$ yield was the one by the improved method reported in [37]; bthis improved method was reported in [38].

In total, sixty-two stable $N$-fluoropyridinium salts possessing different non-nucleophilic counteranions and electron-withdrawing or -donating groups were efficiently synthesized [33]. Figure 2 shows 31 examples and their methods of preparation. Umemoto and co-worker also reported the synthesis of a polymer version, poly(vinyl- $N$-fluoropyridinium salts) of these reagents [36].

The reactivities of many $\mathrm{N}$-fluoropyridinium salts were examined [32] and mainly five kinds of $N$-fluoropyridinium salts, shown in Scheme 11, emerged as useful fluorinating agents due to their availability. The fluorination power greatly changed depending on the electron density at the nitrogen, an aspect con- trolled by the electronic nature of the substituents. The fluorinating power increased in the order of 2,4,6-triMe $\mathbf{5 - 4 j}<$ unsubstituted 4a $<3,5-\mathrm{diCl} \mathbf{4 t}<2,6-\mathrm{diCl} \mathbf{4 r}<$ pentachloro $4 \mathbf{v}$, in good agreement with the decreasing order of the $\mathrm{p} K_{\mathrm{a}}$ values of the pyridines. For example, in order to fluorinate phenol, triMe 5-4j needed heating at $100{ }^{\circ} \mathrm{C}$ in a haloalkane solvent for $24 \mathrm{~h}$, whereas pentachloro 5-4v required only room temperature within $0.1 \mathrm{~h}$ for a successful reaction. The salt $\mathbf{5 - 4 v}$ was so powerful that it fluorinated an equimolar amount of benzene in dichloromethane in $2 \mathrm{~h}$ at $40{ }^{\circ} \mathrm{C}$. In general, triflate salts were more effective than $\mathrm{BF}_{4}$ salts because of the higher solubility of the triflate salts in a haloalkane solvent. 


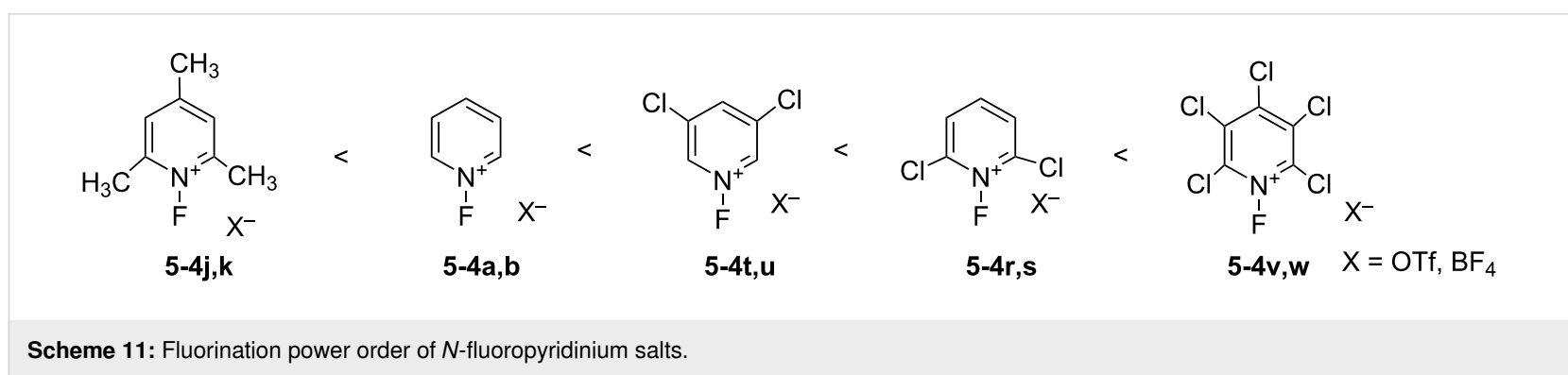

As outlined in Scheme 12, fluorinations of many kinds of substrates with these $N$-fluoropyridinium salts were performed. It was shown that less reactive substrates can be fluorinated well with the more powerful reagents, and reactive substrates can be fluorinated with less powerful reagents, a match process which minimizes side reactions. Thus, these $N$-fluoropyridinium salts made possible the fluorination of a diversity of nucleophilic organic compounds with different reactivities ranging across aromatics, carbanions (Grignard reagents, enolate anions), active methylene compounds, olefins, silyl enol ethers, vinyl acetates, sulfides and so on, under mild conditions with high selectivity and yields [29-32]. All these reactions could be carried out routinely using standard glassware in normal laboratory environments and without any specialist training.

Some interesting observations are noted: $N$-Fluoro-2,6bis(methoxymethyl)pyridinium triflate (5-4l) fluorinated the trimethylsilyl ether of $\gamma$-butyrolactone and 1-cyclohexenyl acetate in much higher yields than the $N$-fluoro-2,4,6-trimethyl salt $\mathbf{5 - 4} \mathbf{j}$ [32]. Thus, as seen in Scheme 13, 5-4l converted the Corey lactone 5-7 via its silyl ether 5-8 to the fluorinated lactone 5-9 in a very satisfactory overall yield [32]. $N$-Fluoro-2,6bis $\left(\mathrm{CH}_{2} \mathrm{OAc}\right)$ pyridinium triflate 5-4n [32], $\mathrm{N}$-fluoro-2,6bis(COOMe)pyridinium triflate $\mathbf{5 - 4 y}[30,32]$, and $N$-fluoro-2cyano- and -2,6-dicyanopyridinium tetrafluoroborates [39] were useful reagents, too. These non-chlorinated reagents avoid chlorinated byproducts, an occurrence that was observed when other powerful fluorinating agents such as $N$-fluoro-2,3,4,5,6pentachloropyridinium salts were used [40].

In 1991, $N$-fluoropyridinium pyridine heptafluorodiborate (NFPy), $\mathrm{C}_{5} \mathrm{H}_{5} \mathrm{NF}\left(\mathrm{C}_{5} \mathrm{H}_{5} \mathrm{~N}\right) \mathrm{B}_{2} \mathrm{~F}_{7}$, was introduced as a fluorinating agent [41]. NFPy was prepared by the reaction of fluorine with pyridine $\mathrm{BF}_{3}$ complex and its fluorination ability is shown in Scheme 14. However, it was subsequently reported that the correct structure was $N$-fluoropyridinium pyridinium tetrafluoroborate trifluorohydroxyborate, $\mathrm{C}_{5} \mathrm{H}_{5} \mathrm{NF}\left(\mathrm{C}_{5} \mathrm{H}_{5} \mathrm{NH}\right) \mathrm{BF}_{4}\left(\mathrm{BF}_{3} \mathrm{OH}\right)$, which was a 1:1 mixture of the $N$-fluoropyridinium salt and $N$-hydropyridinium salt (anion parts; $\mathrm{BF}_{4}$ and $\mathrm{BF}_{3} \mathrm{OH}$ ), based on an X-ray diffraction study of a commercial sample [42].

\section{1-6. N-Fluoroquinuclidinium fluoride}

In 1986 as the $N$-F pyridinium reagents were emerging, Banks et al. disclosed the quaternary ammonium $N$-F reagent, $N$-fluoroquinuclidinium fluoride (6-1) [43]. They subsequently followed with more detailed results in 1988 [44]. Quinuclidine was fluorinated by neat fluorine in trichlorofluoromethane at $-72{ }^{\circ} \mathrm{C}$, affording the product $\mathbf{6 - 1}$ in $86 \%$ yield (Scheme 15 ). Fluorination examples with 6-1 are shown in Scheme 16.

This reagent proved to be very hygroscopic and deteriorated in air. In terms of fluorination yields, $N$-fluoroquinuclidinium fluoride (6-1) was however superior to Purrington's 1-fluoro-2pyridone (3-1) [24,25], but inferior to Barnette's $N$-fluoro- $N$ alkylarenesulfonamides 4-1 [26] and Umemoto's $N$-fluoropyridinium salts 5-4 [29,32].

\section{1-7. N-Fluoroperfluoroalkanesulfonimides}

In 1987, DesMarteau et al. reported the synthesis of a series of $\mathrm{N}$-fluoroperfluoroalkanesulfonimides 7-1. These were prepared by reacting $N, N$-bis(perfluoroalkanesulfonyl)amides with $100 \%$ $\mathrm{F}_{2}$ at $-196{ }^{\circ} \mathrm{C}$ to $22{ }^{\circ} \mathrm{C}$ [45] (Scheme 17). All of these $N$-fluoroperfluoroalkanesulfonimides were stable over time at $22{ }^{\circ} \mathrm{C}$, if stored in a fluoropolymer container. However, 7-1d decomposed at the melting point of $60{ }^{\circ} \mathrm{C}$.

It was shown that $N$-fluorotrifluoromethanesulfonimide 7-1a (mp $-69.8^{\circ} \mathrm{C}$ ) had a much higher reactivity than the sulfonamide reagents such as Barnette's $N$-fluoro- $N$-alkylarenesulfonamides, since the electronic density on the nitrogen was greatly decreased by two strong electron-withdrawing $\mathrm{CF}_{3} \mathrm{SO}_{2}$ groups. Reagent 7-1a reacted slowly with benzene and toluene under neat conditions, whereas activated aromatics such as phenol, cresol, and naphthalene were fluorinated in chloroform at $22{ }^{\circ} \mathrm{C}$ (Scheme 18). The $N$-F imide reagent 7-1a fluorinated the sodium salt of diethyl 1 -methylmalonate at $-10{ }^{\circ} \mathrm{C}$ to give the corresponding fluoro product in high yield (96\%).

Later (1991 and 1992), the same laboratory reported fluorination reactions of functionalized carbonyl compounds, 1,3dicarbonyl derivatives, olefins, and steroids with 7-1a [46-49] (Scheme 19). 

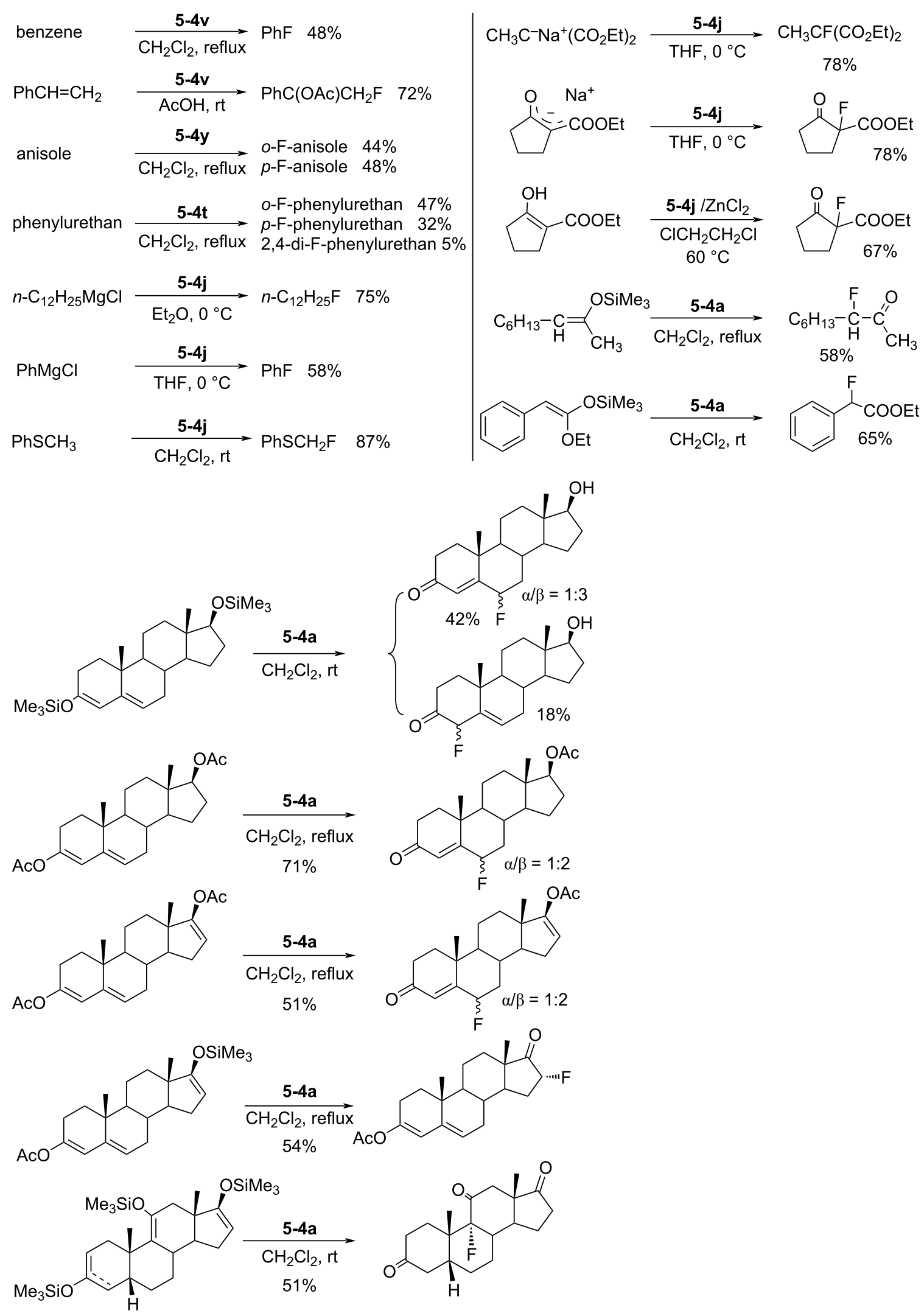
<smiles>CC(C)(C)OC[C@H]1[C@H]([OH+])C[C@@H]2OC(=O)C[C@@H]21</smiles>

Corey lactone 5-7
1. LDA

$\stackrel{\text { 2. } \mathrm{Me}_{3} \mathrm{SiCl}}{\longrightarrow}$ in THF

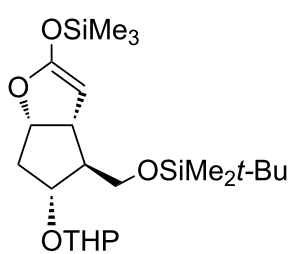

5-8

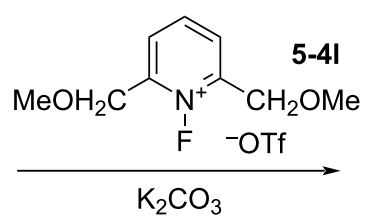

rt, 15 min in $\mathrm{CH}_{2} \mathrm{Cl}_{2}$

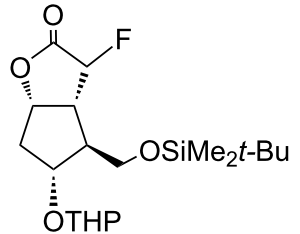

$5-9$ overall $65 \%$

Scheme 13: Fluorination of Corey lactone 5-7 with N-F-bis(methoxymethyl) salt 5-4I.<smiles>CC(=O)OC1=CCC(C(C)(C)C)CC1</smiles><smiles>COc1cccc2ccccc12</smiles><smiles>COc1ccc2c(c1)CCC1C2CCC2(C)C(OC(C)=O)CCC12</smiles><smiles>COC1=CC2=CCC3C(CCC4(C)C(OC(C)=O)CCC34)C2(C)CC1</smiles>

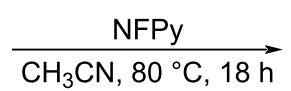

$62 \%$

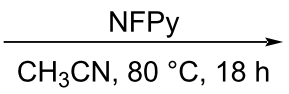

$61 \%$

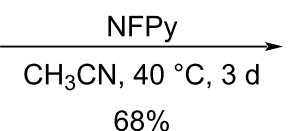

NFPy

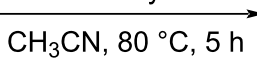

$57 \%$<smiles>CC(C)(C)C1CCC(=O)C(F)C1</smiles><smiles>O=C1c2ccccc2CCC1F</smiles>

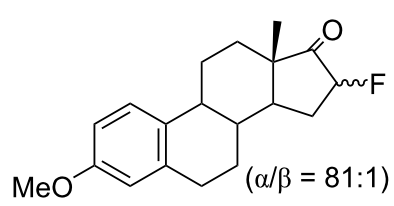<smiles>CC(=O)OC1CCC2C3CC(F)C4=CC(=O)CCC4(C)C3CCC12C</smiles>

Scheme 14: Fluorination with NFPy.

$$
\begin{aligned}
& \prod_{N} \\
& \underset{\mathrm{CFCl}_{3},-72{ }^{\circ} \mathrm{C}}{\stackrel{\text { neat } \mathrm{F}_{2}}{\longrightarrow}}
\end{aligned}
$$

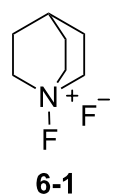

Scheme 15: Synthesis of the $N$-F reagent, $N$-fluoroquinuclidinium fluoride $(6-1)$.

\section{1-8. $N$-Fluoroquinuclidinium triflate}

In 1988, Banks and co-worker developed the stable and nonhygroscopic $N$-fluoroquinuclidinium triflate (8-1) [50], which was an alternative to $N$-fluoroquinuclidinium fluoride (6-1) (Scheme 20). The triflate 8-1 was prepared in high yield by the counteranion replacement reaction developed by Umemoto and co-worker [28]. The fluorinating power of triflate 8-1 was the same as that of the fluoride 6-1, but its nonhygroscopic nature made it a useful fluorinating agent in terms of handling and storage. Details on the synthesis and reactivities of triflate 8-1

$$
\begin{aligned}
& \mathrm{PhC}^{-} \mathrm{Na}^{+}\left(\mathrm{CO}_{2} \mathrm{Et}\right)_{2} \underset{\mathrm{THF},-10 \text { to } 20^{\circ} \mathrm{C}}{\mathbf{6 - 1}} \begin{array}{c}
\mathrm{PhCF}\left(\mathrm{CO}_{2} \mathrm{Et}\right)_{2} \\
\end{array} \\
& \begin{array}{ccc}
\mathrm{Me}_{2} \mathrm{C}^{-}\left(\mathrm{Li}^{+}\right) \mathrm{NO}_{2} & \mathbf{6 - 1} & \mathrm{Me}_{2} \mathrm{CFNO}_{2} \\
\cline { 2 - 2 }, 0{ }^{\circ} \mathrm{C} & 47 \%
\end{array} \\
& \mathrm{PhMgBr} \quad \frac{\mathbf{6 - 1}}{\mathrm{Et}_{2} \mathrm{O},-10 \text { to } 20^{\circ} \mathrm{C}} \quad \mathrm{PhF} 26 \% \\
& \overbrace{}^{\mathrm{MgBr}} \\
& \underset{\mathrm{Et}_{2} \mathrm{O},-10 \text { to } 20{ }^{\circ} \mathrm{C}}{\mathrm{6}-1} \\
& \underset{\mathrm{CH}_{2} \mathrm{Cl}_{2},-196 \text { to } 20{ }^{\circ} \mathrm{C}}{\text { 6-1 }}
\end{aligned}
$$

Scheme 16: Fluorinations achieved with N-F fluoride 6-1. 


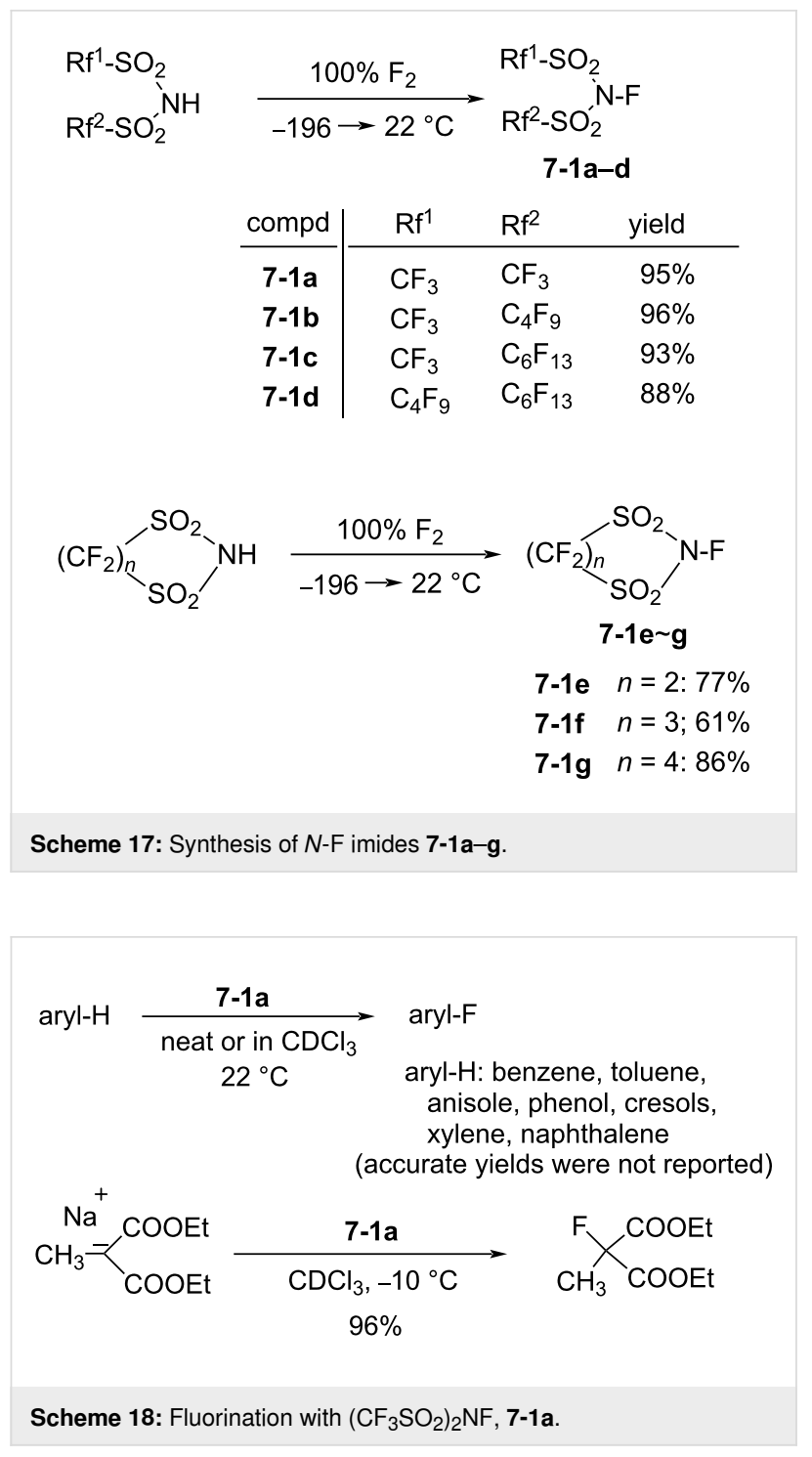

and other salts having $\mathrm{CF}_{3} \mathrm{COO}^{-}, \mathrm{C}_{3} \mathrm{~F}_{7} \mathrm{COO}^{-}$, and $\mathrm{BF}_{4}{ }^{-}$counterions were reported in 1991 [51].

\section{1-9. Optically active $N$-fluorosultams}

In 1988, the first optically active $N$-F fluorinating agents, chiral $N$-fluorosultams, were synthesized by Lang and co-worker [52]. A camphor-derived imine was reduced or methylated, followed by direct fluorination $\left(10 \% \mathrm{~F}_{2} / \mathrm{N}_{2}\right)$ to give optically active $N$-F reagents $\mathbf{9 - 1}$ and $\mathbf{9 - 2}$ in $75 \%$ and $80 \%$ yield, respectively (Scheme 21). These $N$-fluorosultams were stable below $100{ }^{\circ} \mathrm{C}$.

The enantioselectivities of products were examined after the fluorination of different metal enolates. In the best case a $63 \%$ yield and $70 \%$ enantiomeric excess (ee) was obtained. Even though other products gave less satisfactory outcomes, the potential of the $N$-F fluorinating agents for an enantioselective fluorination was demonstrated (Scheme 22).

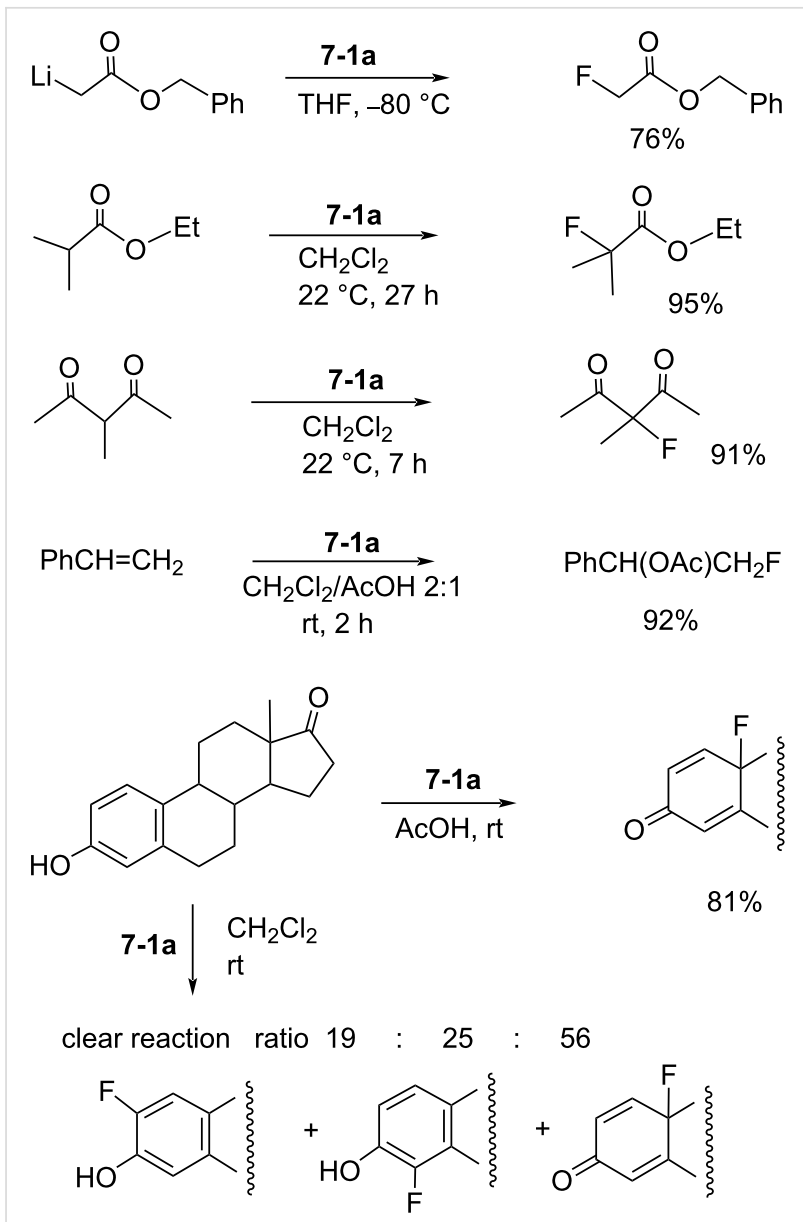

Scheme 19: Fluorination reactions of various substrates with 7-1a.

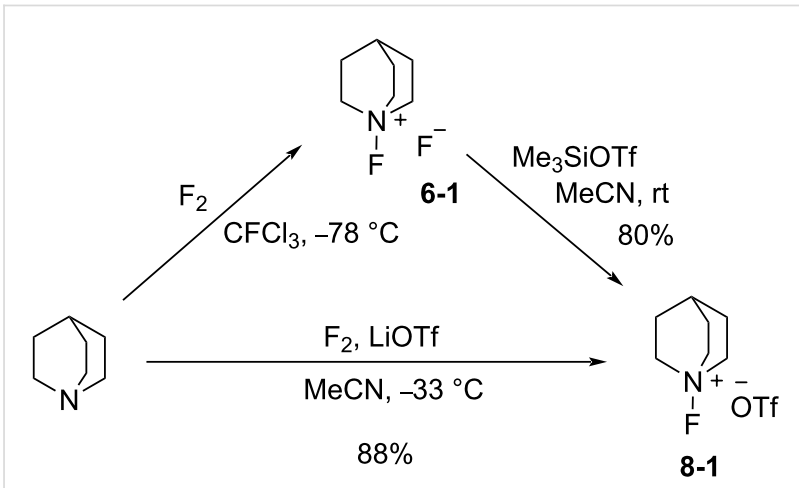

Scheme 20: Synthesis of $N-\mathrm{F}$ triflate 8-1.

\section{1-10. N-Fluoro-3,3-dimethylbenzothiazole dioxide}

In 1989, Lang and co-worker developed the saccharin-derived $\mathrm{N}$-fluorosultam $\mathrm{N}$-fluoro-3,3-dimethyl-2,3-dihydro-1,2-benzothiazole-1,1-dioxide (10-2) from the known precursor 10-1 (Scheme 23) [53]. A direct fluorination using $10 \% \mathrm{~F}_{2} / \mathrm{N}_{2}$ at $-40{ }^{\circ} \mathrm{C}$ gave $N$-F reagent $\mathbf{1 0 - 2}$ in $74 \%$ yield. Another method, via the $N$-trimethylsilylation, was also reported but in low effi- 


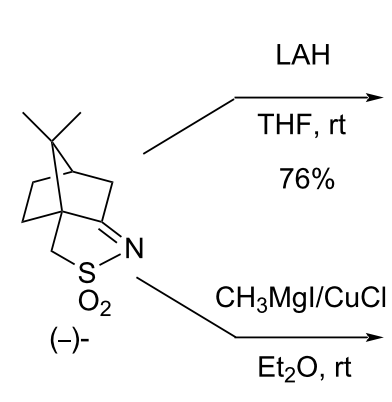

$43 \%$
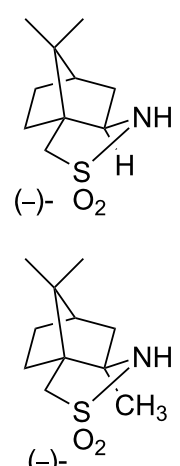

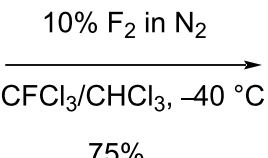

$75 \%$

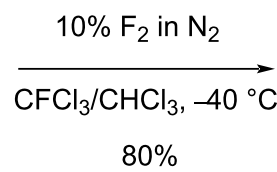

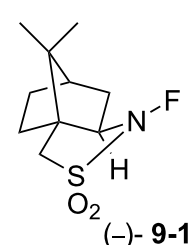

(-) - 9-1

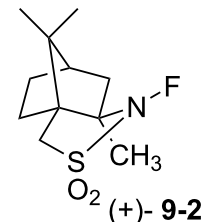

Scheme 21: Synthesis of chiral $N$-fluoro sultams 9-1 and 9-2.
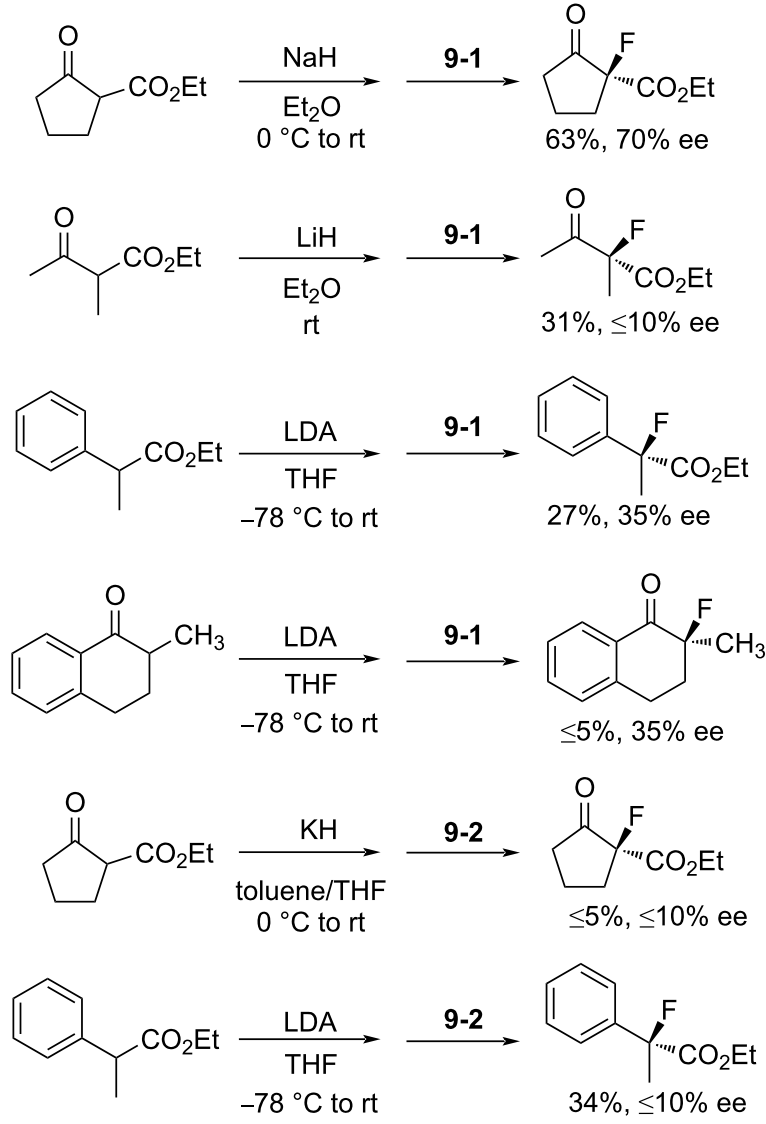

ciency. This $N-\mathrm{F}$ reagent is a colorless, thermally stable $\left(<200{ }^{\circ} \mathrm{C}\right)$ solid with a mp of $114-116{ }^{\circ} \mathrm{C}$.

The reagent 10-2 having no $\alpha$-proton to the $N$-F site proved to be a good choice for fluorinating enolate anions (Scheme 24). The side reaction, involving $\mathrm{HF}$ elimination, and which was a problem in reactions with the Barnette's reagents 4-1 having the $\alpha$-proton(s) except for 4-1b [26], was avoided here. The HF elimination is a decomposition process that is observed with $N$-F reagents that have an $\alpha$-proton and occurs under strong base conditions.

\section{1-11. Perfluoro[ $N$-fluoro- $N$-(4-pyridyl)methanesulfon-} amide]

In 1990, Banks and co-worker reported perfluoro[ $N$-fluoro- $N$ (4-pyridyl)methanesulfonamide] (11-2) [54]. Starting from pentafluoropyridine, the precursor 11-1 was prepared as illustrated in Scheme 25. Treatment of 11-1 with neat $F_{2}$ in acetonitrile at $-10{ }^{\circ} \mathrm{C}$ under reduced pressure gave $N$-fluoro-sulfonamide 11-2 in 89\% yield. This product was however a 9:1 mixture of the $N-\mathrm{F}$ reagent $\mathbf{1 1 - 2}$ and the protonated compound of 11-1.

The fluorination of benzene and anisole under excess substrate conditions gave fluorobenzene and fluoroanisoles in $88 \%$ and $98 \%$ yield, respectively. The reaction with sodium diethyl phenylmalonate gave the fluorinated product in $93 \%$ yield (Scheme 26).

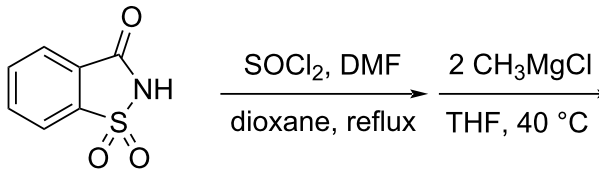

saccharin<smiles>CC1(C)NS(=O)(=O)c2ccccc21</smiles>

10-1

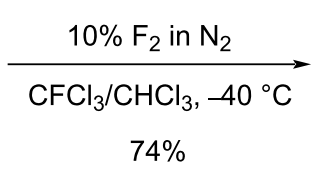

$74 \%$<smiles>CC1(C)c2ccccc2S(=O)(=O)N1F</smiles>

10-2

Scheme 23: Synthesis of saccharin-derived $N$-fluorosultam 10-2. 


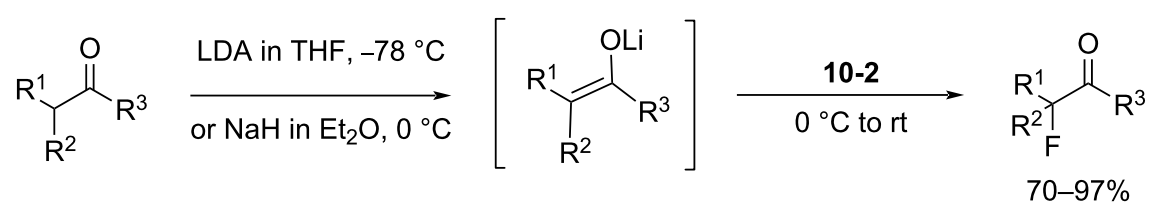

Scheme 24: Fluorination with $N$-fluorosultam 10-2.

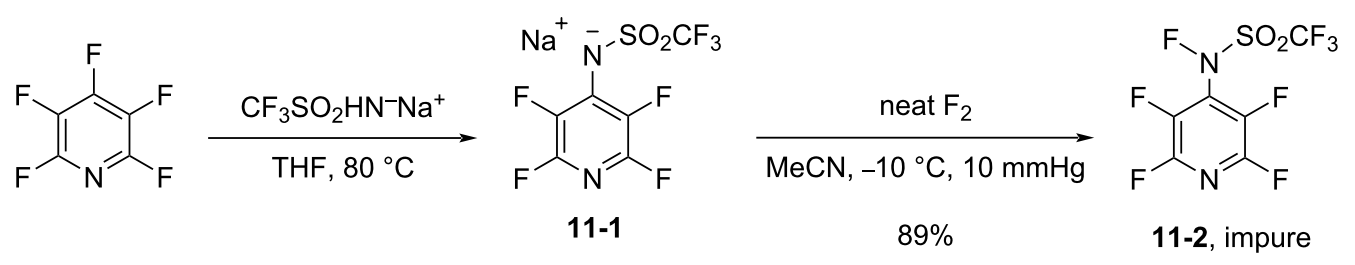

Scheme 25: Synthesis of $N-\mathrm{F}$ reagent 11-2.

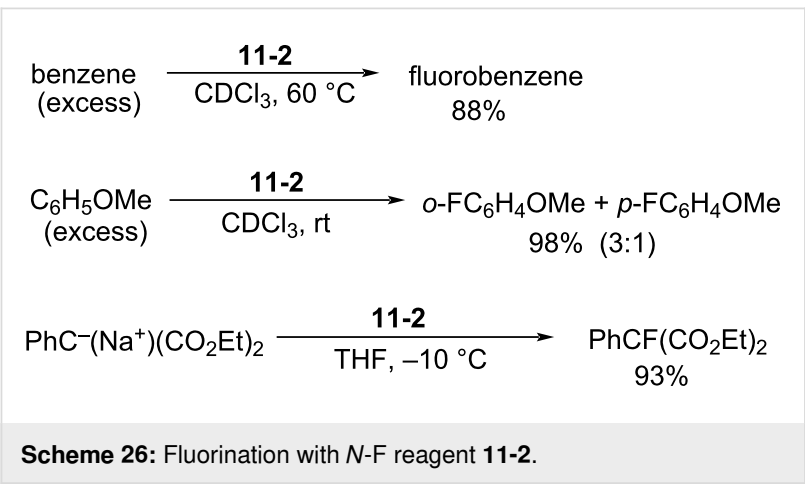

\section{1-12. N-Fluorolactams}

A new class of $N$-F fluorinating agents, $N$-fluorolactams 12-1, was synthesized by Sathyamurthy et al. in 1990 [55]. These compounds had already been prepared by Grakauskas and co-worker in 1970 [56], but in low yields and the $N$-fluorolactams were not recognized as fluorinating agents at that time. For positron emission tomography (PET), Sathyamurthy et al. allowed these lactams to react with $0.05 \%{ }^{18} \mathrm{~F}_{2} / \mathrm{Ne}$ in a freon and obtained the $N$-[ $\left.{ }^{18} \mathrm{~F}\right]$ fluorolactams 12-1 in good yields (Scheme 27 , entry 1 ). The ${ }^{18} \mathrm{~F}$-transfer ability was demonstrated by fluorination reactions with various Grignard reagents in up to $51 \%$ yield (Scheme 27 , entry 2). In the event the $\beta$-elimination of HF proved to be an obstacle for the fluorination of strong bases such as phenyllithium.

\section{1-13. N-Fluoro-o-benzenedisulfonimide}

In 1991, Davis and co-worker reported $N$-fluoro-obenzenedisulfonimide (NFOBS, 13-2) as a fluorination reagent. NFOBS was prepared by the direct fluorination of its corresponding sulfonimide 13-1 with $10 \% \mathrm{~F}_{2} / \mathrm{N}_{2}$ in the presence of $\mathrm{NaF}$ and in high yield (Scheme 28) [57].

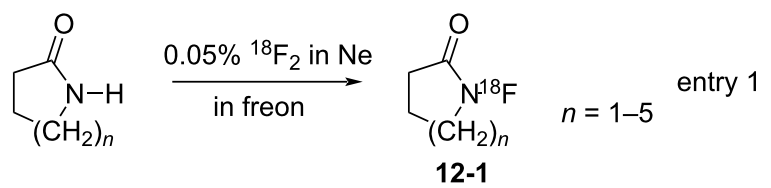

$$
\begin{aligned}
& \text { 33-79\% } \\
& \text { (radiochemical: 19-48\%) } \\
& \mathrm{RMgBr} \longrightarrow \begin{array}{ll}
N-\left[{ }^{18} \mathrm{~F}\right] \text { fluorolactams } \\
\mathbf{1 2 - 1}
\end{array} \quad \begin{array}{l}
\mathrm{R}^{18} \mathrm{~F} \quad 1-51 \% \quad \text { entry } 2 \\
\mathrm{R}=\text { phenyl, } p \text {-tolyl, } \\
\text { 1-naphthyl, cyclohexyl }
\end{array}
\end{aligned}
$$

Scheme 27: Synthesis and reaction of $N$-fluorolactams 12-1.<smiles>O=S1(=O)NS(=O)(=O)S(=O)(=O)c2ccccc21</smiles>

Scheme 28: Synthesis of NFOBS 13-2.

NFOBS is a stable and crystalline solid of mp $139-140{ }^{\circ} \mathrm{C}$ (dec) with good fluorinating power. Its usefulness was demonstrated through fluorination reactions with different types of carbanions (Scheme 29). For example, reactions with enolates gave $\alpha$-fluorinated products in $65-100 \%$ yields. Azaenolates could be fluorinated in moderate yields. A fluorination reaction with phenylmagnesium bromide provided fluorobenzene in $80 \%$ yield, an outcome which was better than that of $N$-fluoropyridinium triflate 5-4j (Umemoto's reagent, 58\%) and $N$-fluorosul- 
<smiles>O=C1CCCc2ccccc21</smiles><smiles>CCO[Pb](=O)OCC</smiles><smiles>[O+2][Co]</smiles><smiles>CC1CCc2ccccc2C1=O</smiles><smiles>CCC(=O)c1ccccc1</smiles><smiles>COC(=O)C(C)c1ccccc1</smiles><smiles>CC1CCCC1(C)[SH](=O)(/N=C1\CC2CCC1(C)C2(C)C)Oc1ccccc1</smiles>

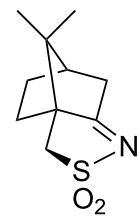

$$
\mathrm{PhMgBr}
$$<smiles>COc1cccc(OC)c1</smiles>
(neat)
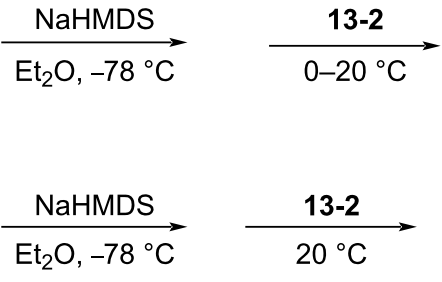

$$
\underset{\mathrm{Et}_{2} \mathrm{O},-78{ }^{\circ} \mathrm{C}}{\stackrel{\text { NaHMDS }}{\longrightarrow}} \frac{\mathbf{1 3 - 2}}{-78 \text { to } 20^{\circ} \mathrm{C}}
$$<smiles></smiles>

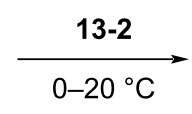<smiles>CC1(F)CCc2ccccc2C1=O</smiles><smiles>CCO[Pb]NC(=O)OCC</smiles><smiles>[14CH3][Mg]</smiles><smiles>CC(F)C(=O)c1ccccc1</smiles>

$87 \%$<smiles>COC(=O)C(C)(F)c1ccccc1</smiles>

$65 \%$<smiles>CC12CCC(C(F)C1=N[S+](=O)(O)Oc1ccccc1)C2(C)C</smiles>

60-65\%<smiles>CC12CCC(CS(=O)(=O)O)(C(F)C(F)C1[O+])C2(C)C</smiles>

$\mathrm{PhF} \quad 80 \%$<smiles>COc1ccc(F)c(OC)c1</smiles>

Scheme 29: Fluorination with NFOBS 13-2.

fonamide 4-1b (Barnette's reagent, 50\%). NFOBS was able to fluorinate 1,3-dimethoxybenzene under neat conditions, while attempts to fluorinate toluene and acetophenone failed. The details of these reactions and applications were described in a full paper later published in 1995 [58].

\section{1-14. N-Fluorobenzenesulfonimide (NFSI)}

In 1991, $N$-fluorobenzenesulfonimide (NFSI, 14-2) was synthesized by Differding and co-worker [59]. It was prepared from benzenesulfonimide 14-1 in good yield by its reaction with $10 \%$ $\mathrm{F}_{2} / \mathrm{N}_{2}$ in acetonitrile at $-40{ }^{\circ} \mathrm{C}$ (Scheme 30 ). NFSI is a stable and non-hygroscopic crystalline solid with a mp of $114-116^{\circ} \mathrm{C}$.

NFSI was shown to fluorinate a variety of nucleophiles. As seen in Scheme 31, trimethylsilyl enol ethers, enolate anions of ketones and esters, and aryl- and vinyllithiums were fluorinated

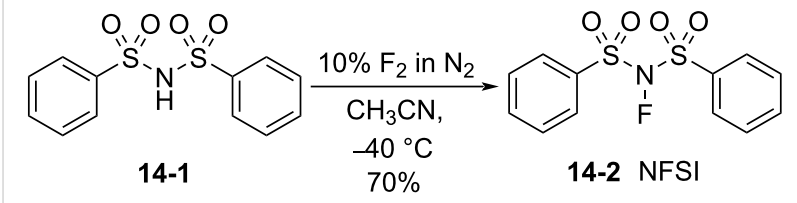

Scheme 30: Synthesis of NFSI (14-2)

with NFSI in moderate to high yields. Although aromatics such as anisole, toluene, and acetanilide could also be fluorinated by NFSI, these reactions required neat conditions and high temperatures, indicating that NFSI was not so powerful.

\section{1-15. $\mathrm{N}$-Fluorosaccharin and $\mathrm{N}$-fluorophthalimide}

In 1991, Gakh et al. reported the synthesis of $N$-fluorosaccharin (15-1) and $N$-fluorophthalimide (15-2) in their studies on the re- 

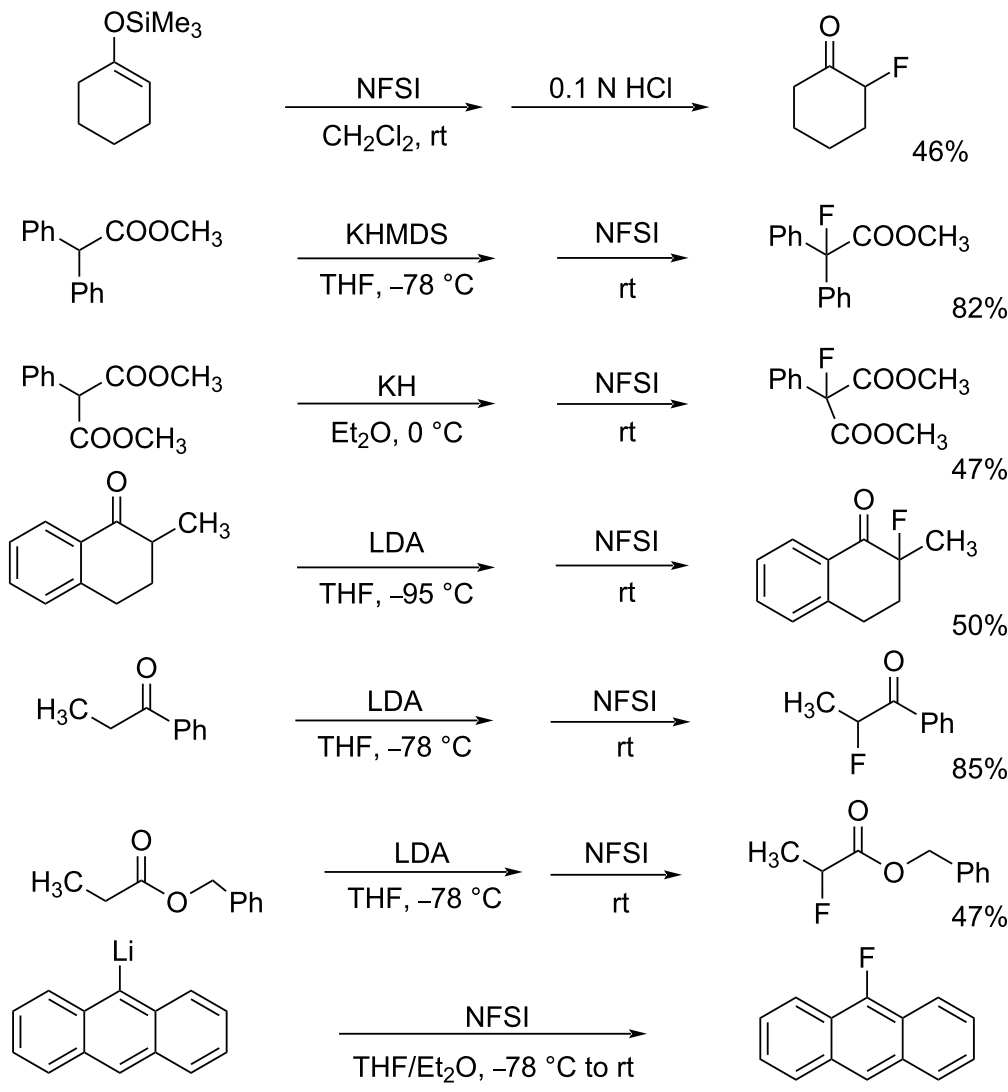<smiles>C/C(Cl)=C/c1ccccc1</smiles><smiles>CCCCCCCCCCOCC</smiles><smiles>C/C(F)=C\c1ccccc1</smiles>

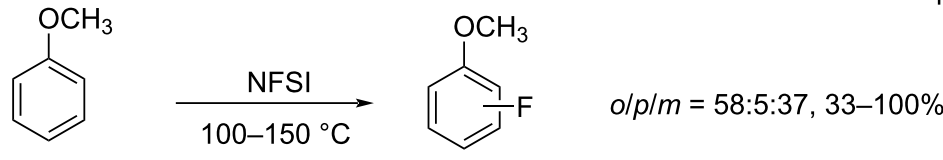

neat

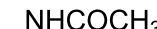<smiles>CNc1ccccc1</smiles><smiles>CC(=O)Nc1cccc(F)c1</smiles>
$o / p / m=62: 0: 38,40 \%$

neat<smiles>Cc1ccccc1</smiles><smiles>CCCCCC</smiles><smiles>Cc1ccccc1F</smiles>
$\mathrm{o} / \mathrm{p} / \mathrm{m}=65: 7: 28,19 \%$

Scheme 31: Fluorination with NFSI 14-2.

activity of cesium fluoroxysulfate $\left(\mathrm{Cs}^{+-} \mathrm{OSO}_{2} \mathrm{OF}\right)$ [60]. Sodium salts of saccharin and phthalimide reacted with cesium fluoroxysulfate in acetonitrile at $0-5{ }^{\circ} \mathrm{C}$ to give $\mathbf{1 5 - 1}$ and $\mathbf{1 5 - 2}$ in $69 \%$ and $48 \%$ yields, respectively (Scheme 32 ). However, they did not report any fluorination reactions with 15-1 and 15-2. A transfer reaction failed to generate $\mathrm{N}$-fluorosuccinimide from the reaction of the sodium salt of succinimide with cesium fluoroxysulfate. 


\section{$\overbrace{x^{\prime} H}^{O}$ \\ $\underset{\mathrm{CH}_{3} \mathrm{CN}, 0-5^{\circ} \mathrm{C}}{\stackrel{\mathrm{Cs}^{+}}{\longrightarrow}}$

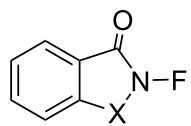 \\ 15-1 $\mathrm{X}=\mathrm{SO}_{2}: 69 \%$ \\ 15-2 $X=\mathrm{CO}: 48 \%$}

Scheme 32: Synthesis of $N$-fluorosaccharin (15-1) and $N$-fluorophthalimide (15-2).

\section{1-16. 1-Alkyl-4-fluoro-1,4-} diazoniabicyclo[2.2.2]octane salts

In 1992, Banks et al. reported a new series of $N$-fluoro diquaternary ammonium salts, 1-alkyl-4-fluoro-1,4-diazoniabicylco[2.2.2] octane salts 16-3a-d (Scheme 33) [42]. The salts 16-3 were synthesized in high yields after alkylation of 1,4diazabicyclo[2.2.2] octane (16-1), followed by the Umemoto's fluorination/counteranion replacement reaction of the resulting monoquaternary ammonium salts $\mathbf{1 6 - 2}$ with $10 \% \mathrm{~F}_{2} / \mathrm{N}_{2}$ in acetonitrile at -40 to $-20{ }^{\circ} \mathrm{C}$. The resultant salts $16-3$ proved to be stable, non-hygroscopic, crystalline solids with high fluorinating power. The salt 16-3a was chosen as the commercial reagent, Selectfluor ${ }^{\mathrm{TM}}$, from a cost-effectiveness viewpoint.

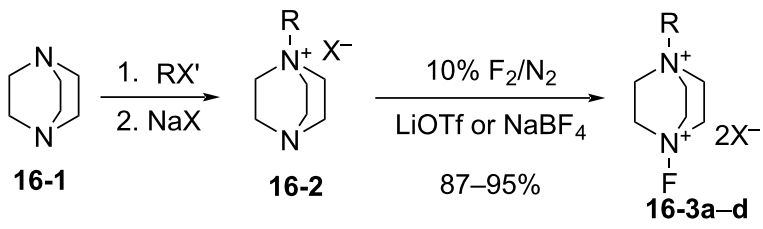

16-3a: $\mathrm{R}=\mathrm{CH}_{2} \mathrm{Cl}, \mathrm{X}=\mathrm{BF}_{4}$ $\left(F_{-T E D A-B F}\right)$, Selectfluor ${ }^{\mathrm{TM}}$

16-3b: $\mathrm{R}=\mathrm{CH}_{2} \mathrm{Cl}, \mathrm{X}=\mathrm{OTf}$ (F-TEDA-OTf)

16-3c: $\mathrm{R}=\mathrm{CH}_{2} \mathrm{CF}_{3}, \mathrm{X}=\mathrm{OTf}$

16-3d: $\mathrm{R}=\mathrm{CH}_{3}, \mathrm{X}=\mathrm{OTf}$

Scheme 33: Synthesis of $N-\mathrm{F}$ salts $16-3$

The fluorinating power of reagents $\mathbf{1 6 - 3}$ strengthened as the electronegativity of the $\mathrm{R}$ group increased in the order of $\mathrm{CH}_{3}<$ $\mathrm{CH}_{2} \mathrm{Cl}<\mathrm{CH}_{2} \mathrm{CF}_{3}$. The reagents $\mathbf{1 6 - 3}$ were able to fluorinate enol and conjugated enol acetates of steroids, sodium malonates, enamines, Grignard reagents, and aromatic compounds under mild conditions. In each case Selectfluor gave the corresponding fluorinated products in good to high yields (Scheme 34).

As can be seen in Figure 3 and Figure 4, two years later (1994), Banks et al. reported mono- and difluorinations of various 1,3dicarbonyl compounds using Selectfluor (16-3a) [61].
In 1995, the same group reported that Selectfluor reacted with quinuclidine to form $N$-fluoroquinuclidinium tetrafluoroborate in quantitative yield [62] (Scheme 35). They described this as a "transfer fluorination" since there was an intermolecular transfer of the fluorine atom of Selectfluor to the nitrogen of quinuclidine. In 1996, full details were published on the reactivities of all 16-3 reagents and the syntheses of 16-3 and intermediates 16-2 including additionally $\mathrm{C}_{2} \mathrm{H}_{5}$ and $\mathrm{C}_{8} \mathrm{H}_{17}$ as $\mathrm{R}$ group and $\mathrm{PF}_{6}{ }^{-}$and $\mathrm{FSO}_{3}{ }^{-}$as anion $\mathrm{X}^{-}[63,64]$.

The generous provision of free samples of Selectfluor after its commercialization resulted in many publications concerning its applications from a diversity of research groups and in a short time period (1992-1995): These included fluorinations of alkylbenzenes (entry 1, Scheme 36) [65], Grignard reagents (entry 2) [65], electron-rich alkenes (entry 3) [65,66], alkyl sulfides (entry 4) [65,67], 1,3-dicarbonyl compounds [65,68], phosphonate esters (entry 5) [65], steroidal silyl enol ethers and enol acetates (entry 6) [65], pyrimidine bases and nucleosides (entry 7) [67,69], phenylalkynes (entry 8) [70], anthraquinones (entry 9) [71], vinylstannanes (entry 10) [72], trialkylstannylindoles [73], and cyclopentadienylthallium (entry 11, Scheme 36) [74].

\section{1-17. Optically active $N$-fluoro-2,10-(3,3-dichloro- camphorsultam)}

In 1993, Davis et al. reported the synthesis of the second optically active $N$-fluoro-2,10-(3,3-dichlorocamphorsultam) 17-2 [75] (Scheme 37).

The maximum enantioselectivity of enolates of $\beta$-ketoesters with (-)-9-1 or (+)-9-2, first prepared by Lang in 1988 (see section 1-9), was $70 \%$ ee. The asymmetric fluorination with (+)- or (-)-17-2 afforded up to $75 \%$ ee as indicated in Scheme 38. The dichloro reagent 17-2 gave higher yields than the non-chloro reagent $\mathbf{9 - 1}$ because of the greater reactivity of 17-2.

\section{1-18. Zwitterionic $N$-fluoropyridinium salts}

In 1995, Umemoto and co-worker disclosed a zwitterionic $\mathrm{N}$-fluoropyridinium salt system 18-2 which had a broad fluorinating power and high selectivity [76]. A series of $N$-fluoropyridinium-2-sulfonates with electron-withdrawing or -donating substituents were synthesized in high yields by fluorination of the corresponding pyridinium-2-sulfonates 18-1 with $10 \%$ $\mathrm{F}_{2} / \mathrm{N}_{2}$ in acetonitrile or a mixture of acetonitrile/water at -40 to $-10{ }^{\circ} \mathrm{C}$ (Figure 5). In a few cases, a catalytic amount of triethylamine was used to improve the yields. The starting pyridinium2 -sulfonates possessing an electron-withdrawing group(s) were prepared in high yields from the reaction of the corresponding 2-chloropyridines with sodium sulfite. All of these $N$-F reagents are easy-to-handle and stable crystalline solids. 
<smiles>CC(=O)OC1CCC2C3CC=C4C=C(C(=O)O)CCC4(C)C3CCC12C</smiles>

$\underset{\mathrm{MeCN}, 25^{\circ} \mathrm{C}}{\stackrel{\text { 16-3a/Selectfluor }}{\longrightarrow}}$

$95 \%$<smiles>CC(=O)OC1CCC2C3CC(F)C4=CC(=O)CCC4(C)C3CCC12C</smiles><smiles>CC(=O)OC1CCC2C3CCC4CC(C(=O)O)CCC4(C)C3CCC12C</smiles>

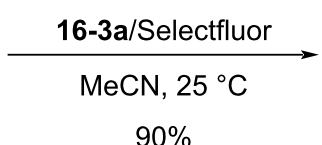<smiles>CC12CCC(C(=O)O)CC1CCC1C2CCC2(C)C1CC(F)C(O)C2(C)C</smiles><smiles>C1=C(N2CCOCC2)CCCC1</smiles>

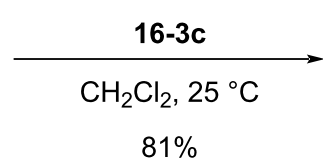<smiles>O=C1CCCCC1F</smiles><smiles>Br[Mg]Br</smiles>

16-3b

$\mathrm{Et}_{2} \mathrm{O}, 25^{\circ} \mathrm{C}$<smiles>Fc1ccccc1</smiles>

$66 \%$<smiles>CC(=O)Nc1ccccc1</smiles>

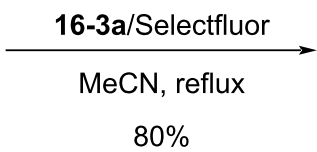<smiles>CC(=O)NC1=CC=CC=[I-]1</smiles>

$o / p=62: 38$

$\mathrm{PhC}^{-}\left(\mathrm{Na}^{+}\right)\left(\mathrm{CO}_{2} \mathrm{Et}\right)_{2}$

$16-3 d$

THF/DMF $2: 1,25^{\circ} \mathrm{C}$

$\operatorname{PhCF}\left(\mathrm{CO}_{2} \mathrm{Et}\right)_{2}$

$93 \%$

Scheme 34: Fluorination with $N-\mathrm{F}$ salts $16-3$<smiles>[R]C(=O)C([R])C([R])=O</smiles>

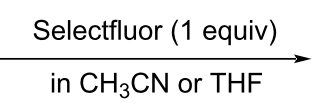
it

\begin{tabular}{cllllll}
\hline entry & $\mathrm{R}^{1}$ & $\mathrm{R}^{2}$ & base & $\mathrm{R}^{3}$ & time & yield \% \\
\hline 1 & $-\left(\mathrm{CH}_{2}\right)_{3}-$ & non & $\mathrm{Me}$ & $19 \mathrm{~h}$ & 84 \\
2 & $\mathrm{Ph}$ & $\mathrm{Ph}$ & non & $\mathrm{H}$ & $5 \mathrm{~h}$ & 84 \\
3 & $\mathrm{Ph}$ & $\mathrm{OEt}$ & non & $\mathrm{H}$ & $54 \mathrm{~h}$ & 22 \\
4 & $\mathrm{Me}$ & $\mathrm{OEt}$ & non & $\mathrm{H}$ & $120 \mathrm{~h}$ & $(57 \mathrm{crude})$ \\
5 & $\mathrm{OEt}$ & $\mathrm{OEt}$ & $\mathrm{NaH}$ & $\mathrm{Ph}$ & $20 \mathrm{~h}$ & 93 \\
6 & $\mathrm{Ph}$ & $\mathrm{NMe}$ & $\mathrm{non}$ & $\mathrm{H}$ & $3 \mathrm{~h}$ & 87 \\
7 & $\mathrm{Ph}$ & $\mathrm{N}(\mathrm{Me}) \mathrm{CH}(\mathrm{Ph}) \mathrm{Me}$ & non & $\mathrm{H}$ & $67 \mathrm{~h}$ & 80
\end{tabular}

Figure 3: Monofluorination with Selectfluor (16-3a).

The nature of the lipophilic alkyl or trifluoromethyl substituents had a significant effect on the reactivity. Previously, $\mathrm{N}$-fluoropyridinium-2-sulfonate and its 6-chloro derivative had

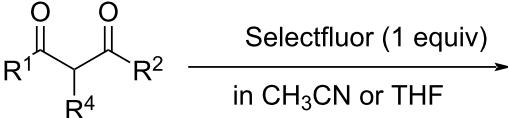<smiles>[R]C(=O)C(F)(F)C([R])=O</smiles>

\begin{tabular}{ccccccccc} 
entry & $\mathrm{R}^{1}$ & $\mathrm{R}^{2}$ & $\mathrm{R}^{4}$ & mol ratio & base & temp & time & yield \% \\
\hline 1 & $\mathrm{Ph}$ & $\mathrm{Ph}$ & $\mathrm{H}$ & 2.1 & non & $\mathrm{rt}$ & $192 \mathrm{~h}$ & 78 \\
2 & $\mathrm{Ph}$ & $\mathrm{NMe}_{2}$ & $\mathrm{H}$ & 3.2 & non & $40{ }^{\circ} \mathrm{C}$ & $647 \mathrm{~h}$ & 91 \\
3 & $\mathrm{Ph}$ & $\mathrm{OEt}$ & $\mathrm{F}$ & 1.1 & $\mathrm{NaH}$ & $\mathrm{rt}$ & $24 \mathrm{~h}$ & 95 \\
4 & $\mathrm{Ph}$ & $\mathrm{NMe}_{2}$ & $\mathrm{~F}$ & 1.2 & $\mathrm{NaH}$ & $\mathrm{rt}$ & $27 \mathrm{~h}$ & 73
\end{tabular}

${ }^{*}$ mol ratio $=$ Selectfluor:substrate

\section{Figure 4: Difluorination with Selectfluor (16-3a).}

been synthesized and shown to have excellent selectivity in fluorination reactions, but these reagents exhibited a low reactivity due to their low solubility in organic solvents [32]. 


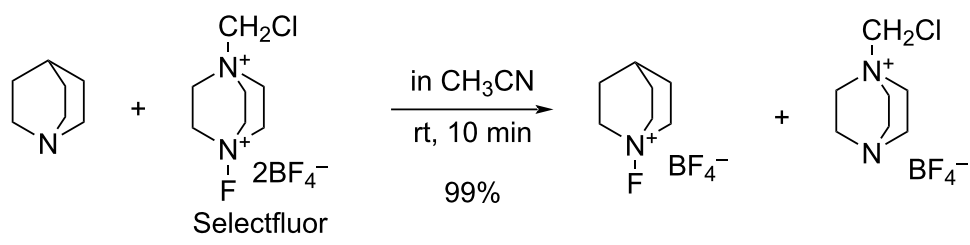

Scheme 35: Transfer fluorination of Selectfluor (16-3a).

$$
\begin{aligned}
& \begin{array}{llll}
\text { toluene } & \text { Selectfluor } & \begin{array}{l}
\text { o-fluorotoluene } \\
\text { p-fluorotoluene }
\end{array} & 60 \% \\
\text { in } \mathrm{CH}_{3} \mathrm{CN} \text {, reflux, } 16 \mathrm{~h} & 20 \% & \text { entry } 1
\end{array} \\
& \mathrm{CH}_{3}\left(\mathrm{CH}_{2}\right)_{11} \mathrm{MgBr} \quad \stackrel{\text { Selectfluor }}{\stackrel{\text { in } \mathrm{Et}_{2} \mathrm{O}, \mathrm{rt}, 16 \mathrm{~h}}{\mathrm{C}_{12} \mathrm{H}_{25} \mathrm{~F}} \quad 58 \%} \quad \text { entry } 2 \\
& \operatorname{PhC}\left(\mathrm{CH}_{3}\right)=\mathrm{CH}_{2} \underset{\mathrm{CH}_{3} \mathrm{CN} / \mathrm{MeOH}}{\mathrm{Selectfluor}} \quad \mathrm{Ph}\left(\mathrm{CH}_{3}\right)(\mathrm{OMe})-\mathrm{CH}_{2} \mathrm{~F} \quad 98 \% \quad \text { entry } 3 \\
& \mathrm{PhSCH}_{3} \stackrel{\text { 1. Selectfluor }}{\cline { 2 - 3 }} \underset{2 . \mathrm{Et}_{3} \mathrm{~N}}{\mathrm{PhS}} \mathrm{Ph}(\mathrm{O}) \mathrm{CH}_{2} \mathrm{~F} \quad 48 \% \quad \text { entry } 4 \\
& \text { 3. NBS } \\
& \mathrm{PhSO}_{2} \mathrm{C}^{-} \mathrm{H}\left(\mathrm{K}^{+}\right) \mathrm{P}(\mathrm{O}) \mathrm{OEt}_{2} \underset{t \text {-BuOH/DMF, rt, } 10 \mathrm{~min}}{\stackrel{\text { Selectfluor }}{\longrightarrow}} \mathrm{PhSO}_{2} \mathrm{CHFP}(\mathrm{O}) \mathrm{OEt}_{2} \quad 63 \% \quad \text { entry } 5 \\
& \text { Selectfluor }
\end{aligned}
$$

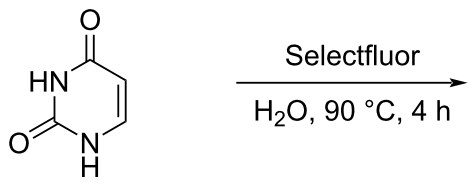

$$
\begin{aligned}
& \mathrm{Ph} \stackrel{\text { Selectfluor }}{=} \underset{\mathrm{CH}_{3} \mathrm{CN} / \mathrm{H}_{2} \mathrm{O} \text {, reflux }}{=} \\
& \text { entry } 6 \\
& 92 \%, \alpha / \beta=95: 5 \\
& \text { entry } 10 \\
& 45 \%
\end{aligned}
$$
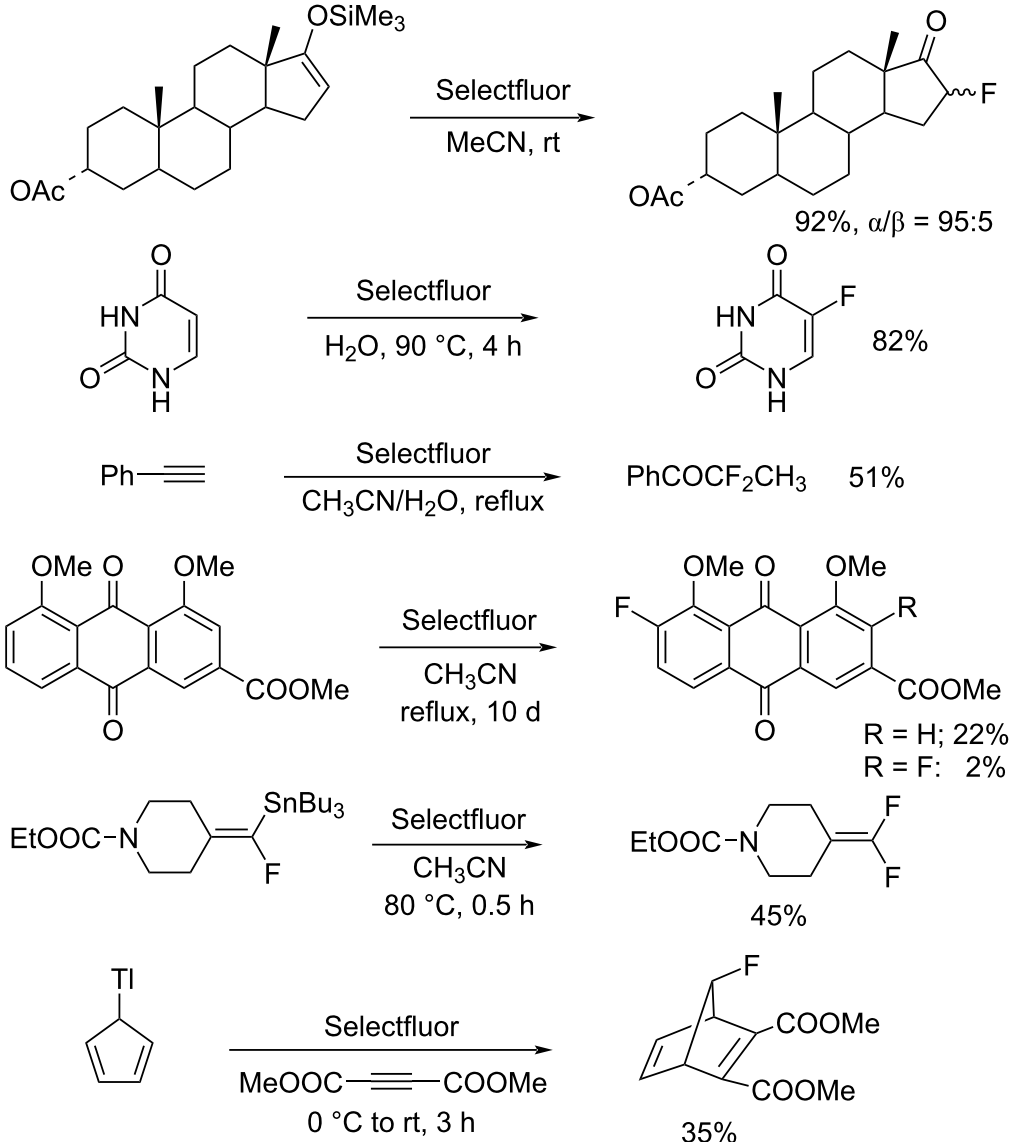

Scheme 36: Fluorination of substrates with Selectfluor (16-3a). 


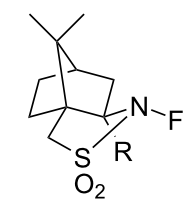

$(-)-9-1: R=H$

$(+)-9-2: R=M e$

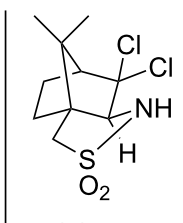

$(+)-17-1$

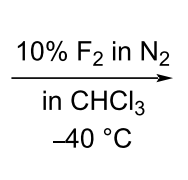

$68 \%$

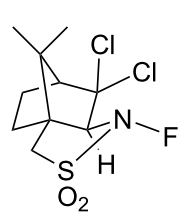

$(+)-17-2$
Scheme 37: Synthesis of chiral $N$-fluoro-sultam 17-2
Their fluorinating power increased in the order of 18-2a $<\mathbf{2 b} \approx$ $\mathbf{2 c} \approx \mathbf{2} \mathbf{d} \approx \mathbf{2} \mathbf{e}<\mathbf{2 f}<\mathbf{2 g}<\mathbf{2 h}$, consistent with the order of the $\mathrm{p} K_{\mathrm{a}}$ values of the pyridines (Scheme 39 ). The least powerful 18-2a was suitable for the fluorination of reactive carbanions and easily oxidizable sulfides, whereas the most powerful $\mathbf{1 8 - 2 h}$ was suitable for less-reactive substrates such as olefins, aromatics, and neutral active methylene compounds. $N$-Fluoro6-(trifluoromethyl)pyridinium-2-sulfonate (18-2f') was prepared later [77].<smiles>CC1CCc2ccccc2C1=O</smiles><smiles>COc1ccc(OC)c2c1CCC(C(C)=O)C2=O</smiles><smiles>CCOC(=O)C1CCCC1=O</smiles><smiles>CCOC(=O)C(C)c1ccccc1</smiles>
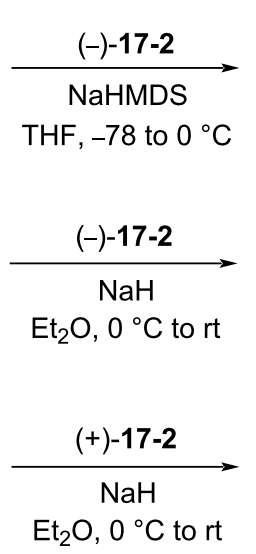

$(+)-17-2$

NaHMDS

THF, $-78^{\circ} \mathrm{C}$<smiles>CC1(F)CCc2ccccc2C1=O</smiles>

$40 \%, 75 \%$ ee<smiles>COC(=O)C1(F)CCc2c(OC)ccc(OC)c2C1=O</smiles><smiles>CCOC(=O)C1(F)CCCC1=O</smiles>

$59 \%, 34 \%$ ee<smiles>CCOC(=O)C(C)(F)c1ccccc1</smiles>

$54 \%, 33 \%$ ee

Scheme 38: Asymmetric fluorination with chiral 17-2<smiles>[R]c1nc([S+]([O])=O)c([R])c([R])c1[R]</smiles>

18-1

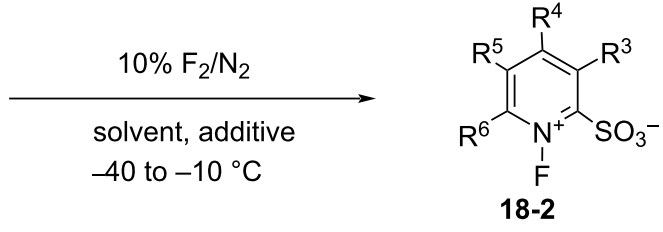

18-2

\begin{tabular}{|c|c|c|c|c|c|c|c|c|c|c|}
\hline \multirow{2}{*}{ entry } & \multirow{2}{*}{$18-1$} & \multicolumn{4}{|c|}{ substituent $\mathrm{R}$} & \multirow[b]{2}{*}{ additive } & \multirow[b]{2}{*}{ solvent } & \multirow[b]{2}{*}{$\begin{array}{l}\text { temp. } \\
\left({ }^{\circ} \mathrm{C}\right)\end{array}$} & \multirow[b]{2}{*}{$\begin{array}{l}\text { product } \\
18-2\end{array}$} & \multirow[b]{2}{*}{$\begin{array}{l}\text { yield of } \\
18-2(\%)\end{array}$} \\
\hline & & $\mathrm{R}^{3}$ & $\mathrm{R}^{4}$ & $\mathrm{R}^{5}$ & $\mathrm{R}^{6}$ & & & & & \\
\hline 1 & $18-1 \mathbf{a}(\mathrm{M}=\mathrm{Na})$ & $\mathrm{H}$ & $\mathrm{CH}_{3}$ & $\mathrm{H}$ & $\mathrm{CH}_{3}$ & - & $\mathrm{CH}_{3} \mathrm{CN} / \mathrm{H}_{2} \mathrm{O} \quad 10: 1$ & -20 & $18-2 a$ & 88 \\
\hline 2 & $18-1 b(M=H)$ & $\mathrm{H}$ & $\mathrm{CH}_{3}$ & $\mathrm{H}$ & $\mathrm{H}$ & $\mathrm{Et}_{3} \mathrm{~N}$ & $\mathrm{CH}_{3} \mathrm{CN}$ & -20 & $18-2 b$ & 91 \\
\hline 3 & $18-1 c(M=H)$ & $\mathrm{H}$ & $\mathrm{C}_{2} \mathrm{H}_{5}$ & $\mathrm{H}$ & $\mathrm{H}$ & - & $\mathrm{CH}_{3} \mathrm{CN}$ & -20 & $18-2 c$ & 79 \\
\hline 4 & $18-1 d(M=H)$ & $\mathrm{H}$ & $t$-Bu & $\mathrm{H}$ & $\mathrm{H}$ & - & $\mathrm{CH}_{3} \mathrm{CN} / \mathrm{H}_{2} \mathrm{O} 20: 1$ & -20 & $18-2 d$ & 84 \\
\hline 5 & 18-1e $(M=H)$ & $\mathrm{H}$ & $\mathrm{H}$ & $\mathrm{H}$ & $\mathrm{CH}_{3}$ & - & $\mathrm{CH}_{3} \mathrm{CN} / \mathrm{H}_{2} \mathrm{O} 10: 1$ & -20 & $18-2 e$ & 65 \\
\hline 6 & $18-1 f(M=H)$ & $\mathrm{H}$ & $\mathrm{H}$ & $\mathrm{CF}_{3}$ & $\mathrm{H}$ & $\mathrm{Et}_{3} \mathrm{~N}$ & $\mathrm{CH}_{3} \mathrm{CN}$ & -20 & $18-2 f$ & 95 \\
\hline 7 & 18-1g $(M=H)$ & $\mathrm{Cl}$ & $\mathrm{H}$ & $\mathrm{CF}_{3}$ & $\mathrm{H}$ & - & $\mathrm{CH}_{3} \mathrm{CN}$ & -10 & $18-2 g$ & 84 \\
\hline 8 & $18-1 \mathrm{~h}(\mathrm{M}=\mathrm{H})$ & $\mathrm{H}$ & $\mathrm{CF}_{3}$ & $\mathrm{H}$ & $\mathrm{CF}_{3}$ & - & $\mathrm{CH}_{3} \mathrm{CN}$ & -40 & $18-2 \mathrm{~h}$ & 95 \\
\hline
\end{tabular}




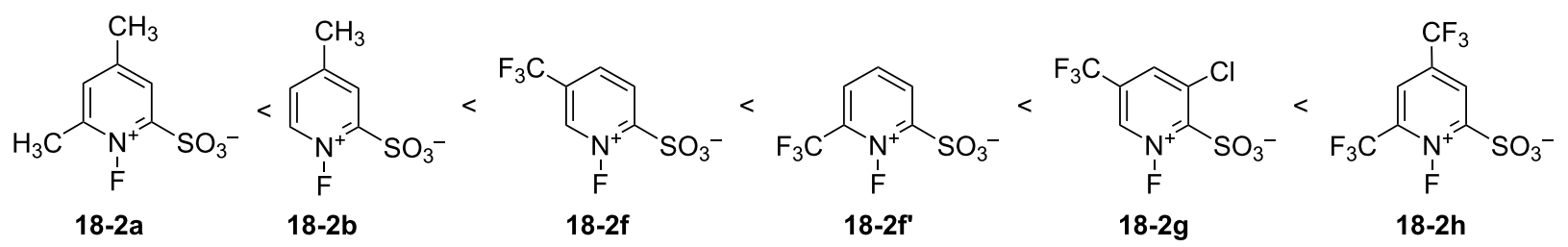

Scheme 39: Fluorinating power order of zwitterionic $N$-fluoropyridinium salts.

As shown in Scheme 40, the 18-2 pyridinium series proved to the fluorination of phenol. This could be attributed to a hydrobe effective fluorinating agents for a wide range of substrates. gen-bonding interaction between the sulfonate anion and the Moreover, an extremely high ortho-selectivity was observed in phenol hydroxy group in the transition state. This assumption

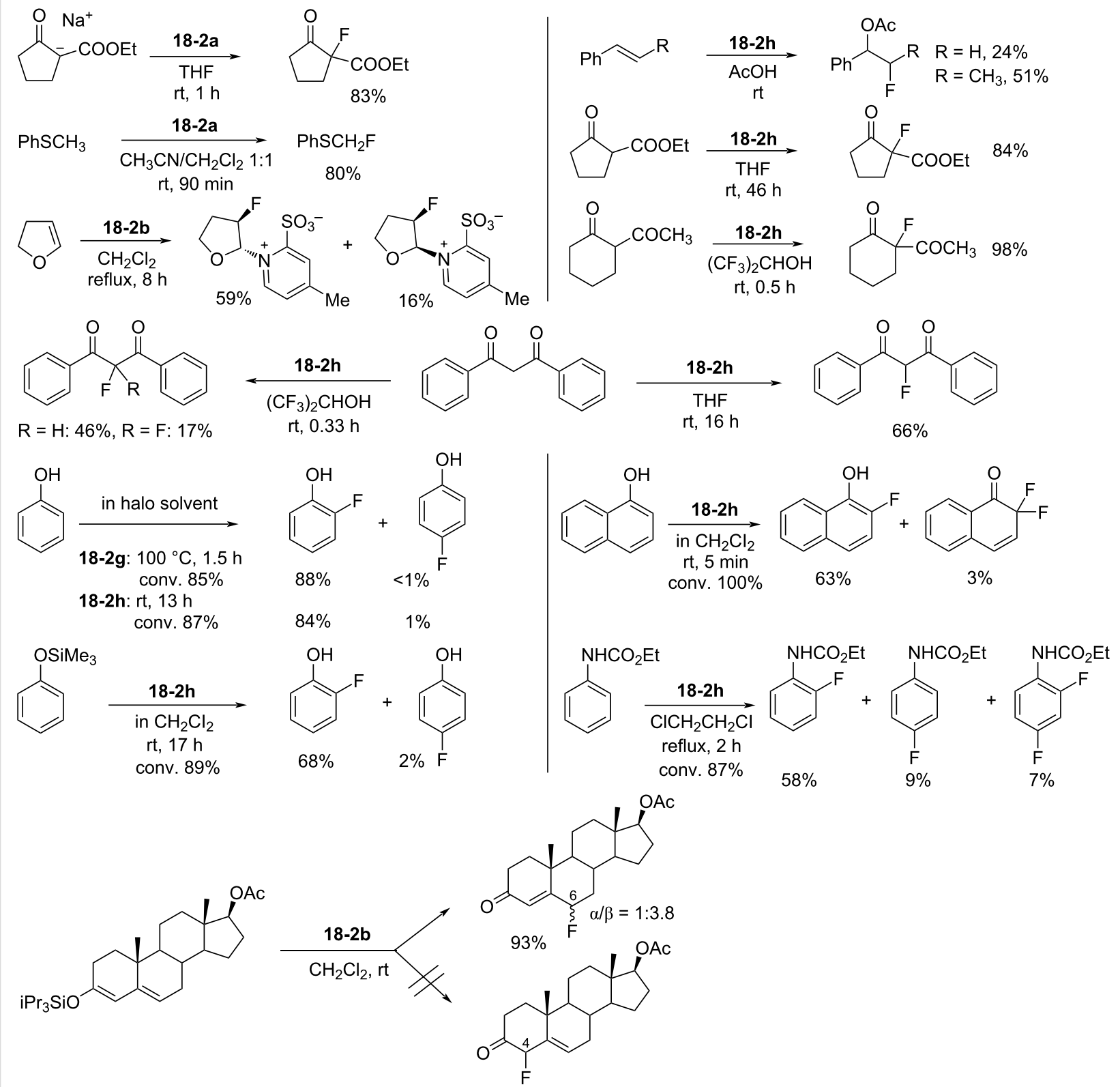


could also explain the high $o$-selectivity obtained in the fluorinations of naphthol, phenylurethane, and trimethylsilyl ether of phenol, and the exclusive 6-selectivity observed in the fluorination of conjugated enol triisopropylsilyl ethers of steroids. An additional advantage of the $\mathbf{1 8 - 2}$ reagents is that, after the fluorinations, the resulting pyridine-sulfonic acids are easily removed in an aqueous work-up.

As illustrated in Scheme 41, triflic acid was shown to promote the fluorination of anisole with $\mathbf{1 8 - 2 h}$. While the reaction time was $\approx 30 \mathrm{~h}$ without the additive (entry 1 , Scheme 41 ), 1 equiv of TfOH shortened this to less than $1 \mathrm{~h}$ (entry 2). Therefore, it would appear that this additive acted as a catalyst. With 0.1 equiv of $\mathrm{TfOH}$, the reaction time was $5.5 \mathrm{~h}$ (entry 3 ) which can be attributed to the strong electron-withdrawing effect of the $2-\mathrm{SO}_{3} \mathrm{H}$ substituent formed by the protonation of the sulfonate anion in $\mathbf{1 8 - 2 h}$

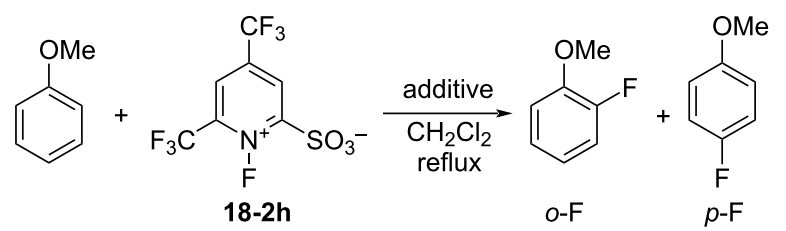

\begin{tabular}{llllll} 
& & & & \multicolumn{2}{c}{ yield $\%$} \\
\cline { 5 - 6 } entry & additive & time $\mathrm{h}$ & conv. $\%$ & $o-\mathrm{F}$ & $p-\mathrm{F}$ \\
2 & non & 29.5 & 80 & 30 & 46 \\
2 & TfOH (1 equiv) & 0.3 & 85 & 26 & 54 \\
3 & TfOH (0.1 equiv) & 5.5 & 81 & 30 & 53
\end{tabular}

Scheme 41: Activation of salt 18-2h with $\mathrm{TfOH}$.

\section{1-19. 1-Fluoro-4-hydroxy-1,4-}

\section{diazoniabicyclo[2.2.2]octane salts (NFTh)}

In 1995, Poss and Shia disclosed the synthesis and fluorination reactivity of 1-fluoro-4-hydroxy-1,4-diazoniabicyclo[2.2.2] octane bis(tetrafluoroborate) (19-2, NFTh/Accufluor ${ }^{\mathrm{TM}}$ ) in a patent [78]. According to the patent, NFTh was prepared by fluorination of 1,4-diazabicyclo[2.2.2] octane $N$-oxide (19-1) in acetonitrile or water with $10 \% \mathrm{~F}_{2} / \mathrm{N}_{2}$ in the presence of $\mathrm{HBF}_{4}$, $\mathrm{NaBF}_{4}, \mathrm{BF}_{3}$ etherate, and/or $\mathrm{BF}_{3}$ at $-35{ }^{\circ} \mathrm{C}$ or $8-9{ }^{\circ} \mathrm{C}$. Scheme 42 shows the preparation of NFTh, a white solid that decomposes at $125^{\circ} \mathrm{C}$.

The fluorination scope of NFTh is shown in Scheme 43 [79,80]. NFTh reacted with aromatics, enols, ketones, activated olefins, and substrates with active methylene groups to produce the corresponding fluorinated products in good to high yields. NFTh is a powerful fluorinating agent comparable to Selectfluor. Since NFTh has an acidic proton, its effectiveness is curtailed in the case of anionic substrates.

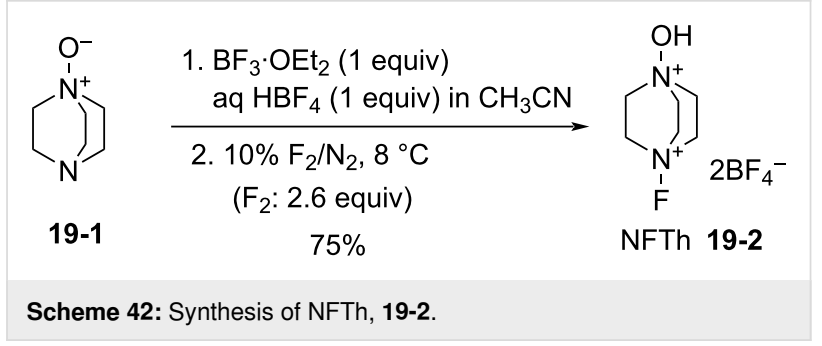

\section{1-20. N-Fluorobenzo-oxathiazone dioxide}

In 1995, Cabrera and co-worker claimed 3-fluorobenzo-1,2,3oxathiazin-4-one 2,2-dioxide (20-2) to be a useful fluorinating agent; 20-2 is a stable crystalline compound that was prepared in $83 \%$ yield by fluorination of its precursor 20-1 with $5 \%$ $\mathrm{F}_{2} / \mathrm{N}_{2}$ in acetonitrile and in the presence of $\mathrm{NaF}$ at $-40{ }^{\circ} \mathrm{C}$ [81] (Scheme 44). They also tried to prepare $N$-fluorosaccharin (20-3) from saccharin with the $\mathrm{F}_{2} / \mathrm{N}_{2}$ system, but failed. Reagent 20-3 was synthesized using cesium fluoroxysulfate in 1991 (see section 1-15).

Reagent 20-2 proved useful for the fluorination of both neutral and anionic nucleophiles under mild conditions. Scheme 45 illustrates some pertinent examples. Phenyl Grignard reagent, active methylene compounds, and a conjugated enol acetate of a steroid were all fluorinated in moderate to high yields. The fluorination of anisole required high temperature and neat conditions suggesting that the fluorination power of $\mathbf{2 0 - 2}$ is not so high.

\section{1-21. Perfluoro[ $N$-fluoro- $N$-(4-pyridyl)acetamide]}

In 1996, the Banks group reported perfluoro[ $N$-fluoro- $N$-(4pyridyl)acetamide] (21-3) as a carboxamide analogue of perfluoro[ $N$-fluoro- $N$-(4-pyridyl)methanesulfonamide] (11-2, see section 1-11) [82]. Its precursor, 21-2, was prepared from pentafluoropyridine by either one of two methods (Scheme 46). Precursor 21-2 was treated with neat $\mathrm{F}_{2}$ at $10-20 \mathrm{mmHg}$ pressure in acetonitrile at $-35{ }^{\circ} \mathrm{C}$ to produce the $N$-F carboxamide 21-3 in 75\% yield but the resulting product was a 79:18 mixture of the desired $N$-F product $\mathbf{2 1 - 3}$ and the protonated compound 21-1.

As a reagent $N$-F carboxamide 21-2 fluorinated electron-rich substrates such as sodium diethyl (phenyl)malonate, 1-morpholinocyclohexene, phenol, and anisole (Scheme 47). The fluorination power of the carboxamide 21-2 was less than that of its $N$-F sulfonamide analog 11-2.

\section{1-22. N,N'-Difluoro-1,4-diazoniabicyclo[2.2.2]octane salts}

In 1996, Umemoto and co-worker reported the successful synthesis of various $N, N^{\prime}$-difluoro-1,4-diazoniabicyclo[2.2.2] oc- 
<smiles>CCCCCCC(C)=O</smiles><smiles>CCCCCC(F)C(C)=O</smiles>

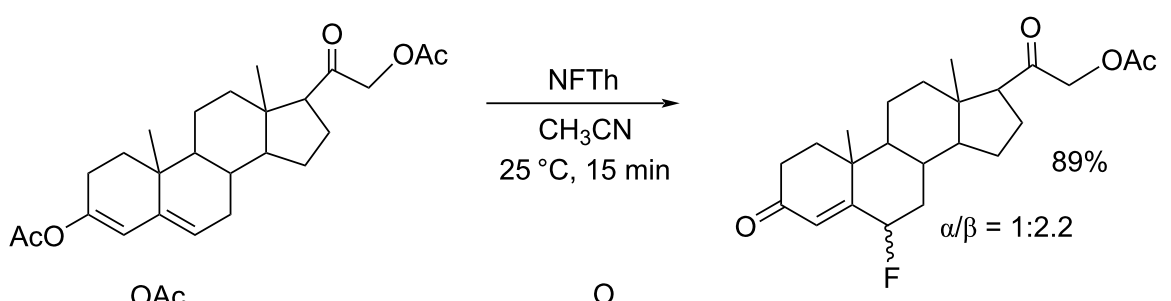<smiles>CC(C)(C)C1CCC(=O)C(F)C1CNc1ccccc1</smiles><smiles>C=C(C)c1ccccc1</smiles>

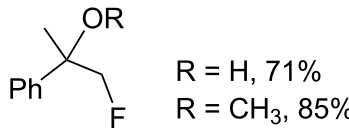

rt, $24 \mathrm{~h}$<smiles>O=C1C=CCCC1</smiles><smiles>CCCCCCCCCC[NH3+]</smiles><smiles>O=C1C=CCCC1F</smiles>
$80^{\circ} \mathrm{C}, 8 \mathrm{~h}$<smiles>CNc1ccccc1</smiles><smiles>[R]c1ccc(F)cc1</smiles>

NFTh

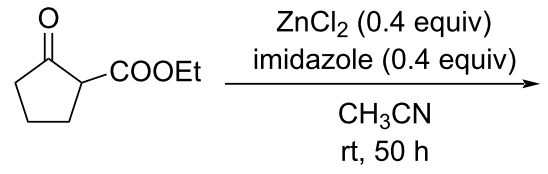<smiles>CCOC(=O)C1(F)CCCC1=O</smiles><smiles>O=C(CC(=O)c1ccccc1)c1ccccc1</smiles>

NFTh (2 equiv) $\mathrm{ZnCl}_{2}$ (0.4 equiv collidine (1 equiv)) $\mathrm{CH}_{3} \mathrm{CN}$ $50{ }^{\circ} \mathrm{C}, 48 \mathrm{~h}$<smiles>O=C(c1ccccc1)C(F)(F)C(=O)c1ccccc1</smiles>

$68 \%$

Scheme 43: Fluorination with NFTh, 19-2.<smiles></smiles>

20-1<smiles>CN(C)CCN[Pb]</smiles>

$-40^{\circ} \mathrm{C}$<smiles>O=C1c2ccccc2OS(=O)(=O)N1F</smiles>
$83 \%$

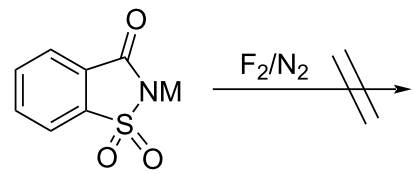

saccharin $\mathrm{M}=\mathrm{H}$ or $\mathrm{Na}$<smiles>O=C1c2ccccc2S(=O)(=O)N1F</smiles> 


$\mathrm{PhMgBr} \quad \stackrel{\text { 20-2 (1 equiv) }}{\stackrel{\mathrm{THF}, \text { rt, } 4 \mathrm{~h}}{\longrightarrow}} \quad \mathrm{Ph}-\mathrm{F} \quad 52 \%$

$\mathrm{PhC}(\mathrm{Na})(\mathrm{COOEt})_{2} \quad \stackrel{\mathbf{2 0 - 2}(1 \text { equiv })}{\stackrel{\mathrm{THF}, \mathrm{rt}, 30 \mathrm{~min}}{\longrightarrow}} \quad \mathrm{PhC}(\mathrm{F})(\mathrm{COOEt})_{2} \quad 86 \%$
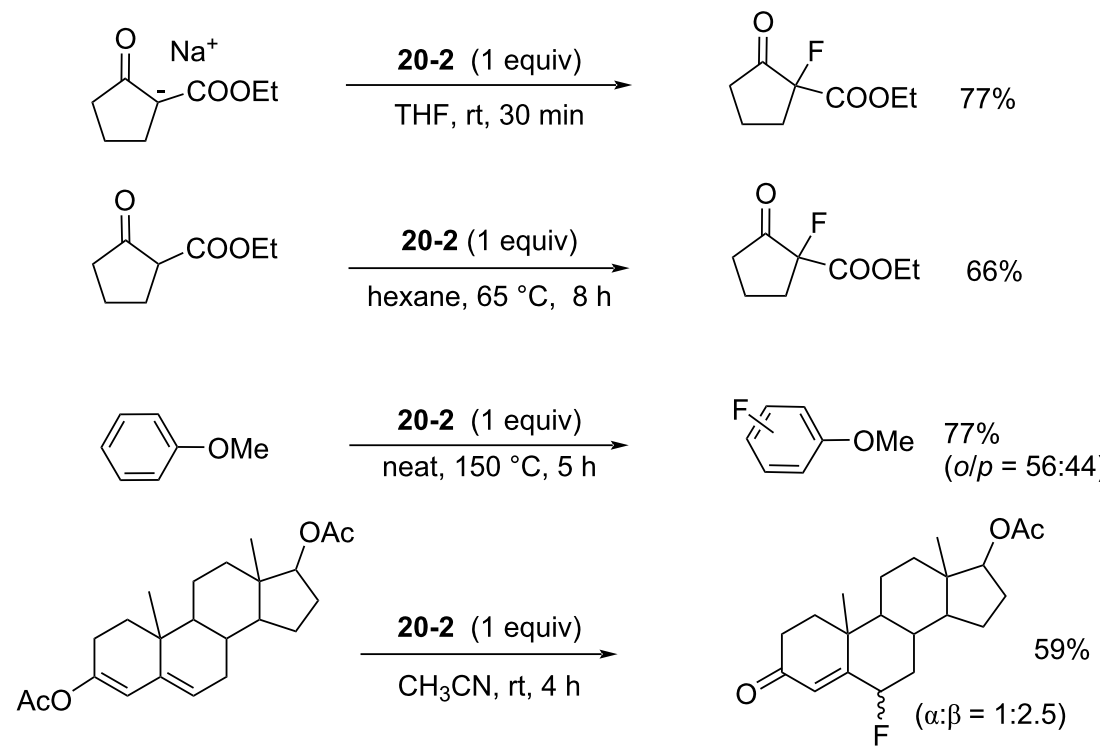

Scheme 45: Fluorination with 20-2.

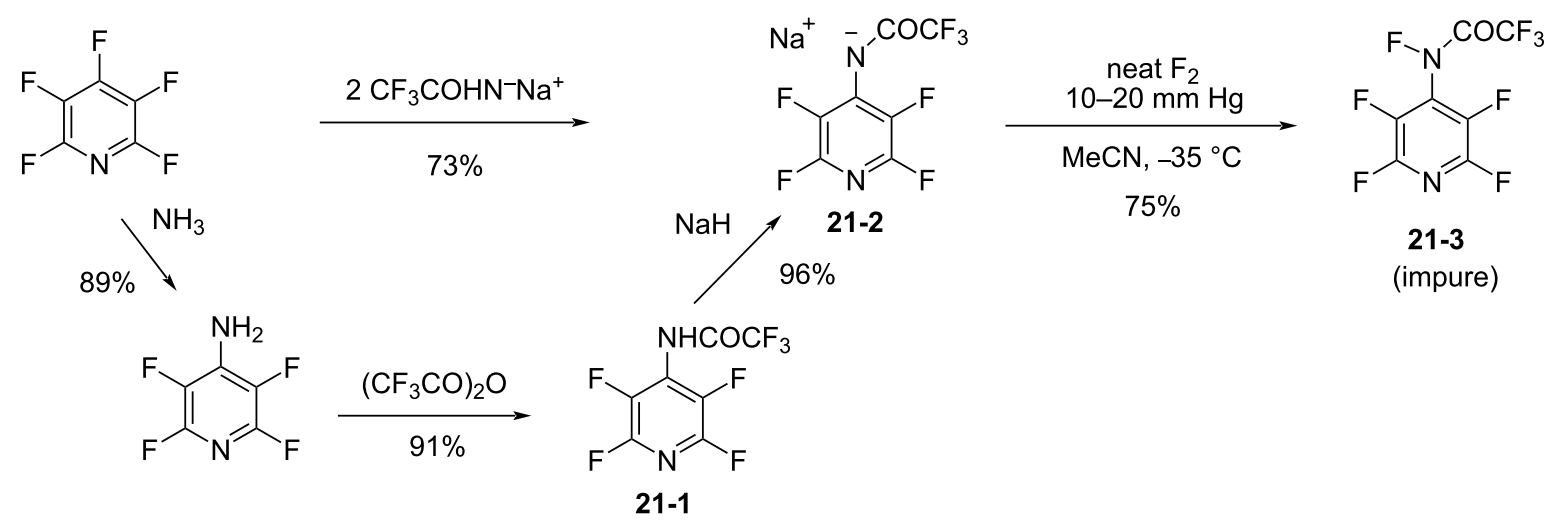

Scheme 46: Synthesis of N-F amide 21-3.

tane salts 22-1a-f in a pure form and in good to excellent yields (Scheme 48) [83]. All the salts were fully identified by elemental analysis and spectral analysis. Previously, in 1992 Banks and co-workers described how attempts to synthesize 22-1 proved to be unsatisfactory [42] and in 1995, they reported their synthesis characterized only by ${ }^{19} \mathrm{~F}$ NMR and described that the salts were moisture-sensitive [84].

The synthesis is sensitive to solvents and the amount of Brønsted acids (HX). N,N'-Difluoro-1,4-diazoniabi- cyclo[2.2.2] octane bistriflate (22-1a), bis(hydrogensulfate) 22-1b, hydrogensulfate bishydrogenfluoride fluoride 22-1c, bishexafluoroantimonate 22-1e, and bishexafluorophosphate 22-1f were prepared in a pure form by fluorination of 1,4-diazabicyclo[2.2.2] octane (DABCO) with $10 \% \mathrm{~F}_{2} / \mathrm{N}_{2}$ in hexafluoroisopropanol in the presence of two molar equivalents or fewer of HX (one-step method, Scheme 48). The bisSbF $_{6}$ salt 22-1e and bisPF ${ }_{6}$ 22-1f could also be prepared in a pure form by using acetonitrile as the solvent. However, bisBF 4 salt $\mathbf{2 2 - 1 d}$ could not be satisfactorily synthesized by this one-step protocol 


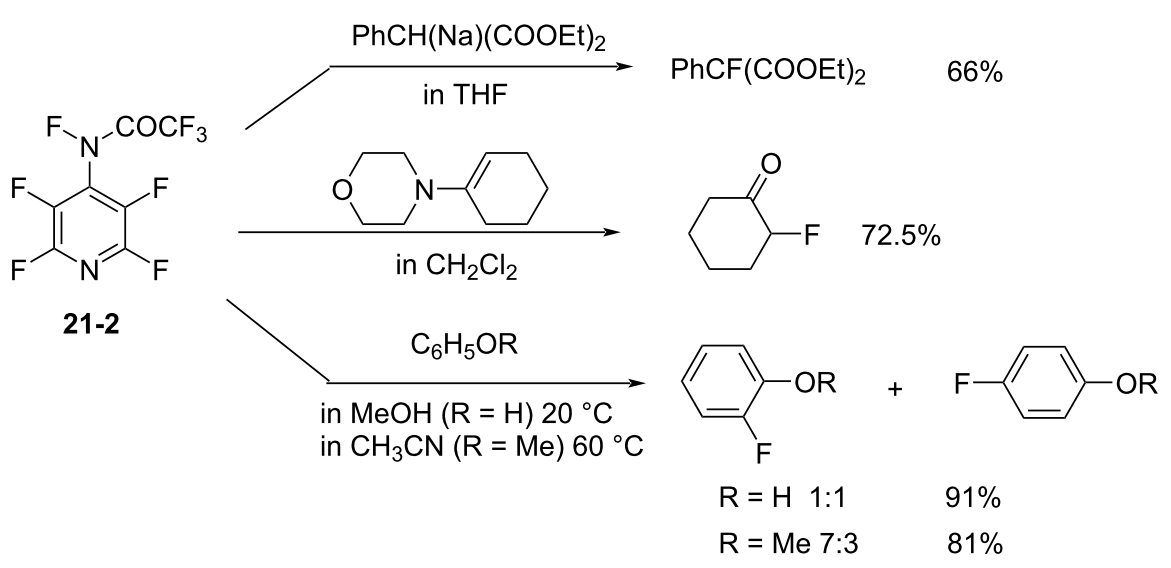

Scheme 47: Fluorination with N-F amide 21-2.

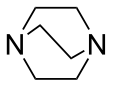

$\mathrm{DABCO}$

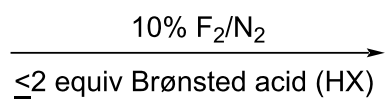

in $\left(\mathrm{CF}_{3}\right)_{2} \mathrm{CHOH},-30$ to $0^{\circ} \mathrm{C}$

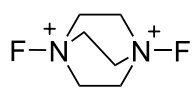

22-1

$\begin{array}{lc}\text { 22-1a; } X^{1}=X^{2}=\text { OTf } & \text { quant }(100 \%) \\ \text { 22-1 }^{-1} ; X^{1}=X^{2}=\mathrm{HSO}_{4} & 87 \% \\ \mathbf{2 2}^{-1} \mathbf{c}: X^{1}=\mathrm{HSO}_{4}, X^{2}=\mathrm{F}(\mathrm{HF})_{2} & 85 \% \\ \mathbf{2 2 - 1 d} ; X^{1}=X^{2}=\mathrm{BF}_{4} \text { (impure) } & 77 \% \\ \mathbf{2 2 - 1 e} ; X^{1}=X^{2}=\mathrm{SbF}_{6} & 56 \% \\ \text { 22-1f; } X^{1}=X^{2}=\mathrm{PF}_{6} & 81 \%\end{array}$

Scheme 48: Synthesis of $N, N^{\prime}$-difluorodiazoniabicyclo[2.2.2] octane salts 22-1.

because an inseparable mixture of $\mathbf{2 2 - 1 d}$ and the DABCO $2 \mathrm{HBF}_{4}$ salt formed.

$\mathrm{BisBF}_{4}$ 22-1d was considered to be commercially valuable because of its low preparative cost. Umemoto and co-worker found a clean counteranion replacement reaction of the intermediate $\left(\mathrm{F}^{-}\right)_{\mathrm{x}}(\mathrm{HF})_{\mathrm{y}}\left(\mathrm{HSO}_{4}{ }^{-}\right)_{\mathrm{z}}$ salts $(\mathrm{x}+\mathrm{z}=2)$ by using $\mathrm{BF}_{3}$ etherate and thus solved the problem with a simple two-step one-pot method; (step 1) fluorination of a mixture of DABCO and 1.5 molar equivalents of $\mathrm{H}_{2} \mathrm{SO}_{4}$ with $10 \% \mathrm{~F}_{2} / \mathrm{N}_{2}$ in acetonitrile at $-20{ }^{\circ} \mathrm{C}$, and (step 2) treatment of the resulting reaction mixture with 2.1 molar equivalents of $\mathrm{BF}_{3}$ etherate at $-20{ }^{\circ} \mathrm{C}$ to room temperature, gave pure $\mathbf{2 2 - 1 d}$ as a white precipitate (Scheme 49). By applying this telescoped method, pure 22-1d was easily obtained in $88 \%$ yield only after simple filtration of the reaction mixture and no further purification was needed. Pure 22-1d is non-hygroscopic and forms a stable crystalline solid with a high decomposition point of ca. $170{ }^{\circ} \mathrm{C}$.

The bisOTf salt 22-1a, bisBF $_{4}$ 22-1d, bisSbF $_{6}$ 22-1e, and bis $\mathrm{PF}_{6} \mathbf{2 2 - 1 f}$ are easy-to-handle because they are non-hygroscopic and stable crystals. As shown in Figure 6, 22-1a,d,e mediated a quantitative conversion of anisole to isomers of fluoroanisole at room temperature after $15 \mathrm{~min}$, whereas Select-

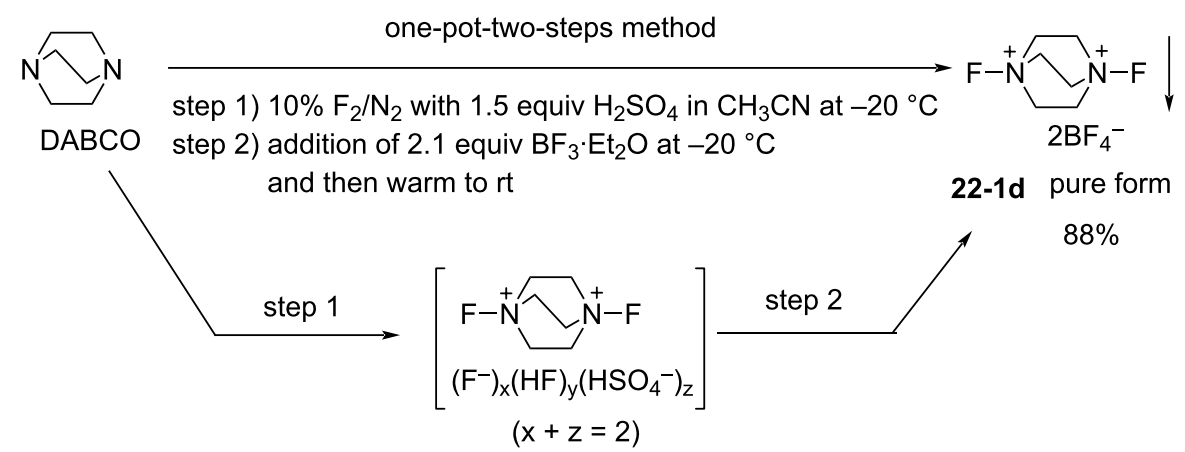

Scheme 49: One-pot synthesis of $N, N^{\prime}$-difluoro-1,4-diazoniabicyclo[2.2.2]octane bistetrafluoroborate salt (22-1d). 


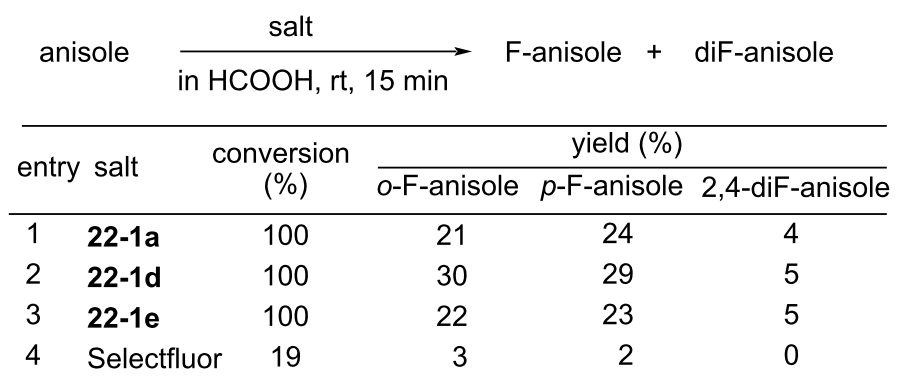

Figure 6: Fluorination of anisole with 22-1a, d, e.

fluor (16-3a) only produced fluoroanisole with a $19 \%$ conversion. This demonstrated that $\mathbf{2 2 - 1}$ is a much more powerful reagent than Selectfluor, a power that is attributed to the high electronegativity of the fluorine atom compared to the $\mathrm{ClCH}_{2}$ group.

By using the bistetrafluoroborate salt 22-1d, many substrates such as aromatics, active methylene compounds and their salts, olefins, and enol acetates were efficiently fluorinated (Scheme 50). It was shown also that only one of the two N-F groups of 22-1 is used for $C$-fluorination, while the other N-F plays an activating role.

\section{1-23. Bis- $N$-fluoro reagents derived from precursors containing two heterocycles}

In 1997, the Banks group reported bis- $N$-fluoro reagents 23-1-3 and related salts $\mathbf{2 3 - 4 , 5}$ by the fluorination of precursors containing two heterocycles (Scheme 51) [85]. Reagents 23-1-3 and $\mathbf{- 5}$ were obtained in good yields and 23-4 was also obtained, but as an impure product. The reagents 23-1 and 23-2 are bisSelectfluor-type reagents and $\mathbf{2 3 - 3}$ is a bis- $N$-fluoropyridinium reagent. The fluorinating ability of reagents $\mathbf{2 3 - 2 , - 4}$, and $-\mathbf{5}$ were examined as shown in Scheme 52.

\section{1-24. N,N'-Difluorobipyridinium salts}

In 1998, the Umemoto group reported a new series of $N, N^{\prime}-$ difluorobipyridinium salts $\mathbf{2 4 - 2}, N, N$ '-difluoro-2,2'-, -2,4'-, $-3,3^{\prime}-$, and $-4,4^{\prime}$-bipyridinium salts. These were synthesized by the direct fluorination of bipyridines 24-1 with $10-20 \% \mathrm{~F}_{2} / \mathrm{N}_{2}$ in the presence of a Lewis acid, a Brønsted acid, or its metal salt in acetonitrile or as a 50:1 mixture of acetonitrile/formic acid at -40 to $0{ }^{\circ} \mathrm{C}$. The yields were good to excellent [86] (Figure 7). The trimer 24-3 and polymer homologues 24-4 were also prepared. The $N, N$ '-difluorobipyridinium salts are stable and generally furnished non-hygroscopic free flowing materials, however, this was less the case for those derivatives with electronwithdrawing substituents.
Controlled fluorination reactions with these reagents (Figure 8) clearly showed a power order of $2,2^{\prime}-(\mathbf{2 4 - 2 a})>>2,4^{\prime}-(\mathbf{2 4 - 2 c})$ $>3,3^{\prime}-(\mathbf{2 4 - 2 f}) \approx 4,4^{\prime}-(\mathbf{2 4 - 2 g})>>N$-fluoropyridinium triflate (Scheme 53), which is again in good agreement with the $\mathrm{p} K_{\mathrm{a}}$ values of the bipyridines. The 2,2'-isomers had the highest power (reactivity) among the dipyridinium isomers, and they were much more reactive than the monomeric $N$-fluoropyridinium triflate (5-4a).

In contrast to the $N, N^{\prime}$-difluoro-1,4-diazoniabicyclo[2.2.2] octane salts 22-1, both of the $N$-F moieties in 24-2 were effective in fluorinations and they reacted sequentially. $N, N$ '-Difluoro-2,2'-bipyridinium bis(tetrafluoroborate) (24-2b, $\mathrm{X}=\mathrm{BF}_{4}$, SynFluor ${ }^{\mathrm{TM}}$, MEC-31) was chosen as a representative of this class to assess fluorination capability because of its low production cost and high fluorine content per molecule. As a result, SynFluor ${ }^{\mathrm{TM}}$ (24-2b) proved to be a practical reagent for the fluorination of many substrates affording the products in good to high yields (Scheme 54 and Scheme 55). SynFluor can be considered a powerful fluorinating agent with a high fluorine content, F: $103 \mathrm{~g} / 1 \mathrm{~kg}$ (comparison; $54 \mathrm{~g} / 1 \mathrm{~kg}$ for Selectfluor).

\section{1-25. N-Fluoro-2,4-dinitroimidazole}

In 1998, Laali et al. reported the fluorination of polycyclic aromatic hydrocarbons (PAHs) with $N$-fluoro-2,4-dinitroimidazole (25-1) [87] (Scheme 56). This reagent is a white solid that was prepared by Forohar et al. through fluorination of 2,4-dinitroimidazole $\left(5 \% \mathrm{~F}_{2}\right.$ in $\mathrm{N}_{2}$ at $\left.-40{ }^{\circ} \mathrm{C}\right)$ [88]. Although additional information on 25-1 was not available, it was noticed [87] that the polynitro compound $\mathbf{2 5 - 1}$ is potentially dangerous towards detonation.

Laali et al. attempted to fluorinate some polycyclic aromatics with Selectfluor, but intractable mixtures were obtained. Thus, they examined the utility of 25-1 in the fluorination of polycyclic aromatics. Although a detailed optimization was con- 


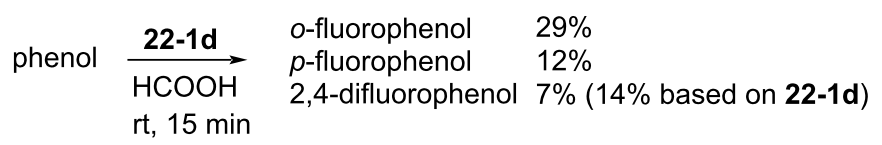<smiles>Oc1ccc2ccccc2c1</smiles>

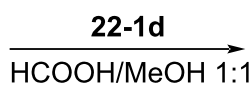

$$
\mathrm{rt}, 15 \mathrm{~min}
$$<smiles>CC(=O)C1CCCCC1=O</smiles><smiles>CC(=O)C1CCCCC1=O</smiles><smiles>CCOC(=O)C1CCCC1=O</smiles><smiles>CC(C)C(=O)O</smiles>

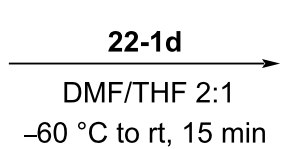
$-60{ }^{\circ} \mathrm{C}$ to $\mathrm{rt}, 15 \mathrm{~min}$

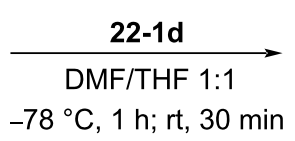
$\mathrm{Na}^{+} \mathrm{MeC}^{-}\left(\mathrm{CO}_{2} \mathrm{Et}\right)_{2}$

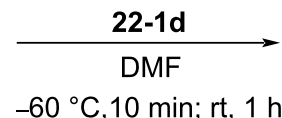

$\mathrm{Na}^{+} \mathrm{PhC}^{-}\left(\mathrm{CO}_{2} \mathrm{Et}\right)_{2}$

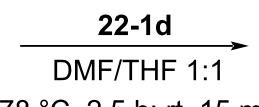

$-78^{\circ} \mathrm{C}, 2.5 \mathrm{~h} ; \mathrm{rt}, 15 \mathrm{~min}$

styrene

22-1d

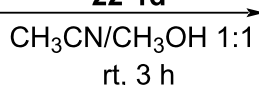

$\mathrm{rt}, 3 \mathrm{~h}$<smiles>Oc1ccc2ccccc2c1F</smiles>

$38 \%$<smiles>CC(=O)OC(C)(F)C1(F)CCCCC1=O</smiles>

$80 \%$<smiles>CC(=O)OC1(F)CCCCC1=O</smiles>

$54 \%$<smiles>CCOC(=O)C1(F)CCCC1=O</smiles>

$75 \%$

$\operatorname{MeCF}\left(\mathrm{CO}_{2} \mathrm{Et}\right)_{2}$

$64 \%$

$\operatorname{PhCF}\left(\mathrm{CO}_{2} \mathrm{Et}\right)_{2}$

$74 \%$

$\mathrm{PhCH}(\mathrm{OMe}) \mathrm{CH}_{2} \mathrm{~F}$

$25 \%$

trans $-\mathrm{PhCH}=\mathrm{CHCH}_{3}$

22-1d

$\mathrm{CH}_{3} \mathrm{CN} / \mathrm{CH}_{3} \mathrm{OH}$ 1:1

rt, $10 \mathrm{~min}$

$\mathrm{PhCH}(\mathrm{OMe}) \mathrm{CHFCH}_{3}$

$46 \%$

trans- $\mathrm{PhCH}=\mathrm{CHCH}_{3}$

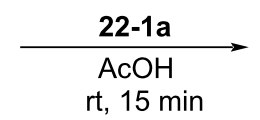

$\mathrm{rt}, 15 \mathrm{~min}$

$\mathrm{PhCH}(\mathrm{OAc}) \mathrm{CHFCH}_{3}$

$52 \%$

$$
\operatorname{PhC}\left(\mathrm{CH}_{3}\right)=\mathrm{CH}_{2}
$$

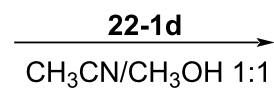

rt, $15 \mathrm{~min}$

$\mathrm{PhC}\left(\mathrm{CH}_{3}\right)(\mathrm{OMe}) \mathrm{CH}_{2} \mathrm{~F}$<smiles>CC(=O)OC1=CC2=CCC3C4CCC(OC(C)=O)C4(C)CCC3[C@@]2(C)CC1</smiles><smiles>O=C1C=Cc2ccccc2C1(F)F</smiles>

$29 \%$

(58\% based on $\mathbf{2 2 - 1 d )}$<smiles>CC(=O)O[C@H]1CCC2C3C[C@H](F)C4=CC(=O)CC[C@]4(C)C3CC[C@]21C</smiles> 


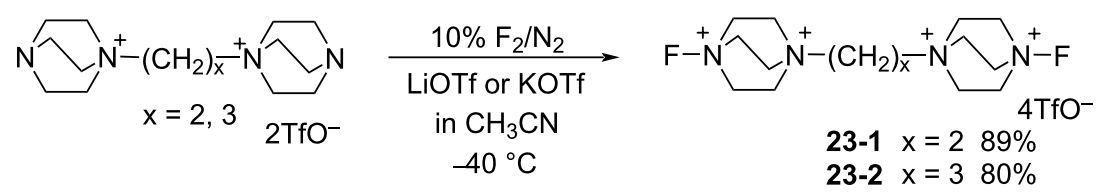

1. neat $\mathrm{F}_{2}$ at $10-20 \mathrm{mmHg}$

in $\mathrm{CFCl}_{3} / \mathrm{CHCl}_{3}$ 1.53:1
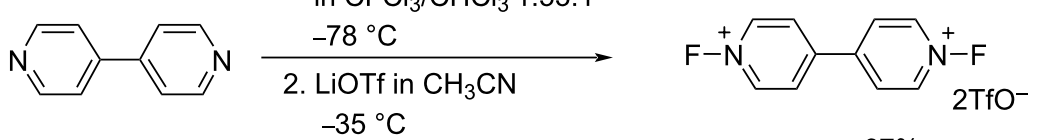

23-3 $67 \%$
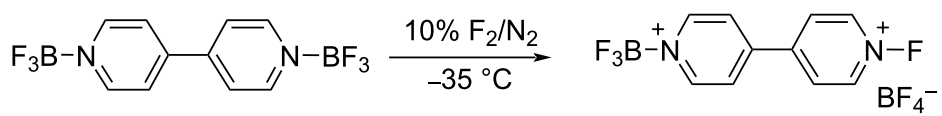

23-4 $62 \%$ impure

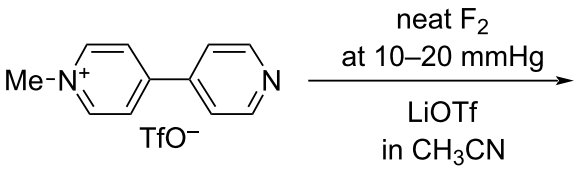

$-35^{\circ} \mathrm{C}$

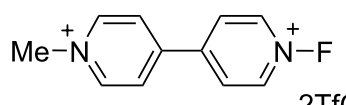

$23-582 \%$
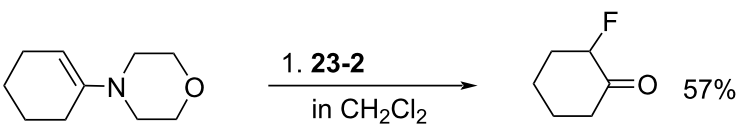

$20{ }^{\circ} \mathrm{C}$ overnight

2. $\mathrm{HCl}$

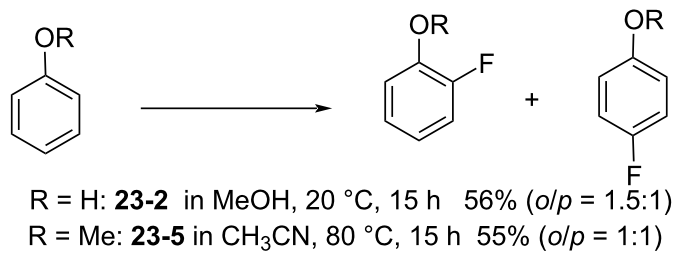<smiles>Oc1ccc2ccccc2c1</smiles>

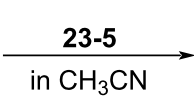

$80^{\circ} \mathrm{C}, 15 \mathrm{~h}$<smiles>Oc1ccc2ccccc2c1F</smiles>

$\mathrm{MeO}$<smiles>[R]c1cc(C)cc(OC)c1</smiles>

$\mathrm{MeO}$<smiles>[R]c1cc(I)cc(OC)c1F</smiles>

$\mathrm{R}=\mathrm{H}: \quad 23-4 \quad$ in $\mathrm{CH}_{3} \mathrm{CN}, 20^{\circ} \mathrm{C}, 18 \mathrm{~h} \quad 52 \%$

$\mathrm{R}=\mathrm{H}$ : $\quad 23-5$ in $\mathrm{CH}_{3} \mathrm{CN}, 20^{\circ} \mathrm{C}, 15 \mathrm{~h} \quad 40 \%$

$\mathrm{R}=\mathrm{OMe}: \mathbf{2 3 - 4}$ in $\mathrm{CH}_{3} \mathrm{CN}, 20^{\circ} \mathrm{C}, 18 \mathrm{~h} \quad 61 \%$

$\mathrm{R}=$ OMe: $23-5$ in $\mathrm{CH}_{3} \mathrm{CN}, 20^{\circ} \mathrm{C}, 18 \mathrm{~h} \quad 50 \%$ ducted, the fluorination of over 20 polycyclic aromatics was poor giving products in very low yields, varying from $27 \%$ to $3 \%$ depending on the substrate. The fluorinations were accompanied by tar formation and dimerization. Scheme 57 illustrates some representative examples.

1-26. Perfluoro-( $N$-fluoro-2,2,6,6-tetramethylpiperidine) and its 2,6-dimethyl analogue

In 1999, the Banks group reported the syntheses of perfluoro( $N$-fluoro-2,2,6,6-tetramethylpiperidine) (26-1) and its 2,6dimethyl analogue 26-2, reagents which do not have $\alpha$-fluorine atoms adjacent to the $N$-F site [89] (Scheme 58). These reagents overcame the drawback of perfluoro- $N$-fluoropiperidine (1-1) which does contain $\alpha$-fluorine atoms (see section 1-1).

The fluorinating ability of reagents $\mathbf{2 6 - 1}$ and $\mathbf{- 2}$ was tested in fluorinations of the sodium salt of a keto ester (Scheme 59). Reagents 26-1 and -2 were superior to 1-1 and 26-3 where the $\alpha$-fluorine atoms can be eliminated after fluorine-transfer from the $N$-F site.

\section{1-27. N-Fluoro-3-ethyl-3-methyldioxobenzothiazi-} none and $(R)$ - and $(S)-N$-fluoro-3-cyclohexyl-3methylbenzoisothiazole dioxide

In 1999, Takeuchi et al. reported $N$-fluoro-3-ethyl-3-methyl1,1-dioxo-2,3-dihydro- $1 H$ - $1 \lambda^{6}$-benzo[ $\left.e\right] 1$,2-thiazin-4-one (27-2) as an efficient reagent for the fluorination of carbanions [90]. 

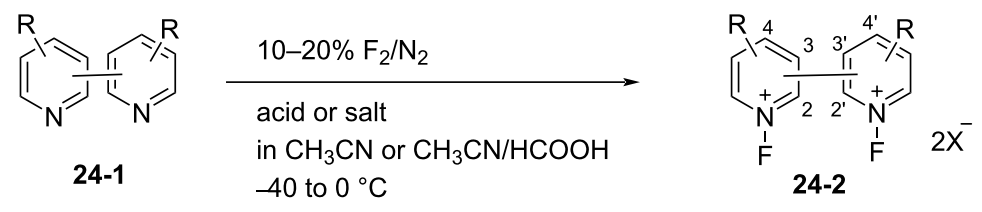

\begin{tabular}{|c|c|c|c|c|c|c|c|c|}
\hline entry & bipyridyl & $\begin{array}{l}\text { acid } \\
\text { or salt }\end{array}$ & solvent & temp & product & $\mathrm{R}+$ bonding & $x$ & yield (\%) \\
\hline 1 & $2,2^{\prime}-$ & $\mathrm{TfOH}$ & $\mathrm{CH}_{3} \mathrm{CN}$ & -20 & $24-2 a$ & $2,2^{\prime}-$ & OTf & 86 \\
\hline 2 & $2,2^{\prime}-$ & $\mathrm{BF}_{3}$ & $\mathrm{CH}_{3} \mathrm{CN} / \mathrm{HCOOH} 50: 1$ & 0 & $-2 b$ & $2,2^{\prime}-$ & $\mathrm{BF}_{4}$ & 89 \\
\hline 3 & 2,4'- & $\mathrm{TfOH}$ & $\mathrm{CH}_{3} \mathrm{CN}$ & -20 & $-2 c$ & $2,4^{\prime}-$ & OTf & 92 \\
\hline 4 & $2,4^{\prime}-$ & $\mathrm{BF}_{3}$ & $\mathrm{CH}_{3} \mathrm{CN}$ & -20 & $-2 d$ & $2,4^{\prime}-$ & $\mathrm{BF}_{4}$ & 86 \\
\hline 5 & $2,4^{\prime}-$ & $\mathrm{HPF}_{6}$ & $\mathrm{CH}_{3} \mathrm{CN}$ & -20 & $-2 e$ & $2,4^{\prime}-$ & $\mathrm{PF}_{6}$ & 64 \\
\hline 6 & $3,3^{\prime}-$ & TfOLi & $\mathrm{CH}_{3} \mathrm{CN}$ & -40 & $-2 f$ & $3,3^{\prime}-$ & OTf & 75 \\
\hline 7 & $4,4^{\prime}-$ & $\mathrm{TfOH}$ & $\mathrm{CH}_{3} \mathrm{CN}$ & -20 & $-2 g$ & $4,4^{\prime}-$ & OTf & 91 \\
\hline 8 & $4,4^{\prime}-$ & $\mathrm{BF}_{3}$ & $\mathrm{CH}_{3} \mathrm{CN} / \mathrm{HCOOH} 49: 1$ & 0 & $-2 h$ & $4,4^{\prime}-$ & $\mathrm{BF}_{4}$ & 95 \\
\hline 9 & $4,4^{\prime}-$ & $\mathrm{SbF}_{5}$ & $\mathrm{CH}_{3} \mathrm{CN}$ & -20 & $-2 \mathbf{i}$ & $4,4^{\prime}-$ & $\mathrm{SbF}_{6}$ & 91 \\
\hline 10 & 4,4'-diMe-2,2'- & $\mathrm{BF}_{3}$ & $\mathrm{CH}_{3} \mathrm{CN}$ & -20 & $-2 \mathbf{j}$ & 4,4'-diMe-2,2'- & $\mathrm{BF}_{4}$ & 73 \\
\hline 11 & 4,4'-diCl-2,2'- & $\mathrm{BF}_{3}$ & $\mathrm{CH}_{3} \mathrm{CN}$ & -20 & $-2 k$ & 4,4'-diCl-2,2'- & $\mathrm{BF}_{4}$ & 79 \\
\hline 12 & 4,4'-diPh-2,2'- & $\mathrm{BF}_{3}$ & $\mathrm{CH}_{3} \mathrm{CN}$ & -20 & -21 & 4,4'-diPh-2,2'- & $\mathrm{BF}_{4}$ & 64 \\
\hline 13 & 4,4'-di(COOMe)-2,2'- & $\mathrm{SbF}_{5}$ & $\mathrm{CH}_{3} \mathrm{CN}$ & -20 & $-2 m$ & 4,4'-di(COOMe)-2,2'- & $\mathrm{BF}_{4}$ & 97 \\
\hline 14 & 5,5'-diCF $3-2,2^{\prime}-$ & $\mathrm{TfOH}$ & $\mathrm{CH}_{3} \mathrm{CN}$ & -20 & $-2 n$ & 4,4'-diCF $3-2,2^{\prime}-$ & OTf & 72 \\
\hline
\end{tabular}

Figure 7: Synthesis of $N, N^{\prime}$-difluorobipyridinium salts 24-2.

\begin{tabular}{llcc}
\hline & & \\
\hline
\end{tabular}

The precursor 27-1, which was prepared in a three step protocol from saccharin, was fluorinated with $\mathrm{FClO}_{3}$ to give 27-2 in good yield (Scheme 60). Direct fluorination of 27-1 with $10 \%$ $\mathrm{F}_{2} / \mathrm{N}_{2}$ had failed because of decomposition. Various ketone enolates were successfully fluorinated with reagent $\mathbf{2 7 - 2}$ in good to high yields [90].

In addition, Takeuchi et al. reported that optically active $N$-fluorosultams, $(R)$ - and $(S)-N$-fluoro-3-cyclohexyl-3-methyl-2,3dihydrobenzo[1,2- $d$ ] isothiazole 1,1-dioxides 27-6 (Scheme 61) were efficient reagents for the asymmetric fluorination of enolates [91].

To showcase his methodology, they first synthesized acyclic optically active $N$-fluoro sulfonamides 27-7-9 (Scheme 62) and attempted the enantioselective fluorination of some enolates in 1997 [92]. However, the best result was an enantiomeric excess of $48 \%$ with a chemical yield of $53 \%$ after the enolate anion of 2-benzyl- $\alpha$-tetralone was treated with $\mathbf{2 7 - 8}$.

As summarized in Scheme 61, Takeuchi et al. prepared the enantiomers of cyclic $N$-F sulfonamide 27-6 by the approach used 


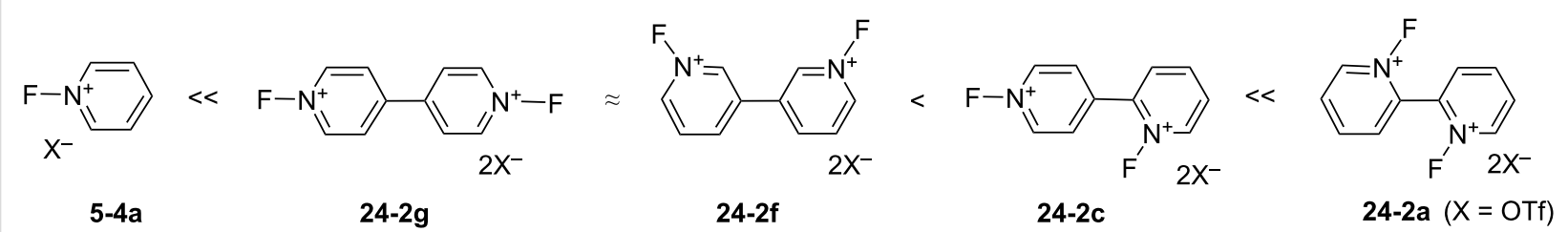

Scheme 53: Fluorinating power of $N, N^{\prime}-$ diF salts $\mathbf{2 4 - 2}$ and $N$-F salt $\mathbf{5 - 4 a}$.

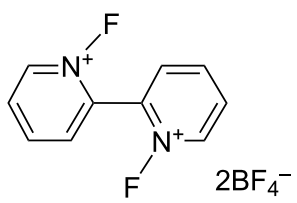<smiles>CC(=O)C1CCCCC1=O</smiles>

Synfluor 24-2b

(0.5 mol equiv) in $\mathrm{CH}_{3} \mathrm{CN}$ reflux, $3 \mathrm{~h}$<smiles>CC(=O)C1CCCCC1=O</smiles><smiles>O=C(CC(=O)c1ccccc1)c1ccccc1</smiles><smiles>CCOC(=O)C(C)C(C)=O</smiles><smiles>CCOC(=O)C1CCCCC1=O</smiles><smiles>Oc1ccccc1</smiles><smiles>Oc1ccccc1</smiles><smiles>COc1ccccc1</smiles>

24-2b (0.5 mol equiv) NaOTf (0.1 mol equiv) in $\mathrm{CH}_{3} \mathrm{CN}$ reflux, $10 \mathrm{~min}$

24-2b (1.0 mol equiv) in $\mathrm{CH}_{3} \mathrm{CN}$ reflux, $48 \mathrm{~h}$

24-2b (0.5 mol equiv) in $\mathrm{CH}_{3} \mathrm{CN}$ reflux, $8 \mathrm{~h}$

24-2b (0.5 mol equiv) in $\mathrm{CH}_{3} \mathrm{CN}$ reflux, $8 \mathrm{~h}$

24-2b (0.5 mol equiv) NaOTf (0.1 mol equiv) in $\mathrm{CH}_{3} \mathrm{CN}$ reflux, $5 \mathrm{~h}$ $\mathrm{TfOH}$ ( 0.1 mol equiv)<smiles>CC(=O)C1(F)CCCCC1=O</smiles>
$82 \%$

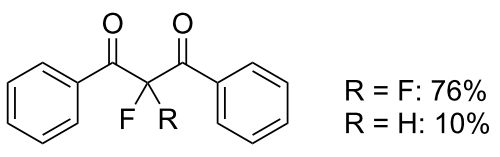<smiles>CCOC(=O)C(C)(F)C(C)=O</smiles><smiles>CCOC(=O)C1(F)CCCCC1=O</smiles>
$76 \%$

$\begin{array}{cll}\stackrel{\text { 24-2b }(0.5 \text { mol equiv })}{\longrightarrow} \longrightarrow & \begin{array}{l}\text { o-fluorophenol } \\ \text { p-fluorophenol } \\ \text { 2,4-difluorophenol }\end{array} & \begin{array}{l}39 \% \\ \mathrm{CH}_{3} \mathrm{CN}\end{array} \\ \text { reflux, } 8 \mathrm{~h} & 5 \%\end{array}$

o-fluorophenol

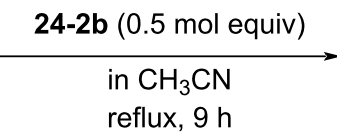
p-fluoroanisol

2,4-difluoroaniso 
$\mathrm{HO}$<smiles>Cc1cccc(O)c1</smiles>

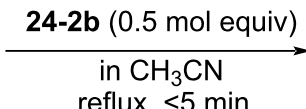
reflux, $<5 \mathrm{~min}$<smiles>CCOC(=O)Nc1ccccc1</smiles>

24-2b (0.5 mol equiv) in $\mathrm{CH}_{3} \mathrm{CN}$ reflux, $48 \mathrm{~h}$

24-2b (0.5 mol equiv) in $\mathrm{HCOOH}$ rt, $10 \mathrm{~min}$

24-2b (0.5 mol equiv)

trans- $\mathrm{PhCH}=\mathrm{CHCH}_{3}$<smiles>O=C1CCc2ccccc2C1</smiles>

24-2b (0.5 mol equiv) in $\mathrm{CH}_{3} \mathrm{CN}$ reflux, $10 \mathrm{~min}$<smiles>CC(=O)OC1=CC2=CCC3C(CCC4(C)C(C(C)=O)CCC34)C2(C)CC1</smiles>

24-2b (0.5 mol equiv) $\mathrm{NaHCO}_{3}$

$\mathrm{CH}_{3} \mathrm{CN}$ $70^{\circ} \mathrm{C}, 1 \mathrm{~h}$<smiles>Oc1ccc2ccccc2c1F</smiles>

$61 \%$ $\mathrm{Ac}$

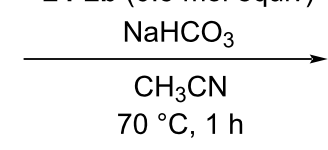<smiles>O=C1CCc2ccccc2C1F</smiles><smiles>Oc1cccc(O)c1F</smiles>

$3 \%$<smiles>CCONc1ccc(F)cc1F</smiles>

$32 \%$<smiles>CCOC(=O)Nc1ccc(F)cc1</smiles><smiles>O=C1C=Cc2ccccc2C1(F)F</smiles>

$18 \%$ (36\% based on $\mathbf{2 4 - 2 b}$ )<smiles>CCOC1=CC2=CCC3C(CCC4(C)C(OC(C)=O)CCC34)C2(C)CC1</smiles>

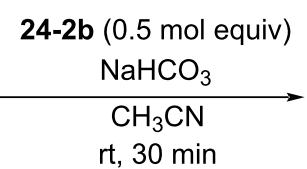

Scheme 55: Additional fluorination reactions with Synfluor ${ }^{\mathrm{TM}}(\mathbf{2 4 - 2 b})$.

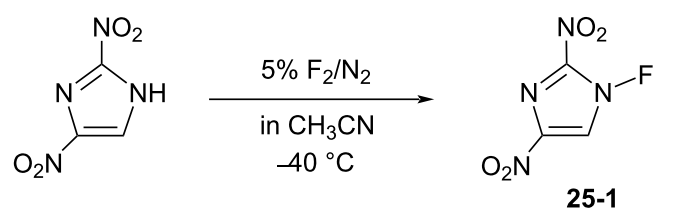

Scheme 56: Synthesis of N-F 25-1. by Lang for $N$-fluorosultams [53]. A cyclohexyl ring was introduced nucleophilically into imine 27-3 and the resulting 27-4 was treated with (-)-menthoxyacetyl chloride, followed by separation of the diastereomers. The chiral auxiliary was then removed with $\mathrm{LiOH}$ and the resulting sultams $\mathbf{2 7 - 5}$ as single enantiomers were fluorinated with $15 \% \mathrm{~F}_{2} / \mathrm{He}$ in the presence of $\mathrm{KF}$ to produce optically pure $N$-fluorosultam reagents $(R)$ - and (S)-27-6. 

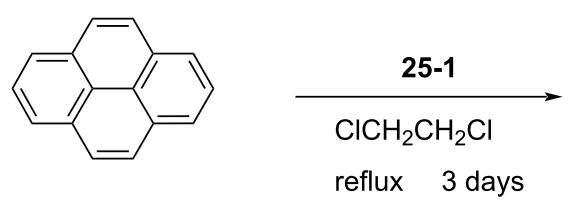

reflux 3 days<smiles>c1ccc2cc3c(ccc4ccccc43)cc2c1</smiles>

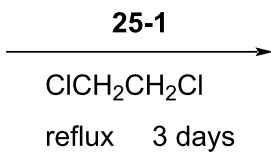<smiles>Fc1c2ccccc2cc2c1ccc1ccccc12</smiles><smiles>Fc1c2ccccc2cc2ccc3ccccc3c12</smiles>

$24 \%(4: 1: 2)$<smiles>Fc1cc2cccc3ccc4cccc1c4c32</smiles>

$3 \%(9: 1)$
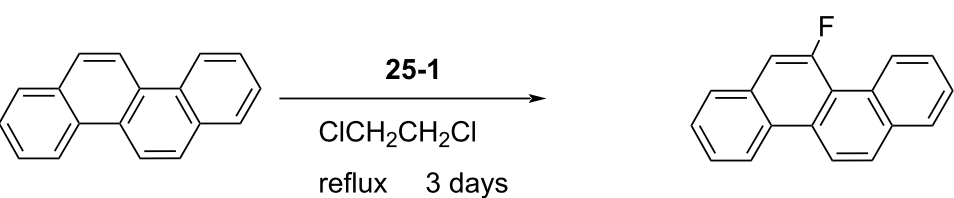

$8 \%$

Scheme 57: Fluorination of polycyclic aromatics with 25-1.<smiles>CC(C)(C)C1=NC(F)(C(F)(F)F)C(F)(F)C(F)(F)C1(F)F</smiles>

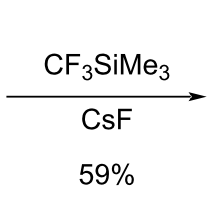

$59 \%$

\%

$82 \%$

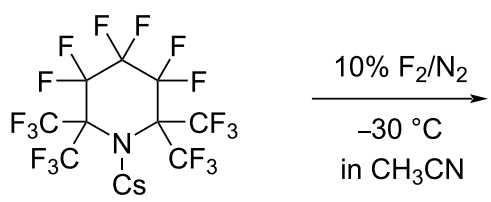

$65 \%$

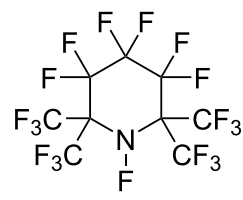

26-1

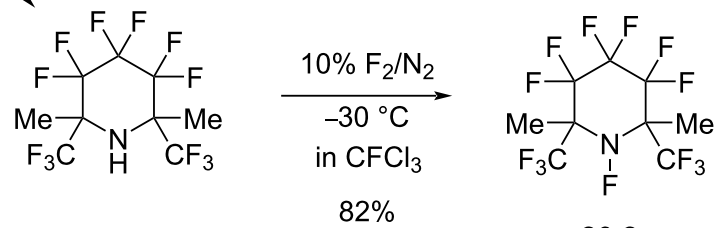

Scheme 58: Synthesis of 26-1 and dimethyl analog 26-2.<smiles>CCOC(=O)C1CCCC1=O</smiles><smiles>[H][R10](=C[AsH2])OCC</smiles><smiles>CCOC(=O)C1(F)CCCC1=O</smiles>
$\mathrm{N}-\mathrm{F}$ reagent

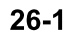

26-2

26-3 $47 \%$<smiles>Fc1c2ccccc2c(F)c2c1ccc1ccccc12</smiles> 
<smiles>O=C1NS(=O)(=O)c2ccccc21</smiles>

saccharin

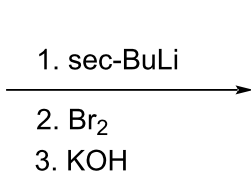

$>40 \%$<smiles>CCC1(C)NS(=O)(=O)c2ccccc2C1=O</smiles>

27-1

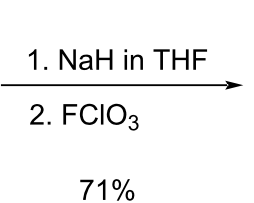

$71 \%$

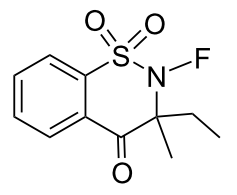

27-2

Scheme 60: Synthesis of $N-\mathrm{F}$ reagent 27-2.<smiles>CC1=NS(=O)(=O)c2ccccc21</smiles>

27-3$$
\text { 27-3 }
$$

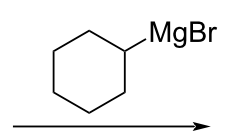

THF $70 \%$

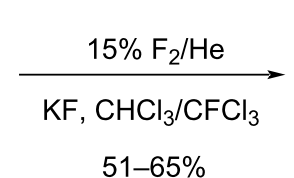
$51-65 \%$<smiles>CCC1(C2CCCCC2)NS(=O)(=O)c2ccccc21</smiles>

1. $\mathrm{NaH}$

(-)-menthoxyacetyl chloride $73 \%$

2. separation

3. $2 \mathrm{~N} \mathrm{LiOH} 93-96 \%$<smiles>[Z16]C1(C2CCCCC2)NS(=O)(=O)c2ccccc21</smiles>

$(R)-$

(S)-<smiles>CC1(C2CCCCC2)c2ccccc2S(=O)(=O)N1F</smiles>

$(R)-(+)$

$(S)-(-)$

Scheme 61: Synthesis of chiral N-F reagents 27-6.<smiles>[R][C@@H](NS([R20])=O)c1ccccc1</smiles>

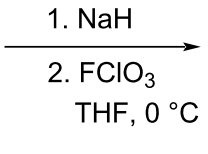<smiles>[R20]ON(F)[C@H]([R])c1ccccc1</smiles>

27-7, 8, 9

27-7: $\mathrm{R}^{1}=\mathrm{CH}_{2} \mathrm{OAc} \mathrm{R}^{2}=p$-tolyl $27 \%$

27-8: $\mathrm{R}^{1}=\mathrm{CH}_{3} \quad \mathrm{R}^{2}=p$-tolyl $\quad 52 \%$

27-9: $R^{1}=\mathrm{CH}_{3} \quad \mathrm{R}^{2}=\mathrm{CH}_{3} \quad 13 \%$

Scheme 62: Synthesis of chiral N-F 27-7-9.

Enantioselective fluorinations of typical enolates were then performed (Scheme 63). The $(R)$-27-6 reagent gave up to 79\% yield and $88 \%$ enantiomeric excess in the case of 2-benzyl- $\alpha$ tetralone.

1-28. $(R)$ - and (S)-N-fluoro-3-tert-butyl-7-nitrobenzothiazine 1,1-dioxides and spiro-type analogues

In 2000, the Takeuchi group reported their second series of chiral $N$-fluorosultam reagents, $(R)$ - and $(S)-N$-fluoro-3-tert-
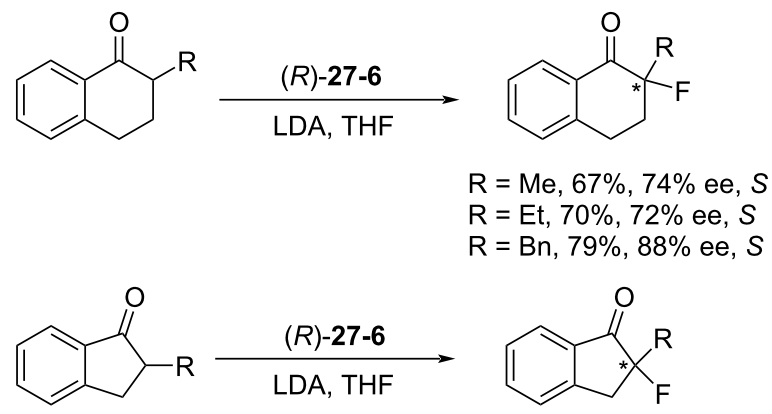

$\mathrm{R}=\mathrm{Me}, 54 \%, 54 \%$ ee, $S$ $\mathrm{R}=\mathrm{Et}, 73 \%, 20 \%$ ee, $S$ $\mathrm{R}=\mathrm{Bn}, 63 \%, 54 \%$ ee, $S$<smiles>CC1Cc2ccccc2C1=O</smiles><smiles>CC1(F)Cc2ccccc2C1=O</smiles>

$62 \%, 48 \%$ ee, $R$<smiles>[R]C1CCCc2ccccc2C1=O</smiles><smiles>[R]C1(F)CCCc2ccccc2C1=O</smiles>

$\mathrm{R}=\mathrm{Et}, 48 \%, 43 \%$ ee $\mathrm{R}=\mathrm{Bn}, 39 \%, 18 \%$ ee

Scheme 63: Asymmetric fluorination with 27-6. 


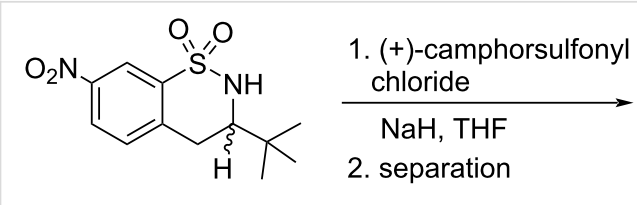

28-1 (racemic)<smiles>CC(C)(C)C1=Cc2ccc([N+](=O)[O-])cc2S(=O)(=O)N1O[Mg]</smiles>

(R)-28-2 21\%

(S)-28-2 31\%

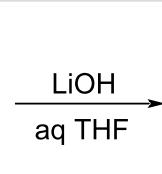

aq THF<smiles>CC(C)(C)[C@H]1Cc2ccc([N+](=O)[O-])cc2S(=O)(=O)N1</smiles>

(R)-28-1 $82 \%$ (S)-28-1 $87 \%$

Scheme 64: Synthesis of chiral N-F reagents 28-3.

butyl-7-nitro-3,4-dihydro-2H-benzo[ $e][1,2]$ thiazine 1,1-dioxides 28-3 [93] (Scheme 64). Racemic 28-1 reacted with (+)-10camphorsulfonyl chloride to give a mixture of the diastereomers of 28-2, which was accompanied by $45 \%$ of unreacted 28-1. Interestingly, pure $(R)$-isomer 28-1 was obtained in $20 \%$ yield from the unreacted 28-1. The diastereomer separation of 28-2 was achieved by column chromatography to separate the $(R)$ - and $(S)$-isomers of 28-2 in 21 and $31 \%$ yields, respectively. Deprotection followed by fluorination with $\mathrm{FClO}_{3}$ gave $(R)$ and $(S)$-28-3 in good yields. X-ray crystallography was used to determine the structure and confirm the absolute stereochemistry of $(S)-\mathbf{2 8 - 3}$.

The optically active reagents $(R)$ - and $(S)$-28-3 were effective in the enantioselective fluorination of cyclic ketones, as is illustrated with representative in Scheme 65.

In addition, the Takeuchi group reported a spiro-type analogue, (2'S,3R,5'R)-2-fluoro-2'-methylethyl-5'-methyl- $2 \mathrm{H}, 4 \mathrm{H}$ -

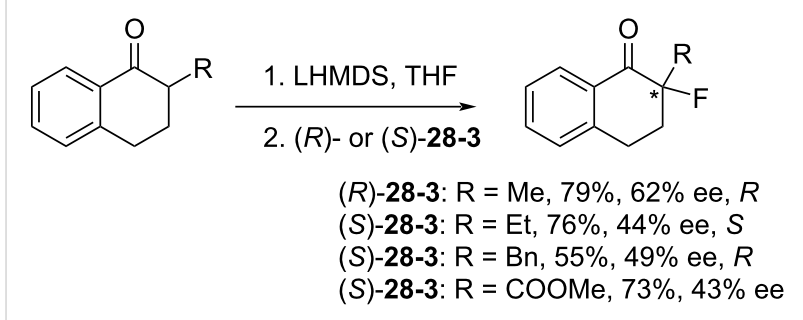

$\underset{R}{\stackrel{\text { 1. LHMDS, THF }}{\text { 2. }(R)-\text { or }(S)-28-3}}$

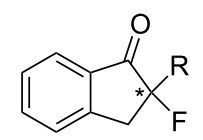

(S)-28-3: $R=M e, 74 \%, 52 \%$ ee, $S$

$(R)$-28-3: $\mathrm{R}=\mathrm{Bn}, 40 \%, 57 \%$ ee, $R$

$(R)-28-3: \mathrm{R}=p-\mathrm{MeOBn}, 70 \%, 69 \%$ ee

Scheme 65: Asymmetric fluorination with 28-3.

spiro[benzo[e][1,2]thiazine-3,1'-cyclohexane]-1,1-dione (28-7a) [94], as their third chiral reagent in this sultam series. As can be seen in Scheme 66, 28-4 was treated with BuLi followed by<smiles>Cc1ccccc1S(=O)(=O)NC(C)(C)C</smiles>

28-4

\section{$\underset{\text { 2. mentone }}{\stackrel{\text { 1. BuLi in THF }}{\longrightarrow}}$}

$95 \%$

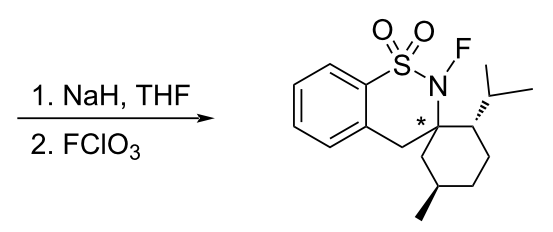<smiles>CC(C)[C@H]1CC[C@@H](C)C[C@]1(O)Cc1ccccc1S(=O)(=O)NC(C)(C)C</smiles>

28-5<smiles>Cc1ccccc1S(=O)(=O)NC1(C(C)C)CCC(C)C1</smiles>

$28-6 a+28-6 b(5.5: 1)$

$(S, R, R)-\mathbf{2 8 - 7 a} ; 81 \%$ (from 28-6a)

$(S, S, R)-28-7 \mathbf{b}: 44 \%$ (from $28-6 b$ ) 
reaction with optically active menthone to give $\mathbf{2 8 - 5}$, which was converted to enantiomers of spiro sultams 28-6a and 28-6b in high yield. The spiro sultams 28-6a and -6b were separated and each was fluorinated with $\mathrm{FClO}_{3}$ to give $\left(2 ' S, 3 R, 5^{\prime} R\right)$-isomer 28-7a and $\left(2 ' S, 3 S, 5^{\prime} R\right)$-isomer $\mathbf{2 8 - 7 b}$ in $81 \%$ and $44 \%$ yield, respectively.

Figure 9 summarizes the outcomes of asymmetric fluorination reactions of enolates of aryl ketones using 28-7a and -7b. In the event isomer 28-7a yielded much better ees than 28-7b. Although 28-7a gave a maximum $70 \%$ ee (entry 6, Figure 9), it was less than that obtained (74\% ee) by $N$-fluorosultam $(R)-27$ 6 with the same substrate (see the previous section 1-27).

\begin{tabular}{|c|c|c|c|c|c|}
\hline & ketone & 1. LHMDS & \multicolumn{3}{|c|}{$\alpha$-fluoro ketone } \\
\hline entry & $N-F$ reagent & product & $\mathrm{R}$ & ee $(\%)$ & $\begin{array}{l}\text { isolated } \\
\text { yield (\%) }\end{array}$ \\
\hline 1 & $28-7 a$ & & $\mathrm{Me}$ & 40 & 76 \\
\hline 2 & $-7 b$ & & $\mathrm{Me}$ & 13 & 69 \\
\hline 3 & $-7 a$ & & $\mathrm{Bn}$ & 54 & 59 \\
\hline 4 & $-7 b$ & & $\mathrm{Bn}$ & 24 & 42 \\
\hline 6 & $-7 a$ & & $\mathrm{Me}$ & 70 & 65 \\
\hline 7 & $-7 b$ & & $\mathrm{Bn}$ & 56 & 61 \\
\hline
\end{tabular}

Figure 9: Asymmetric fluorination with 28-7.

\section{1-29. N-Fluorinated cinchona alkaloid derivatives by} combination with Selectfluor

In 2000, Shibata and Takeuchi reported a far more practical enantioselective fluorination method. They discovered that the fluorination of carbanions with Selectfluor occurred in a highly enantioselective manner when carried out in the presence of cinchona alkaloid derivatives [95]. This method consisted of two simple steps. Firstly, the cinchona alkaloid is reacted with Selectfluor in acetonitrile at room temperature for $1 \mathrm{~h}$, and then this is followed by addition of the substrate. The resulting mixture is stirred at a suitable temperature. They proposed that Selectfluor transfers fluorine to the alkaloid to give a chiral $N$-F alkaloid species, in a manner that followed the fluorine transfer reported by Banks when quinuclidine was $N$-fluorinated with Selectfluor [62] (Scheme 67). Subsequently, in 2001, Shibata et al. presented full details of their studies including the definitive identification of $N$-fluorinated cinchona alkaloids by X-ray crystallography analysis and further applications [96]. This method proved to be far more practical than the enantiomeric sulfonamide-type $N$-F reagents developed until then.

Many cinchona alkaloid derivatives were tested for their ability to fluorinate substrates such as cyclic and acyclic ketones and esters. Scheme 67 shows two typical examples of $N$-F cinchona alkaloid species, 29-2 and 29-4, formed from dihydroquinine 4-chlorobenzoate (DHQB, 29-1) and dihydroquinidine acetate (DHQDA, 29-3) with Selectfluor. As a result, high chemical yields and high enantiomeric excesses were obtained for many substrates as summarized in Scheme 68. The DHQB/Select-<smiles>CCC1CN2CCC1C2[C@H](OC(=O)c1ccc(Cl)cc1)c1ccnc2ccc(OC)cc12</smiles>

DHQB 29-1

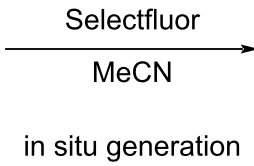

in situ generation

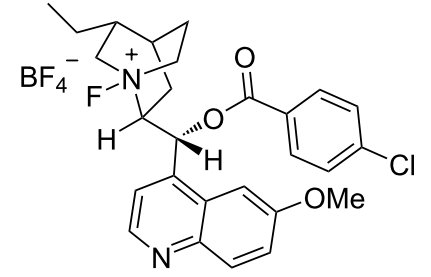

NF-DHQB-BF 4 29-2<smiles></smiles>

DHQDA 29-3

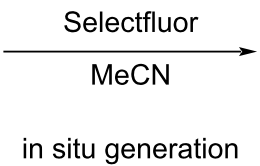

in situ generation

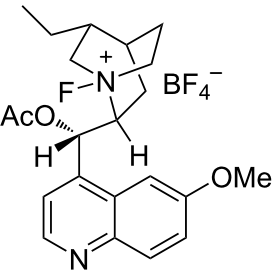

NF-DHQDA-BF 4 29-4 


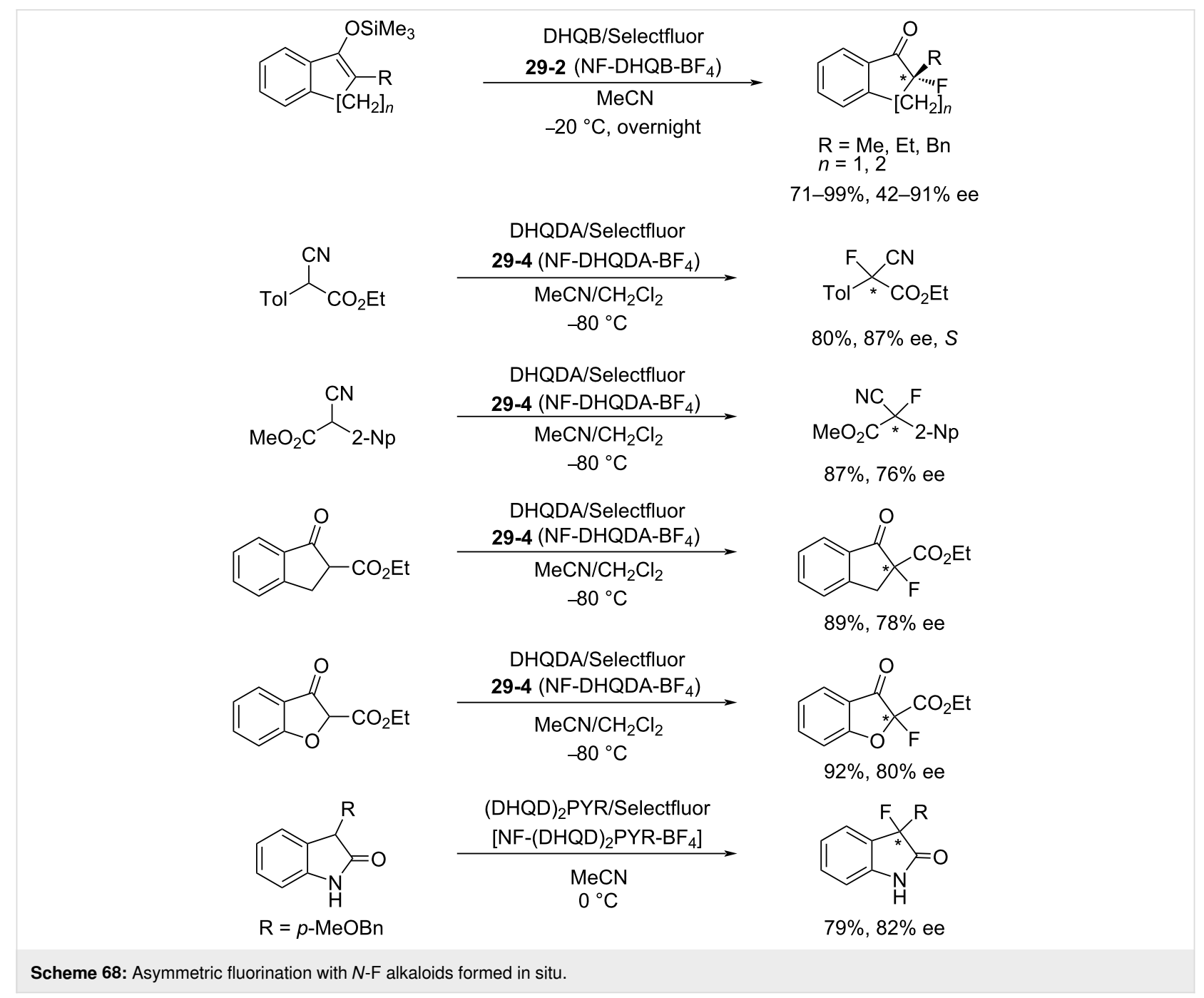

fluor combination was effective for the fluorination of silyl enol ethers of indanones and tetralones, forming the fluorinated products in up to $91 \%$ ee. The DHQDA/Selectfluor combination was effective also for acyclic esters, with outcomes up to $87 \%$ ee, and for cyclic keto esters, up to $80 \%$ ee. For oxindoles, the (DHQD) ${ }_{2} \mathrm{PYR} /$ Selectfluor combination was effective too, generating the products with up to $82 \%$ ee.

\section{1-30. Enantiopure $N$-fluorocinchona alkaloid salts}

Only six days after the report by Shibata and Takeuchi appeared (Oct. 2000), Cahard et al. reported the synthesis and application of similar enantiopure $N$-fluoro salts of cinchona alkaloids through the reaction of the alkaloids with Selectfluor [97]. Following the precedent from Banks's fluorine-transfer reaction from Selectfluor to the $N$-site of quinuclidine [62], Cahard et al. isolated four $N$-fluorocinchona alkaloid salts, $\mathrm{F}-\mathrm{CD}-\mathrm{BF}_{4}$ 30-1, F-CN-BF 4 30-2, F-QN-BF 4 30-3, and F-QD-BF 4 30-4 in good yields (Scheme 69). Soon after in 2001, they reported the $\mathrm{X}$-ray structural analysis of F-CD-BF 4 30-1 [98].
The enantioselective fluorination of the sodium enolate of 2-methyl-1-tetralone was examined using these $N$-F alkaloid salts (Scheme 70). F-CD-BF 4 30-1 gave the highest result with a $56 \%$ ee. $\mathrm{F}-\mathrm{CD}-\mathrm{BF}_{4} \mathbf{3 0 - 1}$ is a nonhygroscopic, free-flowing solid with a high decomposition point $\left(189^{\circ} \mathrm{C}\right.$, dec $)$.

Enantioselective fluorinations of the sodium enolates of other ketones and $\beta$-keto esters with $\mathrm{F}-\mathrm{CD}-\mathrm{BF}_{4}$ 30-1 were also investigated. The trimethylsilyl enol ether of 2-methyl-1-tetralone was examined, too (up to $61 \%$ ee, $93 \%$ yield). These experiments gave the fluorinated products in excellent chemical yields but with lower enantiomeric excesses than the Shibata and Takeuchi's protocol.

1-31. $N$-Fluoro-p-chlorobenzoylquinine salt: another $N-F$ reagent of cinchona alkaloid

In 2003, Cahard et al. reported the transfer fluorination of a cinchona alkaloid, $p$-chlorobenzoylquinine (pClBzQN, 31-1) using not only Selectfluor ${ }^{\mathrm{TM}}\left(\mathrm{F}-\mathrm{TEDA}-\mathrm{BF}_{4}\right)$ but also other 


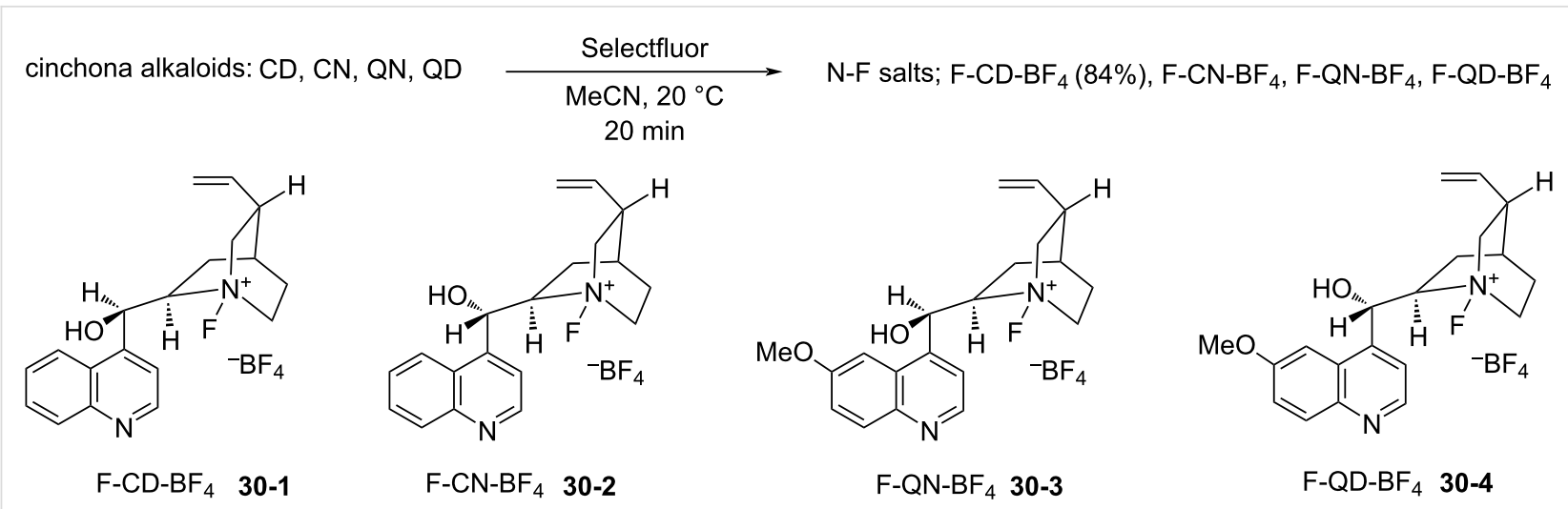

Scheme 69: Synthesis of $N$-fluorocinchona alkaloids with Selectfluor.<smiles>O=C1c2ccccc2CCC1[18O]</smiles><smiles>CC1(F)CCc2ccccc2C1=O</smiles>

(R or $S)$

$\mathrm{F}-\mathrm{CD}-\mathrm{BF}_{4}$ 30-1

$\mathrm{F}-\mathrm{CD}-\mathrm{BF}_{4} 30-1\left(-60^{\circ} \mathrm{C}\right)$

$98 \%, 50 \%$ ee

$\mathrm{F}-\mathrm{CN}-\mathrm{BF}_{4}$ 30-2

$\mathrm{F}-\mathrm{QN}-\mathrm{BF}_{4}$ 30-3

$\mathrm{F}-\mathrm{QD}-\mathrm{BF}_{4} \mathbf{3 0 - 4}$
$70 \%, 40 \%$ ee

$98 \%, 20 \%$ ee

$87 \%, 27 \%$ ee
$80 \%, 56 \%$ ee

Scheme 70: Asymmetric fluorination with 30-1-4.

powerful $\mathrm{N}$-F fluorinating agents such as 1-fluoro-4-hydroxy1,4-diazoniabicyclo[2.2.2] octane bistetrafluoroborate (NFTh, 19-2), $N$-fluorobenzenesulfonimide (NFSI), and $N$-fluoro-2,6dichloropyridinium tetrafluoroborate (5-4s) (Scheme 71) [99].

These reactions produced F-pClBzQN-X 31-2 quantitatively at $20{ }^{\circ} \mathrm{C}$ within $30 \mathrm{~min}$ in acetonitrile or in an ionic liquid such as 1-hexyl-3-methylimidazolinium hexafluorophosphate [hmim] $\left[\mathrm{PF}_{6}\right]$. However, the less powerful reagents, $N$-fluoroquinuclidinium tetrafluoroborate, $N$-fluoro- $N$-methyl- $p$-toluenesulfonamide (4-1a), $N$-fluoropyridinium triflate (5-4a), $N$-fluoro-2,4,6-trimethylpyridinium tetrafluoroborate (5-4k), and $N, N$ '-difluoro-2,2'-bipyridinium bistetrafluoroborate (242b) failed. Among the five effective fluorine-transfer reagents, the 2,6-dichloropyridinium salt $\mathbf{5 - 4} \mathrm{s}$ was more cost effective because it has a higher fluorine content $(\mathbf{5 - 4 s}, 3.94 \mathrm{mmol} / \mathrm{g})$ than the others (Selectfluor, $2.82 \mathrm{mmol} / \mathrm{g}$; F-TEDA-OTf, $2.09 \mathrm{mmol} / \mathrm{g}$; NFTh, $3.11 \mathrm{mmol} / \mathrm{g}$; NFSI, $3.17 \mathrm{mmol} / \mathrm{g}$ ).

The enantioselective fluorination of F-pClBzQN-X 31-2 was examined on trimethylsilyl enol ethers of methyl- and benzylindanones 31-3 and -4 (Figure 10). High chemical yields and ees<smiles>C=C[C@H]1CN2CCC(C2)[C@H]1C(OC(=O)c1ccc(Cl)cc1)c1ccnc2ccc(OC)cc12</smiles>

pCIBzQN 31-1

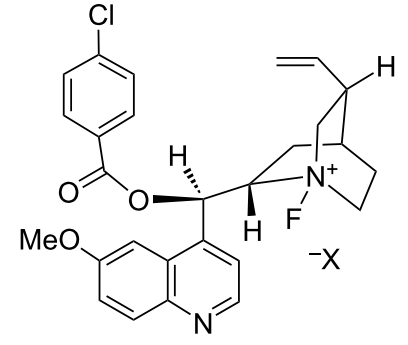

F-pCIBzQN-X 31-2

\begin{tabular}{ll} 
N-F reagent & F-pClBzQN-X \\
\hline Selectfluor (F-TEDA-BF 4$)$ & $\mathrm{X}=\mathrm{BF}_{4}$ \\
F-TEDA-OTf & $\mathrm{X}=\mathrm{OTf}$ \\
NFTh & $\mathrm{X}=\mathrm{BF}_{4}$ \\
NFSI & $\mathrm{X}=\mathrm{N}_{\left(\mathrm{SO}_{2} \mathrm{Ph}\right)_{2}}$ \\
N-F-2,6-diCl-pyridinium $\mathrm{BF}_{4}$ & $\mathrm{X}=\mathrm{BF}_{4}$
\end{tabular}

Scheme 71: Transfer fluorination from various $N-F$ reagents. 
(88-97\% and $81-85 \%$ ee) were obtained in the reactions of benzyl derivative 31-4 with F-pClBzQN-X $\left[\mathrm{X}=\mathrm{BF}_{4}\right.$ or $\left.\mathrm{N}\left(\mathrm{SO}_{2} \mathrm{Ph}\right)_{2}\right]$ prepared in situ from the $N$-F reagents and pClBzQN (entries 4-8 in Figure 10).

\begin{tabular}{|c|c|c|c|c|c|c|}
\hline \multirow{2}{*}{\multicolumn{4}{|c|}{$\begin{array}{c}\downarrow N-F \text { reagent } \\
\underset{\mathrm{n} \mathrm{CH}_{3} \mathrm{CN},-40^{\circ} \mathrm{C}}{\mathrm{F}-\mathrm{pCIBzQN}-\mathrm{X}}\end{array}$}} & \multirow{2}{*}{\multicolumn{3}{|c|}{$\begin{array}{l}31-5 \mathrm{R}=\mathrm{Me} \\
31-6 \mathrm{R}=\mathrm{Bn}\end{array}$}} \\
\hline & & & & & & \\
\hline entry & \multicolumn{2}{|c|}{$N$-F reagent } & substrate & product & $\begin{array}{l}\text { yield } \\
(\%)\end{array}$ & $\begin{array}{l}\text { ee } \\
(\%)\end{array}$ \\
\hline 1 & \multicolumn{2}{|l|}{ Selectfluor } & $31-3$ & $31-5$ & 90 & 64 \\
\hline 2 & \multicolumn{2}{|l|}{ NFSI } & $31-3$ & $31-5$ & 91 & 62 \\
\hline 3 & \multicolumn{2}{|c|}{$N$-F-2,6-diCl-pyridinium $\mathrm{BF}_{4}$} & $31-3$ & $31-5$ & 97 & 67 \\
\hline 4 & \multicolumn{2}{|c|}{ Selectfluor } & $31-4$ & $31-6$ & 98 & 84 \\
\hline 5 & \multicolumn{2}{|l|}{ F-TEDA-OTf } & $31-4$ & $31-6$ & 88 & 81 \\
\hline 6 & \multicolumn{2}{|l|}{ NFTh } & $31-4$ & $31-6$ & 92 & 82 \\
\hline 7 & \multicolumn{2}{|c|}{$\mathrm{NFSI}$} & $31-4$ & $31-6$ & 94 & 85 \\
\hline 8 & \multicolumn{2}{|c|}{$N$-F-2,6-diCl-pyridinium $\mathrm{BF}_{4}$} & $31-4$ & $31-6$ & 97 & 81 \\
\hline
\end{tabular}

Figure 10: Asymmetric fluorination of silyl enol ethers.

\section{1-32. N-Fluoro-2,4,6-trichloro-1,3,5-triazinium tetra- fluoroborate}

In 2003, Banks et al. reported the synthesis of $N$-fluoro-2,4,6trichloro-1,3,5-triazinium tetrafluoroborate (32-2) and its fluorination of aromatic compounds [100]. Although the syntheses of $N$-fluoro-2,4,6-trifluoro-1,3,5-triazinium hexafluoroarsenate and $\mathrm{N}$-fluoro-2,4,6-trichloro-1,3,5-triazinium hexafluoroarsenate had been reported a decade earlier (1993) [101], their fluorination ability had not been disclosed.

Salt 32-2 was prepared in high yield in a small-scale batch reactor (Scheme 72). Accordingly, $100 \% \mathrm{~F}_{2}$ (1 equiv) and $\mathrm{BF}_{3}$ (1 equiv) gas were condensed into a stainless steel autoclave cooled at $-196{ }^{\circ} \mathrm{C}$, which contained cyanuric chloride (32-1, 1 equiv) in $\mathrm{CFCl}_{3}$. This was followed by gradual warming to room temperature and the reaction mixture was stored for
5 days. The resultant salt $\mathbf{3 2 - 2}$ is a moisture-sensitive white solid that decomposes at $153-155{ }^{\circ} \mathrm{C}$.

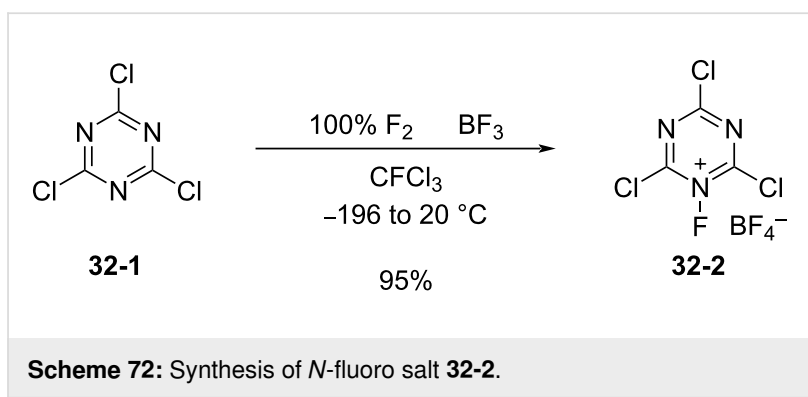

Reagent 32-2 reacted with deactivated benzenes such as chlorobenzene and nitrobenzene at ambient temperature (Scheme 73). This outcome indicated that $\mathbf{3 2 - 2}$ was a more powerful fluorinating reagent than the $N$-fluoropentachloropyridinium salts $\mathbf{5 - 4 v , w}$. However, reagent 32-2 is not easy-tohandle because of its moisture-sensitivity.

\section{1-33. Bulky $N$-fluorobenzenesulfonimides (NFBSI)}

In 2011, Shibata et al. reported a bulky NFSI analog, $N$-fluoro(3,5-di-tert-butyl-4-methoxy)benzenesulfonimide (NFBSI, 33-3) [102]. This stable and crystalline reagent was synthesized in 57\% yield by fluorination of bis(3,5-di-tert-butyl-4-methoxybenzenesulfonyl)amide (33-2) with $10 \% \mathrm{~F}_{2} / \mathrm{N}_{2}$ in the presence of $\mathrm{NaF}$ in acetonitrile at $-40{ }^{\circ} \mathrm{C}$ (Scheme 74). X-ray crystal structure analysis revealed that the fluorine atom of NFBSI was surrounded by four bulky tert-butyl substituents.

This feature improved the enantioselectivity in cinchona alkaloid-catalyzed enantioselective fluorinations. The enantiomeric excesses of the products obtained with NFBSI 33-3 increased by $18 \%$ compared to that of $\left(\mathrm{PhSO}_{2}\right)_{2} \mathrm{NF}$ (NFSI, 14-2), while the chemical yields decreased (Scheme 75). Since the active fluorination agent in these reactions is considered to be the in situ generated $N$-fluorocinchona alkaloid salt, after fluorine transfer from NFBSI or NFSI to generate a counter anion, the bulky in situ generated counter anion may help enhance the $\%$ ee of the products.

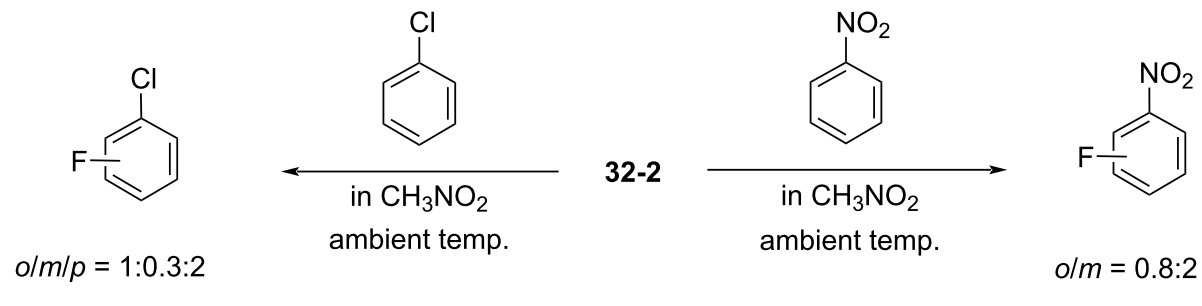


<smiles>COc1c(C(C)(C)C)cccc1C(C)(C)C</smiles>

33-1

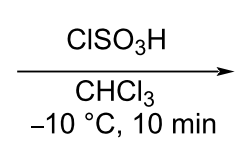

$37 \%$

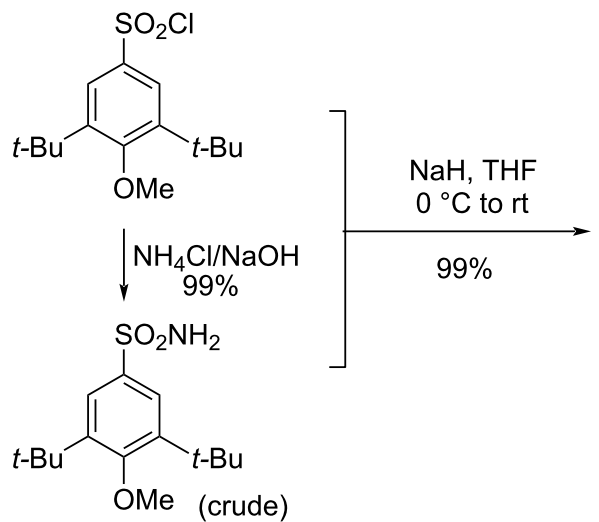

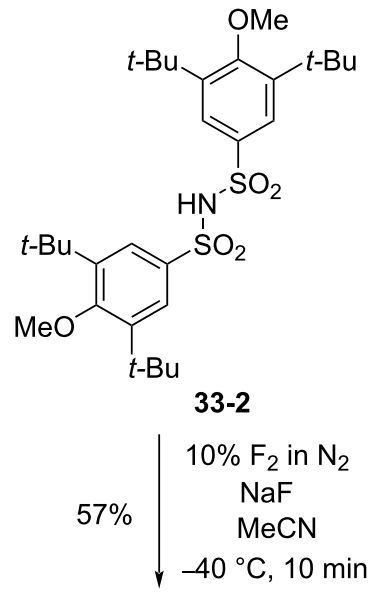<smiles>COc1c(C(C)(C)C)cc(C(F)(F)c2cc([N+](=O)[O-])cc(C(C)(C)C)c2OC)cc1C(C)(C)C</smiles>

NFBSI 33-3

Scheme 74: Synthesis of bulky $N$-fluorobenzenesulfonimide NFBSI 33-3.<smiles>COC1=C(Cc2ccccc2)Cc2ccccc21</smiles><smiles>COC1=C(C)Cc2ccccc21</smiles>

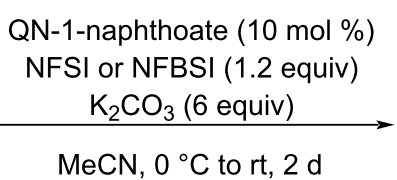

$\mathrm{MeCN}, 0^{\circ} \mathrm{C}$ to rt, $2 \mathrm{~d}$

$(\mathrm{DHQ})_{2} \mathrm{PYR}(10 \mathrm{~mol} \%)$ $\mathrm{NFSI}$ or NFBSI (1.2 equiv) $\mathrm{K}_{2} \mathrm{CO}_{3}$ (6 equiv)

$\mathrm{MeCN}, 0^{\circ} \mathrm{C}$ to rt, $2 \mathrm{~d}$

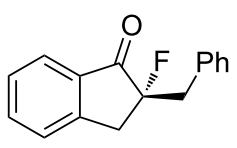

NFSI: $79 \%, 52 \%$ ee NFBSI: $75 \%, 70 \%$ ee

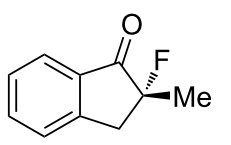

NFSI: $78 \%, 40 \%$ ee NFBSI: $41 \%, 58 \%$ ee

Scheme 75: Comparison of NFSI and NFBSI.

\section{1-34. $p$-Substituted $N$-fluorobenzenesulfonimides}

In 2012, Yang et al. reported an efficient process for the preparation of $p$-substituted $N$-fluorobenzenesulfonimides 34-3 [103]. The traditional process involved the direct fluorination of benzensulfonimides in acetonitrile in the presence of a large excess of NaF. They prepared the sodium salts 34-2 (precipitates) with $2 \%$ aq $\mathrm{NaOH}$ solution and treated the air-dried precipitates with $10 \% \mathrm{~F}_{2} / \mathrm{N}_{2}$ in acetonitrile (Scheme 76). This process considerably improved the yields of the $N$-fluorobenzenesulfonimides 34-3. 


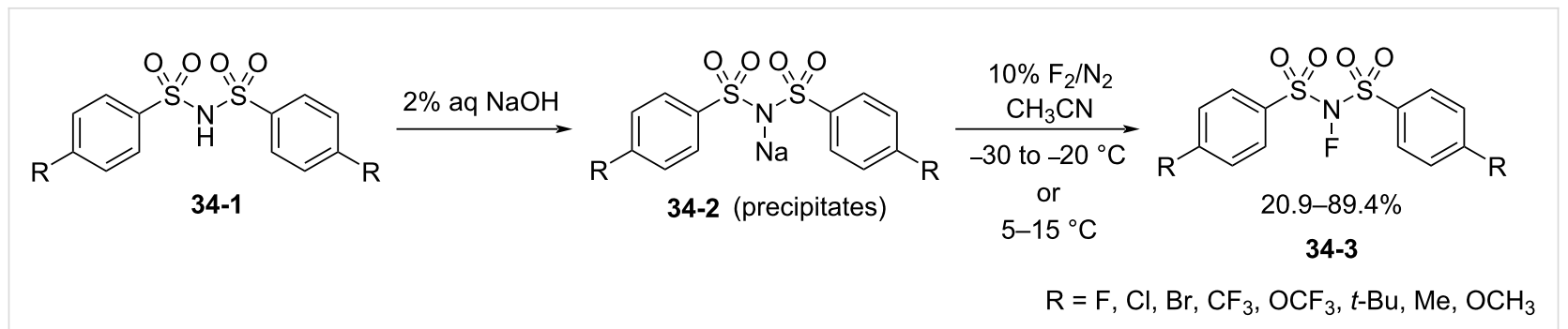

Scheme 76: Synthesis of $p$-substituted $N$-fluorobenzenesulfonimides 34-3.

In 2013, the same group reported the enantioselective fluorination of oxindoles 34-5 with 34-3 in the presence of a catalytic amount of bis-cinchona alkaloid (DHQD) ${ }_{2}$ PHAL 34-4 (Figure 11) [104]. In these reactions, the actual enantioselective fluorinating agents should be the $N$-F cinchona alkaloid salts formed in situ after the transfer from 34-3. Electron-donating groups (R) afforded higher enantioselectivities compared to $\mathrm{R}=\mathrm{H}$ (NFSI, 14-2), while chemical yields were decreased. For example, while NFSI afforded $56 \%$ ee and $66 \%$ chemical yield (entry 1, Figure 11), R = OMe (34-3a) and tert-butyl (34-3b) gave $94 \%$ ee and $96 \%$ ee (entries 2 and 3 in Figure 11), but with only $49 \%$ and $17 \%$ chemical yields, respectively. Electronwithdrawing groups, $\mathrm{R}=\mathrm{CF}_{3} \mathbf{3 4 - 3 c}$ and $\mathrm{OCF}_{3} \mathbf{3 4 - 3 d}$, failed to furnish the fluorinated product under the same conditions (entries 8 and 9, Figure 11).
A year later (2014), the Yang group published the synthesis of other substituted NFSI derivatives and examined the enantioselective fluorination of 2-oxindoles catalyzed by chiral palladium complexes [105].

1-35. Two Selectfluor analogues, 1-fluoro-4-[3',4'bis(trifluoromethyl)phenylmethyl]- and -(pentafluorophenyl)methyl-1,4-diazoniabicyclo[2.2.2]octane salts In March 2013, Toste et al. reported the enantioselective 1,4fluoroamination of conjugated dienes using Selectfluor in an anionic, phase-transfer catalysis in a nonpolar solvent [106]. Diene 35-1 was treated with Selectfluor and (R)-TCYP 35-3 as a catalyst to give $\mathbf{3 5 - 2}$ in $91 \%$ chemical yield and $96 \%$ ee (Scheme 77). In this case, the actual fluorinating species was considered to be the salt containing 1-chloromethy-4-fluoro-<smiles>[R]c1ccc(C2C(=O)N(C(=O)OCc3ccccc3)c3ccc([R])cc32)cc1</smiles>

34-5 reagent 34-3

$(\mathrm{DHQD})_{2} \mathrm{PHAL}(5 \mathrm{~mol} \%)$

$\mathrm{K}_{2} \mathrm{CO}_{3}$ (6.0 equiv)

$\mathrm{CH}_{2} \mathrm{Cl}_{2} / \mathrm{CH}_{3} \mathrm{CN} 3: 4$

$-80^{\circ} \mathrm{C}$<smiles>[R]c1ccc([C@]2(F)C(=O)N(C(C)(C)C)c3ccc([R])cc32)cc1</smiles>

34-6<smiles>CCC1CC2CCC1N2[C@H](c1ccnc2ccc(OC)cc12)[C@H](C)Oc1nnc(O[C@H](C)c2ccnc3ccc(OC)cc23)c2ccccc12</smiles>

$(\mathrm{DHQD})_{2} \mathrm{PHAL} \quad \mathbf{3 4 - 4}$

\begin{tabular}{|c|c|c|c|c|c|c|}
\hline entry & substrate & \multicolumn{2}{|c|}{ reagent NFSI, 34-3a-d } & time & yield & ee \\
\hline 1 & $\mathrm{R}^{1}=\mathrm{R}^{2}=\mathrm{H}$ & NFSI & $=\mathrm{H}$ & $48 \mathrm{~h}$ & $66 \%$ & $56 \%$ \\
\hline 2 & $\mathrm{R}^{1}=\mathrm{R}^{2}=\mathrm{H}$ & $34-3 a$ & OMe & $96 \mathrm{~h}$ & $49 \%$ & $94 \%$ \\
\hline 3 & $\mathrm{R}^{1}=\mathrm{R}^{2}=\mathrm{H}$ & $34-3 b$ & $t-\mathrm{Bu}$ & $96 \mathrm{~h}$ & $17 \%$ & $96 \%$ \\
\hline 4 & $\mathrm{R}^{1}=\mathrm{R}^{2}=\mathrm{Me}$ & NFSI & $\mathrm{H}$ (NFSI) & $36 \mathrm{~h}$ & $99 \%$ & $70 \%$ \\
\hline 5 & $\mathrm{R}^{1}=\mathrm{R}^{2}=\mathrm{Me}$ & $34-3 c$ & $\mathrm{~F}$ & $36 \mathrm{~h}$ & $98 \%$ & $75 \%$ \\
\hline 6 & $\mathrm{R}^{1}=\mathrm{R}^{2}=\mathrm{Me}$ & $34-3 a$ & OMe & $96 \mathrm{~h}$ & $57 \%$ & $70 \%$ \\
\hline 7 & $\mathrm{R}^{1}=\mathrm{R}^{2}=\mathrm{Me}$ & $34-3 b$ & $t-\mathrm{Bu}$ & $96 \mathrm{~h}$ & $40 \%$ & $88 \%$ \\
\hline 8 & $\mathrm{R}^{1}=\mathrm{R}^{2}=\mathrm{Me}$ & $34-3 c$ & $\mathrm{CF}_{3}$ & $84 \mathrm{~h}$ & $0 \%$ & - \\
\hline 9 & $\mathrm{R}^{1}=\mathrm{R}^{2}=\mathrm{Me}$ & $34-3 d$ & $\mathrm{OCF}_{3}$ & $72 \mathrm{~h}$ & $0 \%$ & - \\
\hline
\end{tabular}


<smiles>CC(C)(C)c1ccc(C(=O)NCC2=C(/C=C/[Al])c3ccccc3CC2)cc1</smiles>

35-1 $\left(\mathrm{Ar}=2-\mathrm{MeC}_{6} \mathrm{H}_{4}\right)$<smiles>CC(C)(C)c1ccc(C(=O)N2CC3(F)CCc4ccccc4C3=C[C@@H]2Br)cc1</smiles>

35-2 $91 \%, 96 \%$ ee $(d r>20: 1)$<smiles>[R]Oc1c(-c2c(-c3c([R])cc([R])cc3[R])c(-c3c([R])cc([R])cc3[R])cc3ccccc23)c(OP(=O)(O)O)cc2ccccc12</smiles>

(R)-TCYP 35-3 $(\mathrm{R}=$ cyclohexyl)

Scheme 77: 1,4-Fluoroamination with Selecfluor and a chiral catalyst.

1,4-diazoniabicyclo[2.2.2] octane as the cation and (R)-TCYP as the anion, which could be formed in the non-polar organic layer.

However, since the reaction with the less reactive diene 35-6a occurred in very low yield $(<10 \%)$ (Figure 12 , entry 1$)$, they synthesized two new Selectfluor analogues, 1-fluoro-4-[3',4'bis(trifluoromethyl)phenylmethyl]- and -(pentafluorophenyl)methyl-1,4-diazoniabicyclo[2.2.2]octane bistetrafluoroborates 35-5a and 35-5b, by treating the precursor 35-4 with $\mathrm{XeF}_{2}$ in the presence of sodium tetrafluoroborate [106] (Scheme 78).<smiles>CC(C)(C)c1ccc(C(=O)NCC2=C(/C=C/[13CH3])CCCC2)cc1</smiles>

35-6

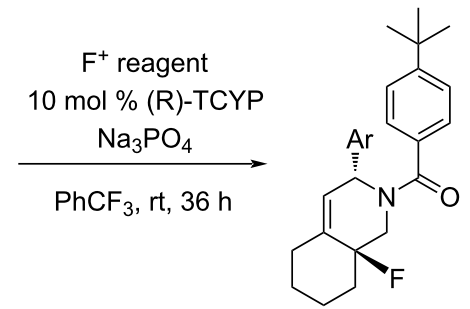

35-7

\begin{tabular}{cllllll} 
entry & $\mathrm{F}^{+}$reagent & product & Ar & $\begin{array}{l}\text { yield } \\
(\%)\end{array}$ & $\begin{array}{l}\text { ee } \\
(\%)\end{array}$ & dr \\
\hline 1 & Selectfluor & 35-7a & phenyl & $<10$ & 0 & - \\
2 & 35-5a & 35-7a & phenyl & 70 & 76 & $14: 1$ \\
3 & 35-5b & 35-7a & phenyl & 15 & 5 & - \\
4 & 35-5a & 35-7b & 2-Me-phenyl & 65 & 73 & $8.3: 1$ \\
5 & 35-5a & 35-7c & 4-Me-phenyl & 75 & 89 & $>20: 1$
\end{tabular}

Figure 12: Asymmetric fluoroamination with $35-5 a$, b.

Reagent 35-5a showed much improved chemical yields $(65-75 \%)$ and enantioselectivities $(73-89 \%$ ee) in fluorocyclization reactions with diene 35-6 (Figure 12, entries 2, 4, and 5) than reagent 35-5b. Although there may be an electron-defi-

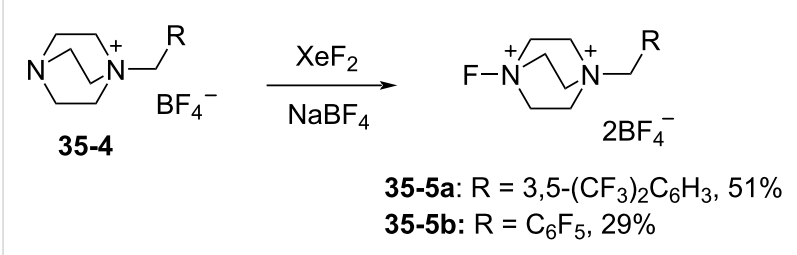

Scheme 78: Synthesis of Selectfluor analogs 35-5a, b.

ciency effect, this could also be attributed to the strong lipophilic effect of the bis $\left(\mathrm{CF}_{3}\right)$ phenyl group in 35-5a to the organic layer $\left(\mathrm{PhCF}_{3}\right)$.

\section{1-36. Chiral dicationic DABCO-based $N-F$ reagents}

In June 2013, Gouverneur et al. reported the synthesis of chiral dicationic DABCO-based $N$-F reagents 36-5 that made possible the asymmetric electrophilic fluorocyclization of monoolefins with carbon nucleophiles [107]. This can be contrasted with Toste's method, described in section 1-35 above, for asymmetric fluorocyclization of dienes with nitrogen nucleophiles using Selectfluor and an optically active phase-transfer catalyst, a reaction which did not work for monoolefins with carbon nucleophiles.

As shown in Scheme 79, the chiral DABCO core 36-3 was prepared from an enantiopure vicinal diamine 36-1 using the reported method. The precursor 36-4 was fluorinated with either $10 \% \mathrm{~F}_{2} / \mathrm{N}_{2}$ or $\mathrm{N}$-fluoropentachloropyridinium triflate $(\mathbf{5 - 1 v})$ to produce optically active products $\mathbf{3 6 - 5 a}, \mathbf{- 5 b}$, and $\mathbf{- 5 c}$ in high yields. This fluorination which uses the shelf-stable, easy-tohandle $N$-fluoropentachloropyridinium triflate (5-1v) was advantageous as it allowed the in situ formation of the chiral reagents 36-5.

The solubility, reactivity, and enantioselectivity of these types of reagents could be tuned by varying the substituents on the 


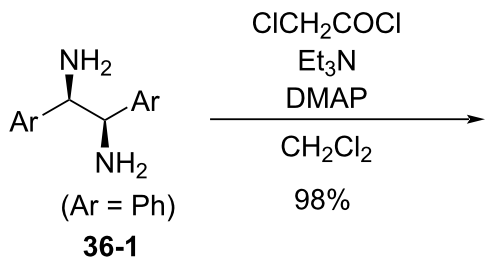<smiles>O=C(CCl)NC(Br)C(Br)NC(=O)CCl</smiles>

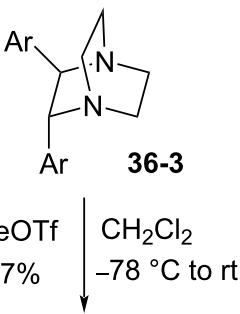

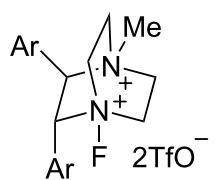

36-5

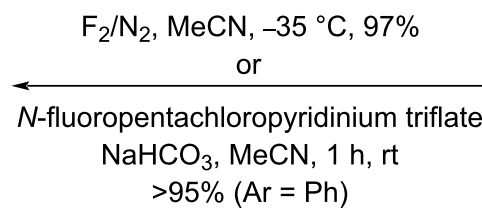

$>95 \%(\mathrm{Ar}=\mathrm{Ph})$

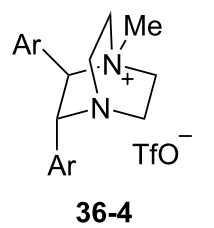

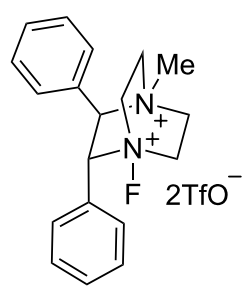

$(2 R, 3 R)-\mathbf{3 6 - 5 a}$<smiles>CCO[N+]1(F)C2CCC1([N+]1(C)CCCC1)C(c1ccc(C(F)(F)F)cc1)C2c1ccc(C(F)(F)F)cc1</smiles>

$(2 S, 3 S)-36-5 b$

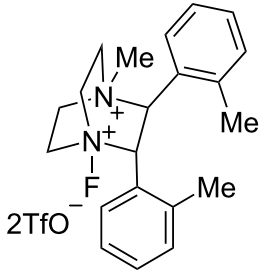

$(2 S, 3 S)-36-5 c$

Scheme 79: Synthesis of chiral dicationic DABCO-based N-F reagents $\mathbf{3 6 - 5}$

aryl rings and the $p$-trifluoromethyl-derivative $\mathbf{3 6 - 5 b}$ proved to be the most efficient for this type of reaction (Scheme 80). Up to $99 \%$ chemical yield and an average of $71 \%$ ee were obtained for a series of indene derivatives. However, the enantioselectivity was low $(19 \%$ ee) for the case of a dihydronaphthalene derivative (the bottom in Scheme 80). Racemates of these fluoro products were prepared in high yields with $N$-fluoro-2,6dichloropyridinium triflate (5-1r).

\section{1-37. Chiral $N$-fluorobinaphthyldisulfonimides}

In June 2013, the same month as the report described above from Gouverneur's lab, Shibata, Ma, and Cahard disclosed a chiral $N$-fluorobinaphthyldisulfonimide 37-2a and its bis[3,5bis(trifluoromethyl)phenyl] derivative $\mathbf{3 7 - 2 b}$ as enantioselective fluorination agents, compounds which were prepared in $67 \%$ and $27 \%$ yields, respectively, by fluorination of the $\mathrm{NH}$ precursors 37-1 with $0.2 \% \mathrm{~F}_{2} / \mathrm{N}_{2}$ (Scheme 81 ) [108]. In both cases, side-products were formed but not characterized. The precursors 37-1 had been synthesized by List [109] and Giernoth [110] and previously used as organocatalysts.

The fluorination ability of $\mathbf{3 7 - 2 a}$ and $\mathbf{- 2 b}$ was evaluated with $\beta$-keto ester derivatives (Scheme 82). Moderate yields and good enantioselectivities of the fluorinated products were obtained.
Reagent 37-2b clearly gave a better selectivity than the unsubstituted 37-2a ( $86 \%$ ee vs $17 \%$ ee).

For an enantioselective synthesis of the potent Maxi-K potassium channel opener MaxPost 37-4 $(\mathrm{R}=\mathrm{H})$, the $N$-Boc-protected substrate 37-3 was fluorinated with $\mathbf{3 7 - 2 b}$, giving the precursor 37-4 $(\mathrm{R}=\mathrm{Boc})$ in $51 \%$ yield and with $57 \%$ ee (Scheme 83).

The oxidative aminofluorination of indene (37-5) with 37-2a and -2b gave four diastereomers 37-6a and -6b in 77 and $76 \%$ yield, respectively; however, no asymmetric induction was observed (Scheme 84).

\section{1-38. N-Fluoromethanesulfonimide (Me-NFSI)}

In 2016, Shibata et al. reported the synthesis and reactivity of $\mathrm{N}$-fluoromethanesulfonimide (Me-NFSI, 38-2) [111]. Me-NFSI was first reported in a patent in 1994 [112], however, the reported fluorinations were vague. Prior to Shibata's report, Me-NFSI had not appeared in the literature in over 20 years. Although Me-NFSI is vulnerable with acidic protons on the methyl groups, Shibata realized the high atom economy of Me-NFSI and claimed that Me-NFSI was more effective for the fluorination of active methines than $\left(\mathrm{PhSO}_{2}\right)_{2} \mathrm{NF}$ (NFSI, 14-2) 
<smiles>CC1(C)C(C[NH2+]c2ccccc2)=Cc2ccccc21</smiles>

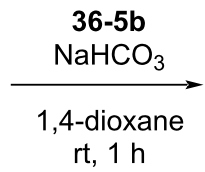<smiles>CC1(C)c2ccccc2[C@H]2c3ccccc3[NH+]([SH2+])CC21F</smiles>

$75 \%, 71 \%$ ee<smiles></smiles>

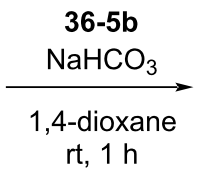<smiles>CC1(C)c2ccccc2[C@H]2c3cc(Cl)ccc3[NH+]([SH2+])CC21F</smiles>

$70 \%, 73 \%$ ee<smiles>CC(C)c1ccc(N(CC2=Cc3ccccc3C2(C)C)S(=O)(=O)[O-])cc1</smiles><smiles>CC(C)c1ccc2c(c1)[C@H]1c3ccccc3C(C)(C)C1(F)CN2S(=O)(=O)[O-]</smiles>

$99 \%, 70 \%$ ee<smiles>CC(C)(C)C1=Cc2ccccc2C1(C)C</smiles>

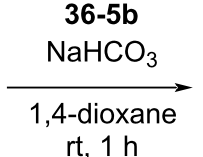
$\mathrm{rt}, 1 \mathrm{~h}$<smiles>CN1CC2(F)[C@H](c3cc(Cl)ccc31)c1ccccc1C2(C)C</smiles>

$68 \%, 71 \%$ ee<smiles></smiles>

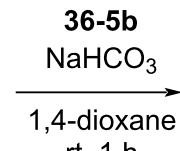<smiles>CS(=O)(=O)[NH+]1CC(F)(F)CCc2ccccc21</smiles>

$83 \%, 19 \%$ ee

Scheme 80: Asymmetric fluorocyclization with chiral 36-5b.

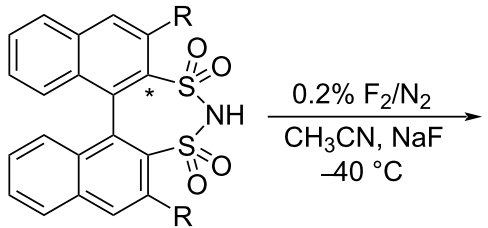

37-1<smiles>[R]c1cc2ccccc2c(-c2c(S(=O)(=O)N(F)F)c([R])cc3ccccc23)c1S(=O)(=O)[O-]</smiles>

37-2a, b

37-2a: $(R)$ isomer, $\mathrm{R}=\mathrm{H}, 67 \%$

37-2b: $(S)$ isomer, $\mathrm{R}=3,5-\left(\mathrm{CF}_{3}\right)_{2} \mathrm{C}_{6} \mathrm{H}_{3}, 27 \%$

Scheme 81: Synthesis of chiral 37-2a,b.<smiles>COC(=O)C1Cc2ccccc2C1=O</smiles>
37-2b: $48 \%, 86 \%$ ee<smiles>CCOC(=O)C1Cc2ccccc2C1=O</smiles><smiles>CCCOC(=O)C1(F)Cc2ccccc2C1=O</smiles>
37-2b: $63 \%, 76 \%$ ee<smiles>COC(=O)C1CCc2ccccc2C1=O</smiles><smiles>COC(=O)C1(F)CCc2ccccc2C1=O</smiles>

Scheme 82: Asymmetric fluorination with chiral 37-2a,b.<smiles>COc1ccc(Cl)cc1C1C(=O)N(C(=O)OC(C)(C)C)c2cc(C(F)(F)F)ccc21</smiles><smiles>[R]N1C(=O)[C@](F)(c2ccc(Cl)cc2OC)c2ccc(C(F)(F)F)cc21</smiles>

$51 \%, 57 \%$ ee

Scheme 83: Asymmetric fluorination with chiral 37-2b.
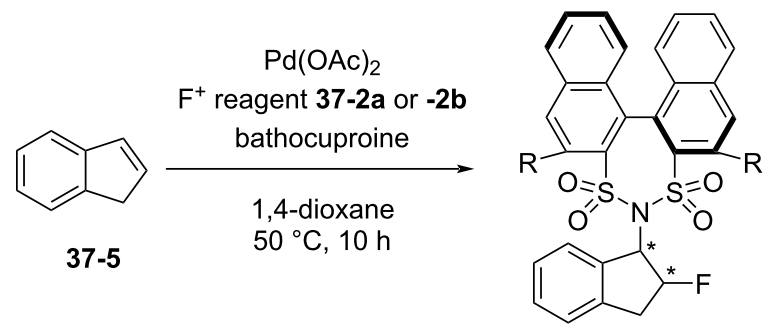

37-6a: $\mathrm{R}=\mathrm{H}, 77 \%$ 37-6b: $\mathrm{R}=3,5-\left(\mathrm{CF}_{3}\right)_{2} \mathrm{C}_{6} \mathrm{H}_{3}, 76 \%$

4 diastereoisomers

Scheme 84: Reaction of indene with chiral 37-2a,b.

under Lewis acid-catalysis and non-catalysis. Me-NFSI was prepared in good yield by the fluorination of methanesulfonimide 38-1 with $10 \% \mathrm{~F}_{2} / \mathrm{N}_{2}$ in acetonitrile at $-40{ }^{\circ} \mathrm{C}$ in the presence of $\mathrm{NaF}$ (Scheme 85). 


\begin{tabular}{|c|c|c|c|c|}
\hline \multirow{4}{*}{$\mathrm{NH}_{4} \mathrm{Cl}$} & $\mathrm{CH}_{3} \mathrm{SO}_{2} \mathrm{Cl}$ & $\mathrm{SO}_{2} \mathrm{CH}_{3}$ & $10 \% \mathrm{~F}_{2} / \mathrm{N}_{2}$ & $\mathrm{SO}_{2} \mathrm{CH}_{3}$ \\
\hline & $10 \mathrm{M} \mathrm{NaOH}$ & $\mathrm{SO}_{2} \mathrm{CH}_{3}$ & $\mathrm{NaF}$ & $\mathrm{SO}_{2} \mathrm{CH}_{3}$ \\
\hline & acetone $/ \mathrm{H}_{2} \mathrm{O} 3: 2$ & $61 \%$ & $\mathrm{CH}_{3} \mathrm{CN}$ & \\
\hline & $0^{\circ} \mathrm{C}$ & $38-1$ & $-40^{\circ} \mathrm{C}$ & $76 \%$ \\
\hline
\end{tabular}

Me-NFSI 38-2

Scheme 85: Synthesis of Me-NFSI, 38-2.

Many active methine compounds were fluorinated in high yields using Me-NFSI in the presence of $10 \mathrm{~mol} \% \mathrm{Ti}(\mathrm{OiPr})_{4}$ in methylene chloride as a solvent at room temperature (Scheme 86). The reactions with Me-NFSI were faster than those with NFSI. In particular, the fluorination of sterically demanding tert-butyl keto ester 38-3b with Me-NFSI gave the product 38-4b in $90 \%$ yield within only $5 \mathrm{~min}(92 \%$ in $3 \mathrm{~h}$ ), while NFSI gave the product in $20 \%$ yield after $10 \mathrm{~min}$ and the yield gradually increased to $80 \%$ over $24 \mathrm{~h}$. The faster reaction of Me-NFSI was explained by the activation of its $N$-F moiety via the stronger complexation with the Lewis acid $\mathrm{Ti}(\mathrm{OiPr})_{4}$ than NFSI.

For the fluorination of malonates, different conditions were needed. Treatment with 2 equiv of Me-NFSI in the presence of $20 \mathrm{~mol} \% \mathrm{Ti}(\mathrm{OiPr})_{4}$ in toluene at reflux temperature gave the fluorinated malonates in satisfactory yields (Scheme 87).

Keto esters were fluorinated in high yields with Me-NFSI employing methanol or water as solvent under catalysis-free conditions (entries 1-3, Scheme 88).

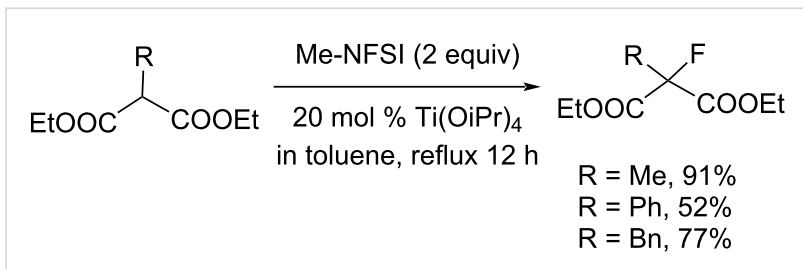

Scheme 87: Fluorination of malonates with Me-NFSI.

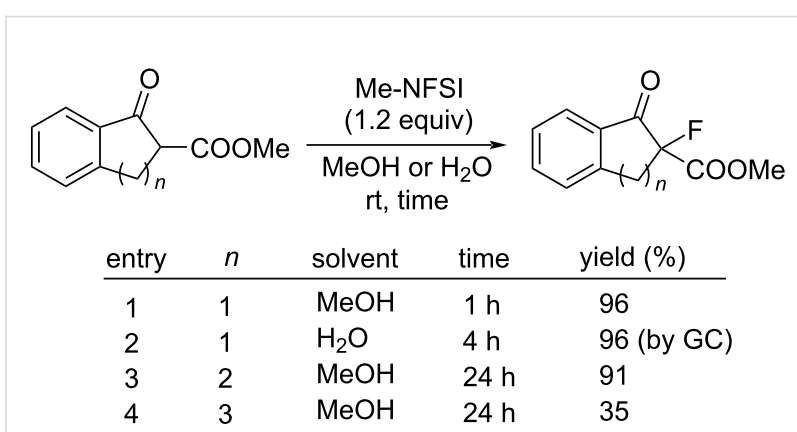

Scheme 88: Fluorination of keto esters with Me-NFSI. $\begin{array}{ccc}\substack{\text { (1 equiv) } \\ \mathbf{3 8 - 3}} & \stackrel{\text { Me-NFSI (1.2 equiv) }}{\longrightarrow} & \text { fluorinated methine compound } \\ & \begin{array}{c}10 \mathrm{~mol} \% \mathrm{Ti}(\mathrm{OiPr})_{4} \\ \text { in } \mathrm{CH}_{2} \mathrm{Cl}_{2}, \mathrm{rt}\end{array} & \mathbf{3 8 - 4}\end{array}$<smiles>COC(=O)C1(F)Cc2ccccc2C1=O</smiles>

38-4a $90 \%(3 h)$<smiles>CCOC(=O)C1(F)Cc2ccccc2C1=O</smiles>

38-4b $92 \%(3 \mathrm{~h})$<smiles>COC(=O)C1(F)CCc2ccccc2C1=O</smiles>

$38-4 \mathrm{c} 85 \%(6 \mathrm{~h})$<smiles>COC(=O)C1(F)CCCc2ccccc2C1=O</smiles>

$92 \%(24 \mathrm{~h})$<smiles>COC(=O)C1(F)CCCC1=O</smiles>

$48 \%(6 \mathrm{~h})$<smiles>CCOC(=O)C1(F)CCCC1=O</smiles>

$54 \%(24 \mathrm{~h})$<smiles>CC(=O)C1(F)CCCCC1=O</smiles>

$23 \%(24 \mathrm{~h})$<smiles>CC(=O)OC1(F)CCCCCC1=O</smiles>

$18 \%(24 \mathrm{~h})$<smiles>CCOC(=O)C(F)C(=O)c1ccccc1</smiles>

$63 \%(24 \mathrm{~h})$<smiles>CC(C)(C)OC(=O)N1C(=O)C(C)(F)c2ccccc21</smiles>

$86 \%(1 \mathrm{~h})$<smiles>O=C1Nc2ccccc2C1(F)c1ccccc1</smiles>

$92 \%(1 \mathrm{~h})^{\text {Boc }}$ 


\section{1-39. An $N-F$ reagent derived from the ethano-}

\section{Tröger's base}

In 2016, Gouverneur and Cvengroš reported the synthesis of a novel $N$-F reagent 39-3 derived from the ethylene-bridged Tröger's base 39-1 [113]. The fluorination of the precursor 39-2, obtained from 39-1, was achieved only after reaction with $\mathrm{N}$-fluoropentachloropyridinium triflate (5-1v) in acetonitrile at $-35{ }^{\circ} \mathrm{C}$, giving the $N-\mathrm{F}$ reagent $\mathbf{3 9 - 3}$ in higher than $95 \%$ conversion (Scheme 89). All other attempts to fluorinate, either with $\mathrm{F}_{2}, \mathrm{XeF}_{2}$, Selectfluor, or $N$-fluoro-2,6-dichloropyridinium triflate (5-1r) failed. This suggested that reagent 39-3 was more reactive than the other known reagents such as Selectfluor, but less active than the $N$-fluoropentachloropyridinium salts. The salt 39-3 is not stable and decomposition occurred when a solution of 39-3 in acetonitrile was left standing at room temperature for 8 hours or more. Therefore, 39-3 was best prepared with 5-1v immediately before use. The characterization of 39-3 was made by high-resolution mass spectrometry and NMR spectroscopic analyses containing $2 \mathrm{D}{ }^{19} \mathrm{~F}-{ }^{15} \mathrm{~N}$ heteronuclear correlation experiments.

Reagent 39-3 had the ability to formally transfer $\mathrm{F}^{+}$onto the Selectfluor precursor 39-4 to form a Selectfluor analog 39-5 (Scheme 90). The fluorine transfer of 39-3 to the precursor 39-4 was completed after $5 \mathrm{~min}$ at room temperature in acetonitrile.

The ability of 39-3 to fluorinate $C$-substrates was investigated. The fluorination of benzene, anisole, and fluorobenzene with 39-3 occurred faster than with Selectfluor (Scheme 91). The fluorination of styrenes 39-10 provided the expected addition products 39-11-14 in good yields. However, 39-3 did not react with less-activated alkenes, such as cyclohexene.

\section{1-40. 1-Cyanomethyl-4-fluoro-1,4-} diazoniabicyclo[2.2.2]octane bistriflate

In early 2018, Lan and Liu reported the synthesis of 1-cyanomethyl-4-fluoro-1,4-diazoniabicyclo[2.2.2]octane bistriflate (Selectfluor ${ }^{\mathrm{CN}}$ ) employing the same method as for Selectfluor (Scheme 92) [114].

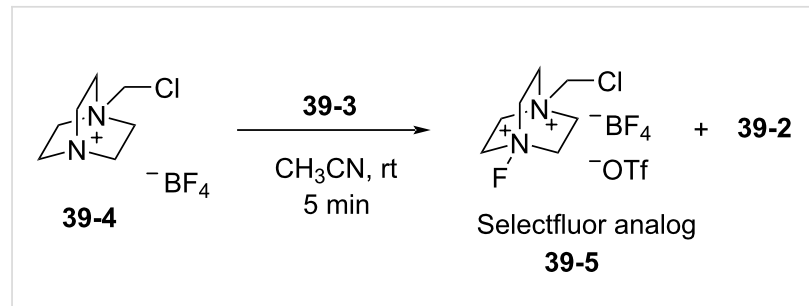

Scheme 90: Fluorine transfer from N-F 39-3.

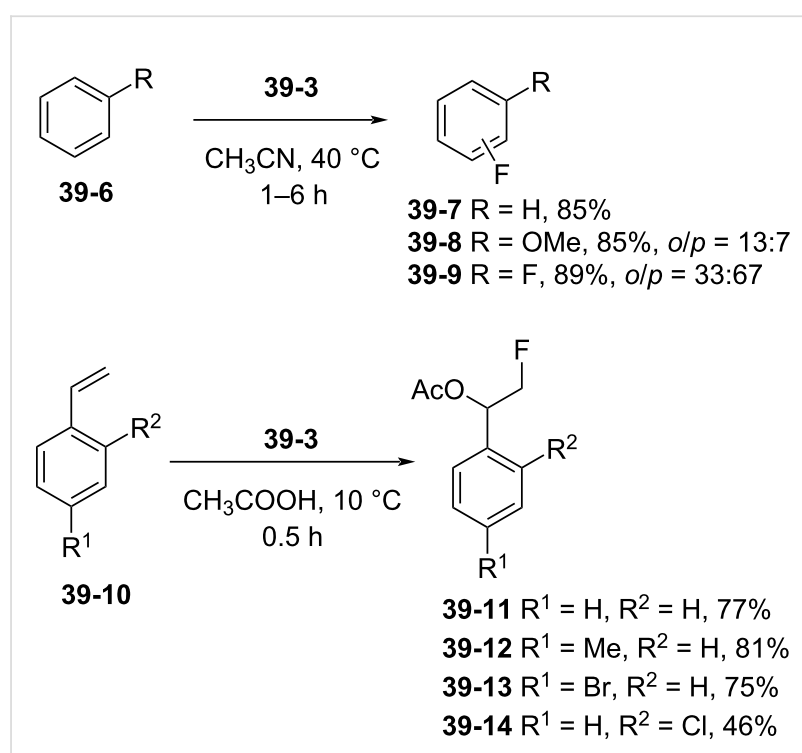

Scheme 91: Fluorination with N-F 39-3.

As shown in Scheme 93, Selectfluor ${ }^{\mathrm{CN}}$ was used as an oxidant to improve the Pd-catalyzed bistrifluoromethoxylation of alkenes with $\mathrm{AgOCF}_{3}$. It was shown that the yield of the bis $\left(\mathrm{CF}_{3} \mathrm{O}\right)$ product 40-4 increased as the fluorinating power of the $N$-F reagent increased in the order of NFSI $<\mathbf{1 6 - 3}(\mathrm{R}=\mathrm{Me})$ $<$ Selectfluor $\left(\mathrm{R}=\mathrm{CH}_{2} \mathrm{Cl}\right)<$ Selectfluor ${ }^{\mathrm{CN}}\left(\mathrm{R}=\mathrm{CH}_{2} \mathrm{CN}\right)$. A considerable number of olefin derivatives were bistrifluoromethoxylated using this method with Selectfluor ${ }^{\mathrm{CN}}$ [114].

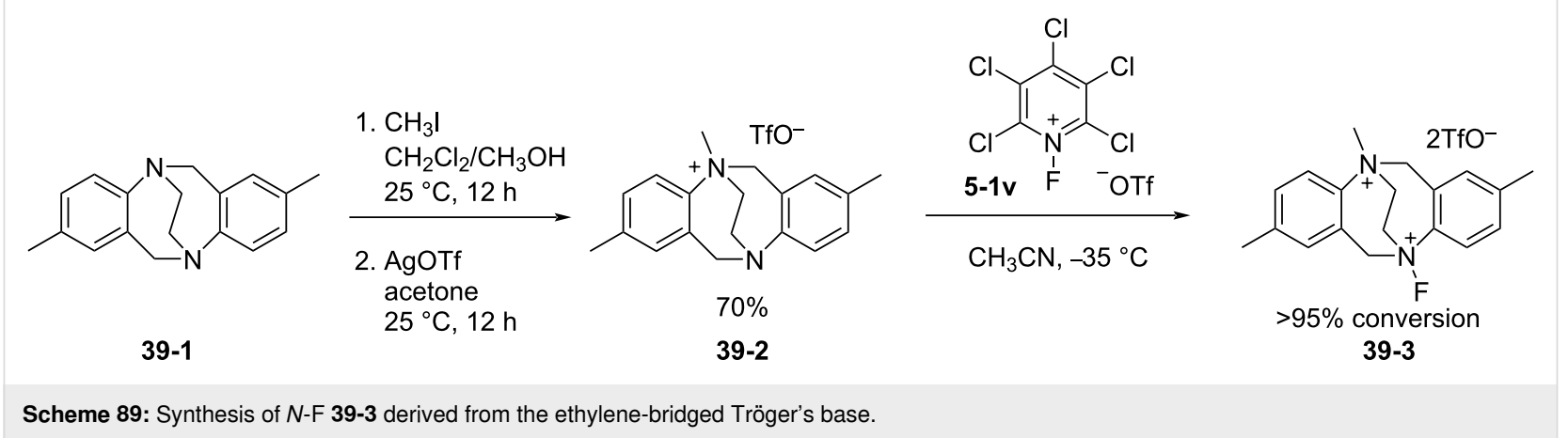




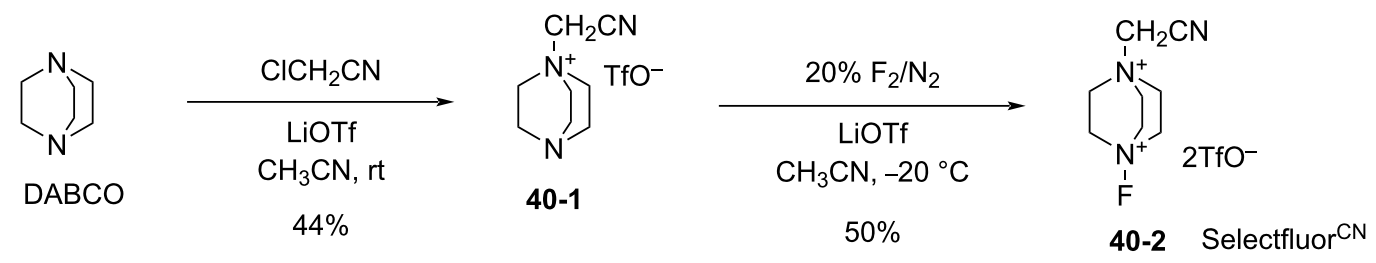

Scheme 92: Synthesis of Selectfluor ${ }^{\mathrm{CN}}$.

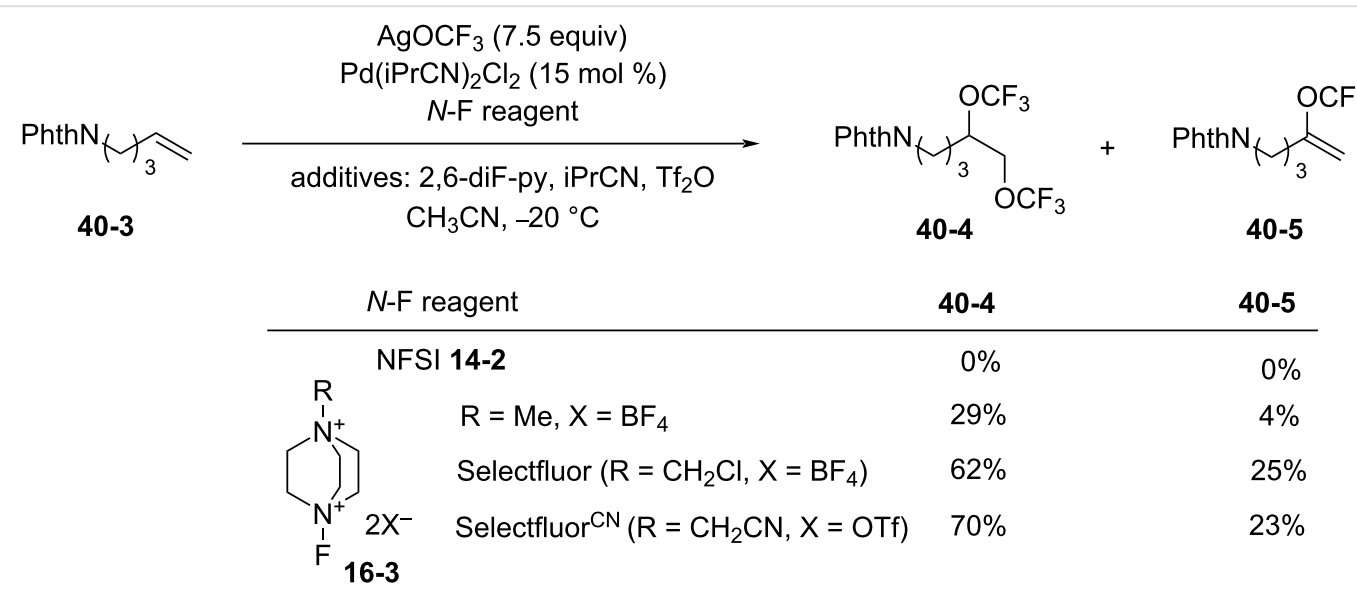

Scheme 93: Bistrifluoromethoxylation of alkenes using Selectfluor $\mathrm{CN}$.

\section{1-41. $\mathrm{N}$-Fluoro- $\mathrm{N}$-aryl-arenesulfonamides (NFAS)}

In 2018, Zipse and Renaud reported the synthesis of a series of $N$-fluoro- $N$-aryl-arenesulfonamides (NFAS) 41-2 suitable for radical fluorination, by reacting 41-1 with NFSI in the presence of cesium carbonate in methylene chloride and in moderate to good yields (Figure 13) [115]. They suggested that NFAS belongs to a third generation of radical fluorinating agents.

These authors designed NFAS $\mathbf{4 1 - 2 a}-\mathbf{i}$ as having a low $N-\mathrm{F}$ homolytic bond-dissociation energy (BDE). They demonstrated experimentally that NFAS 41-2 were more useful for radical fluorinations than $N$-fluoro- $N$-alkyl-arenesulfonamides 4-1, $N$-fluoro- $N$-alkyl-arylamides, NFSI 14-2, and Selectfluor, all of which have higher $\mathrm{N}-\mathrm{F}$ homolytic BDEs than NFAS 41-2 (Scheme 94).

The hydrofluorinated products were obtained in moderate yields along with good stereoselectivities in some cases (Scheme 95).

As for the less nucleophilic terminal alkenes, remote fluorinated products were favored via the $1,5 \mathrm{H}$-atom abstraction process (Scheme 96).

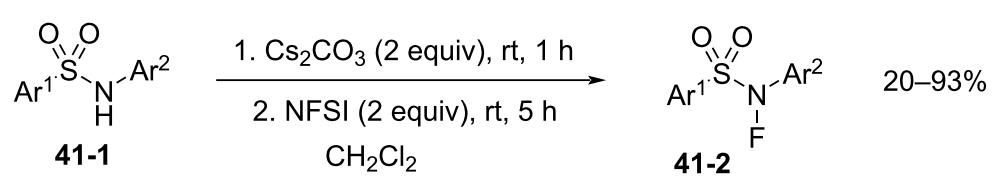

\begin{tabular}{|c|c|c|c|c|c|c|c|}
\hline & $\mathrm{Ar}^{1}$ & $\mathrm{Ar}^{2}$ & yield $(\%)$ & & $\mathrm{Ar}^{1}$ & $\mathrm{Ar}^{2}$ & yield $(\%)$ \\
\hline $41-2 a$ & phenyl & 4-CF -phenyl & 80 & $41-2 f$ & 2,4,6-triMe-phenyl & 4-CF - -phenyl & 89 \\
\hline$-2 b$ & phenyl & 3,5-diCF -phenyl & 93 & $-2 g$ & g 2,4,6-tri-iPr-phenyl & 4-CF - -phenyl & 72 \\
\hline$-2 c$ & phenyl & 3,5-diF-phenyl & 20 & $-2 h$ & h 4-MeO-2,6-diMe-phenyl & 4-CF - -phenyl & 53 \\
\hline$-2 d$ & 4-Cl-phenyl & 4-CF - -phenyl & 42 & $-2 \mathbf{i}$ & 2,4,6-triMe-phenyl & 3-CF - -phenyl & 40 \\
\hline$-2 e$ & 4-MeO-pheny & 4-CF - -phenyl & 87 & & & & \\
\hline
\end{tabular}




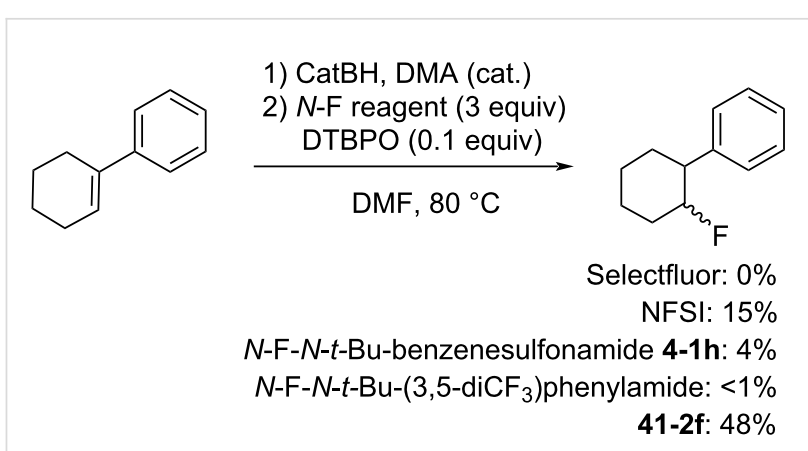

Scheme 94: Radical fluorination with different $N$-F reagents.

Decarboxylative fluorination of tert-butyl peresters also proved that these NFAS (41-2a and -2f) were better choices than NFSI and Selectfluor (Scheme 97).

\section{Evaluation of fluorinating power of $N-\mathrm{F}$ fluorinating agents}

It emerges from the overview above that many $N$-F fluorination reagent variants have been developed, each with a different fluorination power (reactivity). Therefore, the power ordering of $\mathrm{N}$-F reagents has become a matter of interest. Early on, Umemoto et al. revealed that the fluorinating power of $\mathrm{N}$-fluoropyridinium salt systems could be tuned by the electron densi- ty at the nitrogen site, a property which is controlled by the electronic nature of the substituents. In order to quantitatively explain the variability of the $N$-F reagents, many attempts have been made: Theoretical calculations were performed by Hachisuka and Umemoto in 1991 [116,117], Woolf in 1994 [118], and Fainzil'berg in 1994 and 2001 [119,120]; N-F 19-fluorine NMR chemical shift analysis was accessed by Umemoto in 1991 [34]; measurements of peak reduction potentials were carried out by Gilicinski in 1992 [121], Differding in 1992 [122], Evans in 1999 [123], Zhang in 2013 [104], and reported by Umemoto in 2016 [124]; relative fluorination rates (kinetic data) were conducted by Togni in 2004 [125], and electromotive forces with $\mathrm{Li}, \mathrm{Mg}$, and $\mathrm{Zn}$ metals were reported by Umemoto in 2016 [124].

In a significant advancement in this regard, in 2016 Xue and Cheng published a comprehensive energetic scale for the quantitative estimation of the fluorinating power of $N$-F reagents [126,127]. They applied the Fluorine Plus Detachment (FPD) energy parameter, introduced by Christe and Dixon in 1992 [128], to electrophilic $N$-F reagents and calculated the FPD energies of $130 \mathrm{~N}$-F reagents (Scheme 98).

As seen in Figure 14, a large number of $N$-F reagents were clearly arranged in their power order; the smaller the FPD value<smiles>C1=C(c2ccc(-c3ccccc3)cc2)CCCC1</smiles>

1) $\mathrm{CatBH}, \mathrm{DMA}$ (cat.)

2) $41-2 f$ ( 3 equiv) DTBPO ( 0.5 equiv)

$\mathrm{DMF}, 60^{\circ} \mathrm{C}$<smiles>CC(C)CCCC1=CCC2CC1C2(C)C</smiles>

1) $\mathrm{CatBH}, \mathrm{DMA}$ (cat.)

2) 41-2a (3 equiv) DTBPO (0.5 equiv) DMF, $60^{\circ} \mathrm{C}$<smiles>FC1CCCCC1c1ccc(-c2ccccc2)cc1</smiles>

1) $(+)-\mathrm{IpcBH}_{2}$

2) $\mathrm{CH}_{3} \mathrm{CHO}$

3) catechol<smiles>C1=C(c2ccc(-c3ccccc3)cc2)CCC1</smiles>

4) 41-2f (3 equiv) DTBPO, DMF $60{ }^{\circ} \mathrm{C}, 1 \mathrm{~h}$

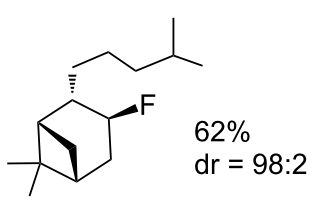

$1-2 f(3$ equiv)<smiles>[13CH3]C1CCC=CCCC1</smiles>
DTBHN DMF, $60^{\circ} \mathrm{C}$

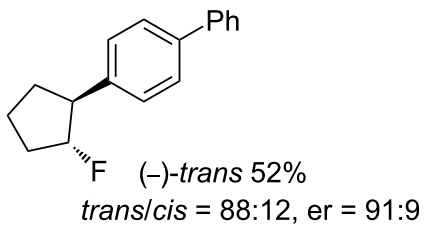<smiles>FC1CCC=CCCC1</smiles>

$31 \%$<smiles>F[C@H]1CC[C@@H]2CCC[C@@H]12</smiles>

$22 \%$ 

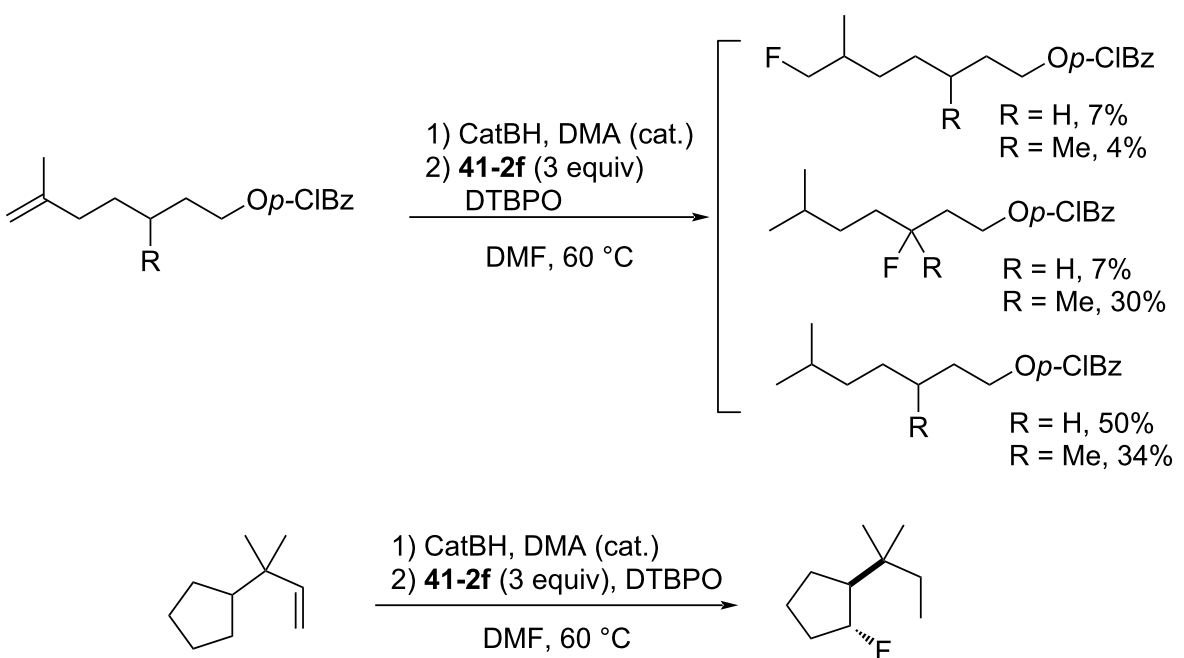

1) CatBH, DMA (cat.)
$\underset{\text { 2) } 41-2 f(3 \text { equiv), DTBPO }}{\stackrel{\text { DMF, } 60^{\circ} \mathrm{C}}{\longrightarrow}}$

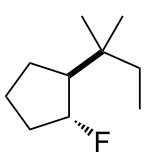

$68 \%$, trans $/$ cis $=98: 2$

Scheme 96: Radical fluorination of alkenes with NFAS 41-2f.

$$
\begin{aligned}
& \stackrel{\mathrm{R}^{1}}{\mathrm{Ru}_{\mathrm{Bu}_{3} t-}^{\mathrm{R}^{3}}} \\
& \underset{\mathrm{C}_{6} \mathrm{H}_{5} \mathrm{Cl} \text { or } \mathrm{CH}_{3} \mathrm{CN}, 110^{\circ} \mathrm{C}}{\longrightarrow} \\
& \mathrm{R}^{\mathrm{R}^{2^{1}}} \mathrm{R}_{\mathrm{F}}
\end{aligned}
$$
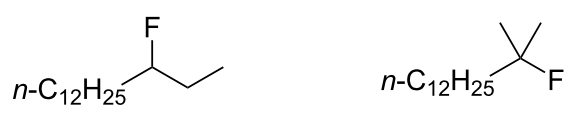

NFSI: $\quad 7 \%$

Selectfluor: $<2 \%$

NFSI: $3 \%$

41-2a: $46 \%$

41-2a: $\quad 48 \%$

41-2f: $47 \%$

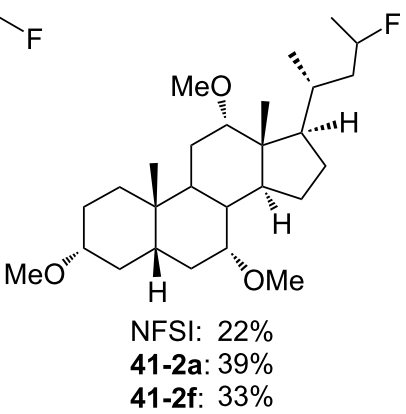

Scheme 97: Decarboxylative fluorination with NFAS 41-2a,f.

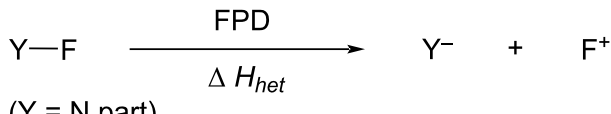

$$
\begin{aligned}
& \text { ( } \mathrm{Y}=\mathrm{N} \text { part })
\end{aligned}
$$

Scheme 98: Fluorine plus detachment (FPD).

the stronger the fluorinating power. This energetic scale is useful for an evaluation of the electrophilic fluorinating power of the $N$-F reagents.

In addition, since some $N$-F reagents have been proven to be useful radical fluorinating agents [129-135], Xue and Cheng introduced the $\mathrm{N}$-F homolytic bond-dissociation energy (BDE) parameter for radical fluorination abilities of $N$-F reagents in
2017 (Scheme 99) $[127,136]$. They calculated the BDE strength of $88 \mathrm{~N}$-F reagents and clearly arranged them in terms of their radical fluorination power; the smaller the BDE value the stronger the radical fluorinating power (Figure 15). The BDE is useful for identifying and designing new atomic fluorine sources.

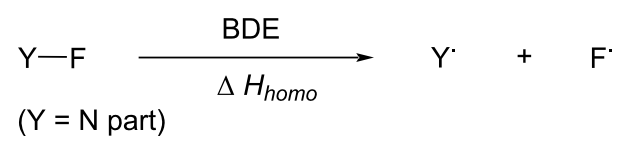

Scheme 99: N-F homolytic bond dissociation energy (BDE).

In 2018, another significant advancement was reported. Since FPD and BDE are thermodynamic parameters, they cannot be 


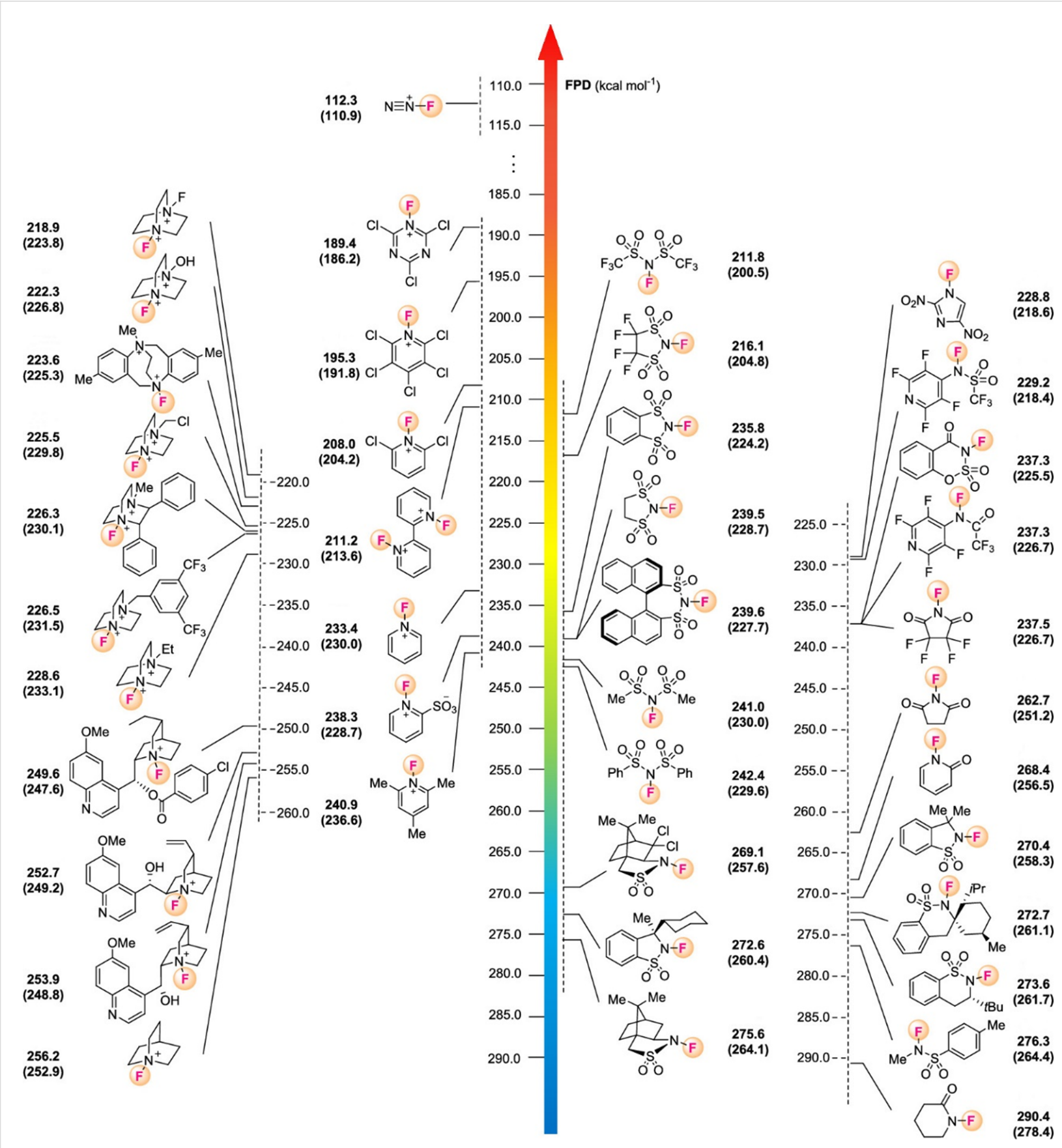

Figure 14: $\mathrm{FPD}$ values of representative $\mathrm{N}-\mathrm{F}$ reagents in $\mathrm{CH}_{2} \mathrm{Cl}_{2}$ and $\mathrm{CH}_{3} \mathrm{CN}$ (in parentheses). Adapted with permission from ref. [127]. Copyright 2020 American Chemical Society.

directly used for predicting reaction rates. Mayr et al. [137] and Hodgson et al. [138] independently reported the quantitative reactivity scales for electrophilic fluorinations of popular $N-\mathrm{F}$ reagents. They provided detailed kinetic fluorination studies of a series of popular $N$-F fluorinating agents such as $N$-fluoropyridinium salt derivatives, NFSI, and Selectfluor ${ }^{\mathrm{TM}}$ with enamines, carbanions, or 1,3-diketones. Figure 16 shows the relative reactivity scale of the popular $N$-F reagents, which covers eight orders of magnitude. These reactivity scales can be used for predicting the actual fluorination rates of $N$-F fluorinating agents. Hodgson et al. further advanced their kinetic studies with $N$-F fluorinating agents in 2019 [139] and 2020 [140].

In 2019, Zhang et al. reported detailed theoretical calculations of the fluorination of benzene with 16 different disubstituted $\mathrm{N}$-fluoropyridinum salts in acetonitrile solution and as a result, 


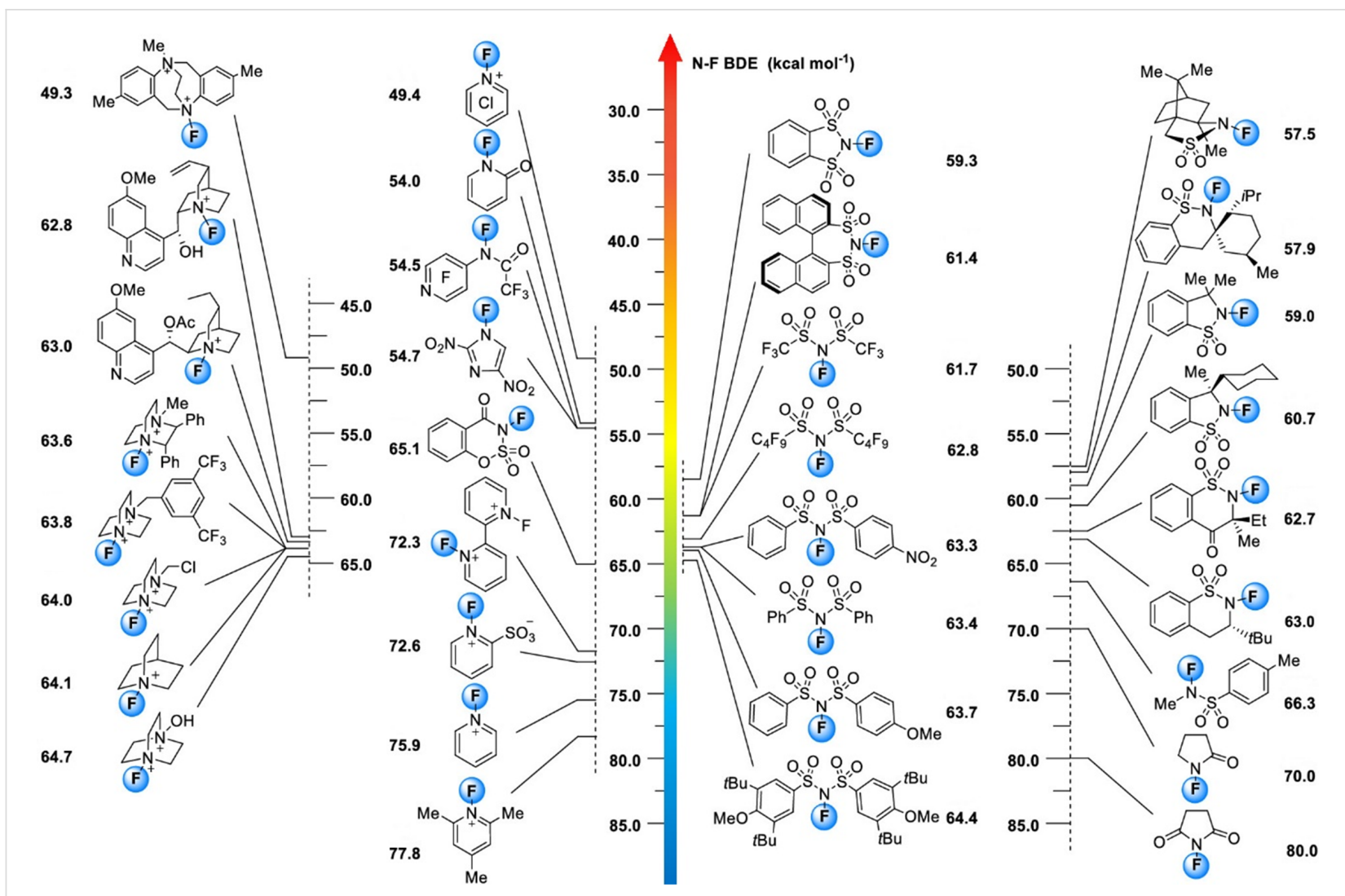

Figure 15: $\mathrm{BDE}$ values of representative $\mathrm{N}-\mathrm{F}$ reagents in $\mathrm{CH}_{3} \mathrm{CN}$. Adapted with permission from ref. [127]. Copyright 2020 American Chemical Society.

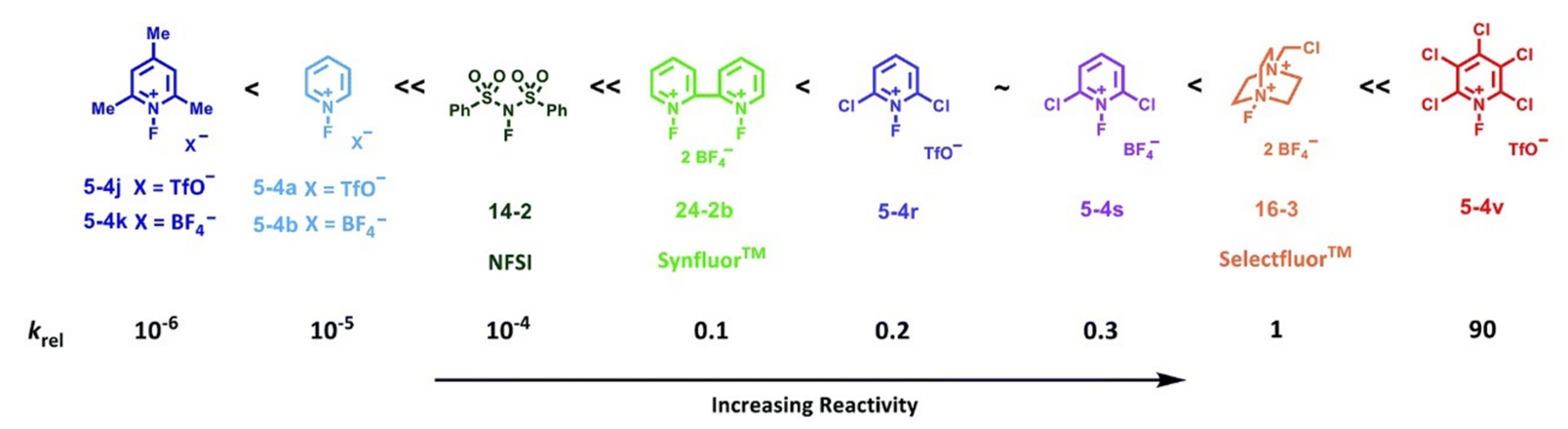

Figure 16: Quantitative reactivity scale for popular N-F reagents. Adapted with permission from ref. [138], published by the Royal Society of Chemistry.

suggested a 2,6-dinitro-substituted $N$-fluoropyridinium salt as the most promising fluorinating reagent [141].

\section{Reaction mechanisms of $N-F$ fluorinating agents}

Another noteworthy issue is the reaction mechanism for the fluorination with $N$-F reagents. There have been long standing arguments regarding which mechanism is operating in these fluorinations: a single-electron transfer (SET) or a nucleophilic substitution $\left(\mathrm{S}_{\mathrm{N}} 2\right)$ mechanism (Scheme 100) [22,142]. In the SET process, a single-electron transfer from a substrate $\left(\mathrm{Nu}^{-}\right)$to a $N$-F reagent $[\mathrm{N}-\mathrm{F}]$ occurs to form a radical anion $[\mathrm{N}-\mathrm{F}]^{--}$and a $\mathrm{Nu}$ radical, and the former undertakes the homolytic $\mathrm{N}-\mathrm{F}$ bond cleavage to give a $\mathrm{F}^{*}$ radical and a $\mathrm{N}^{-}$anion, and then the $\mathrm{F}$. radical and the $\mathrm{Nu}$ radical combine to generate the final product $\mathrm{Nu}-\mathrm{F}$. In the $\mathrm{S}_{\mathrm{N}} 2$ mechanism, a nucleophile directly attacks the $\mathrm{F}$ atom of the $N$-F reagent to give the fluorinated product via the heterolytic cleavage of the N-F bond. The key point is 


\section{SET mechanism}

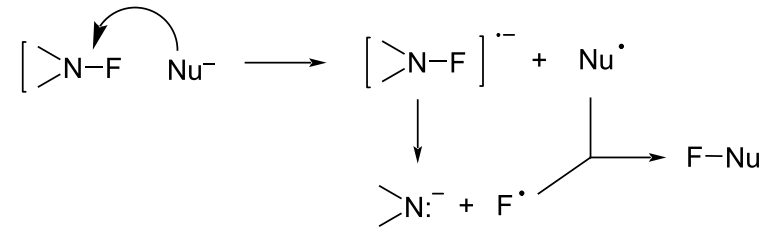

$\mathrm{S}_{\mathrm{N}} 2$ mechanism

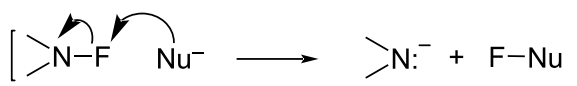

Scheme 100: SET and $\mathrm{S}_{\mathrm{N}} 2$ mechanisms.

whether the N-F bond cleaves homolytically or heterolytically. The prime cause of this argument is based on the fact that the formation of $\mathrm{F}^{+}$requires extremely high energy (ionization potential of $\mathrm{F}, 1681.0 \mathrm{~kJ} / \mathrm{mol}$ ) and contrasts significantly with that of other halogenations $(\mathrm{Cl}, 1251.2 \mathrm{~kJ} / \mathrm{mol} ; \mathrm{Br}$, $1139.9 \mathrm{~kJ} / \mathrm{mol})$.

In 1991, Umemoto et al. explained the observed fluorination reactions of $N$-fluoropyridinium salts with anionic and neutral substrates by SET processes involving a $F^{*}$ radical species [32]. Soon after, in 1992, Kochi et al. reported fluorination reactions of aromatic compounds with $\mathrm{N}$-fluoropyridinium salts via electron donor-acceptor complexes, with outcomes which also supported the SET mechanism [143,144]. In 1992, DesMarteau et al. proposed a similar SET process for the fluorination with $N$-fluoroperfluoroalkanesulfonimide [48]. On the other hand, in 1991, Differding and co-worker investigated radical clock experiments to monitor the reaction for the presence of intermediate radicals [145] (Scheme 101).

As illustrated in Scheme 102, the reactions of potassium enolate I of citronellic ester with the $N$-F reagents 10-1, 14-2 (NFSI), or

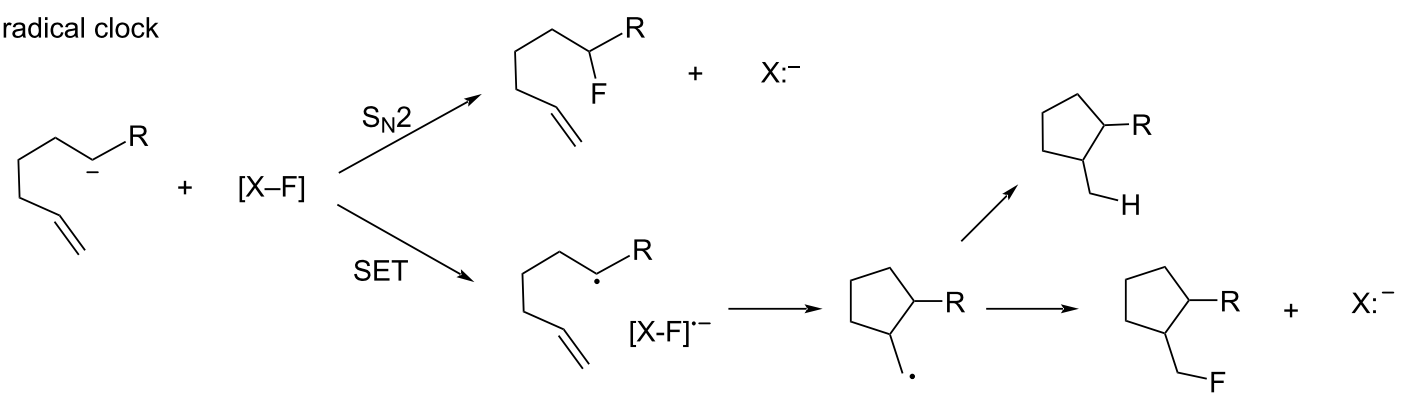
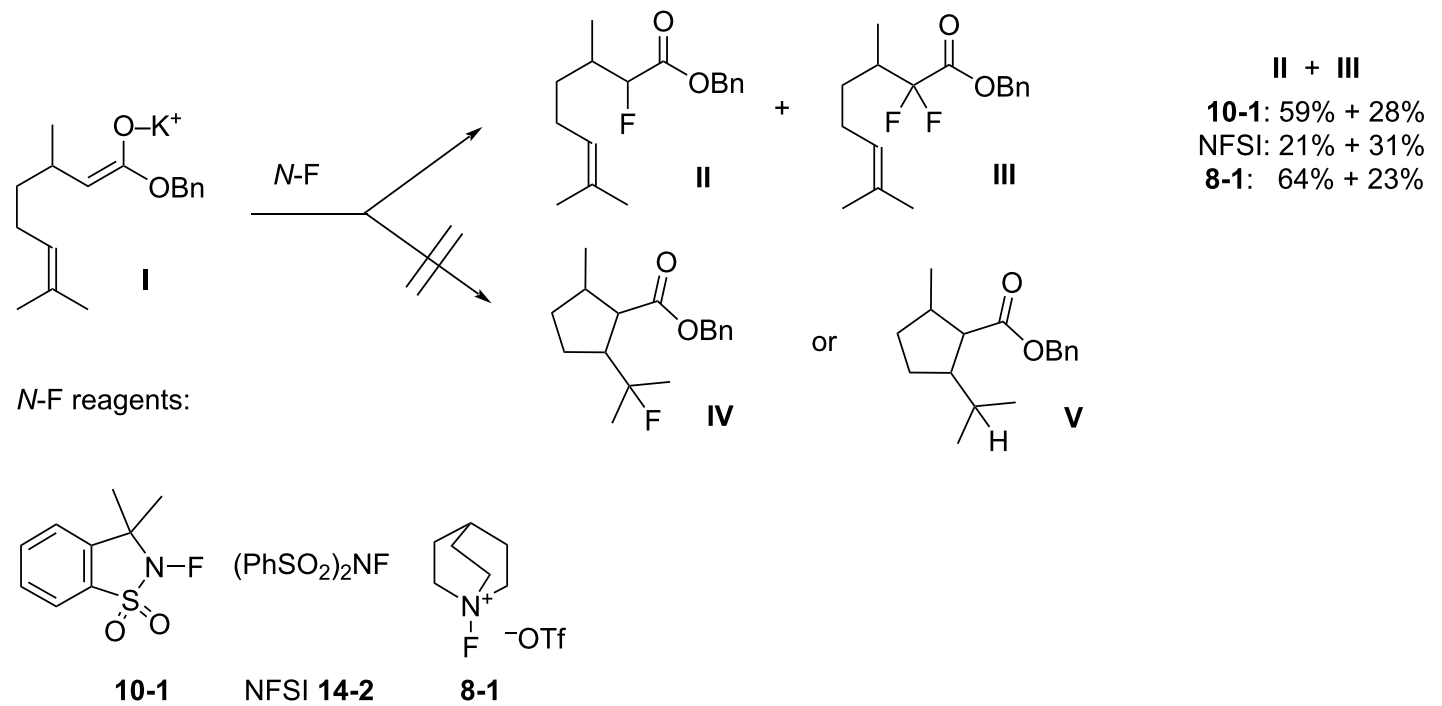
8-1 produced only the non-cyclized products II and III. They also showed that the observed reaction rates were much faster than the calculated electron-transfer rates and therefore they concluded that a $\mathrm{S}_{\mathrm{N}} 2$ mechanism occurred to give the fluorinated products [146].

In 1995, based on the study on the fluorination reactions of the $N$-F reagent NFOBS 13-2, Davis et al. described that all of their available data supported the $\mathrm{S}_{\mathrm{N}} 2$ reaction process, but the SET mechanism could not be rigorously excluded [58]. In 1998, Zupan et al. studied the reactions of norbornene with Selectfluor, NFTh 19-2, and $N$-fluoro-2,6-dichloropyridinium triflate [147]. Although their results ended toward $\mathrm{S}_{\mathrm{N}} 2$, they too could not completely exclude the SET. Soon after, in 1999, Wong et al. reported their studies using compound VI having a phenylcyclopropyl moiety which was the hypersensitive radical probe (rate: $10^{11} \mathrm{~s}^{-1}$ ) (Scheme 103) [148].

They found that Selectfluor (OTf salt) produced product VII in $45 \%$ yield with no rearrangement products despite the complete consumption of VI (entry 1, Scheme 103). This result is aligned with the $S_{N} 2$ mechanism, however, the reaction of VI with Selecfluor was completely blocked by the radical scavenger, 2,2,6,6-tetramethylpiperidinoxyl (TEMPO), which suggested a SET mechanism. The reaction of VI with NFSI gave VII $(40 \%)$ and a product IX (5\%) derived from the rearrangement fluoro product VIII (entry 2 in Scheme 103). This result is consistent with the SET mechanism. In their review published in 2005 [149], Wong discussed these results in more detail.
Since the reactivity of the radical $\left(\mathrm{F}^{*}\right)$ is extremely fast and diffusion-controlled, the combination of $\mathrm{F}^{*}$ with any alkyl radical $\mathrm{R}^{\prime}$ should proceed at an equal or greater rate than the cyclization of the alkyl radical as observed in the case of Differding [145] and the ring-opening of the cyclopropyl radical in the case of Wong [148]. Despite extensive research, the mechanism remains unclear as a result of the difficulty of assessing reaction rates. The key may be the lifetime of the intermediate $\mathrm{N}-\mathrm{F}$ radical or radical anion, $[\mathrm{N}-\mathrm{F}]^{\cdot}$ or $[\mathrm{N}-\mathrm{F}]^{--}$, which releases the radical $\mathrm{F}$. Finally, Wong mentioned that, if these radicals react faster than the rates of diffusion, anything beyond that would probably remain unproven [149].

In the meantime, in 2002, Togni and Rothlisberger provided evidence which strongly supported the SET mechanism from their studies on the fluorination mechanism of $\beta$-ketoesters with Selectfluor and a chiral $\mathrm{TiCl}_{2}$ (TADDOLato) catalyst [150]. Their computational study suggested a one-electron transfer followed by simultaneous N-F bond cleavage and the accompanying experimental outcomes demonstrated that a chlorination side reaction was quenched by a radical scavenger, while the fluorination reaction was unaffected. Since Selectfluor is inert towards chloride, they proposed that any $[\mathrm{N}-\mathrm{F}]^{*}$ radical formed by the SET process would react with chloride ions $\left(\mathrm{Cl}^{-}\right)$present in the reaction solution to form the relatively stable $\mathrm{Cl}^{\circ}$ radical, which caused the side chlorination.

On the other hand, in 2002, Laali and co-worker reported that competitive fluorination studies of mesitylene and durene with

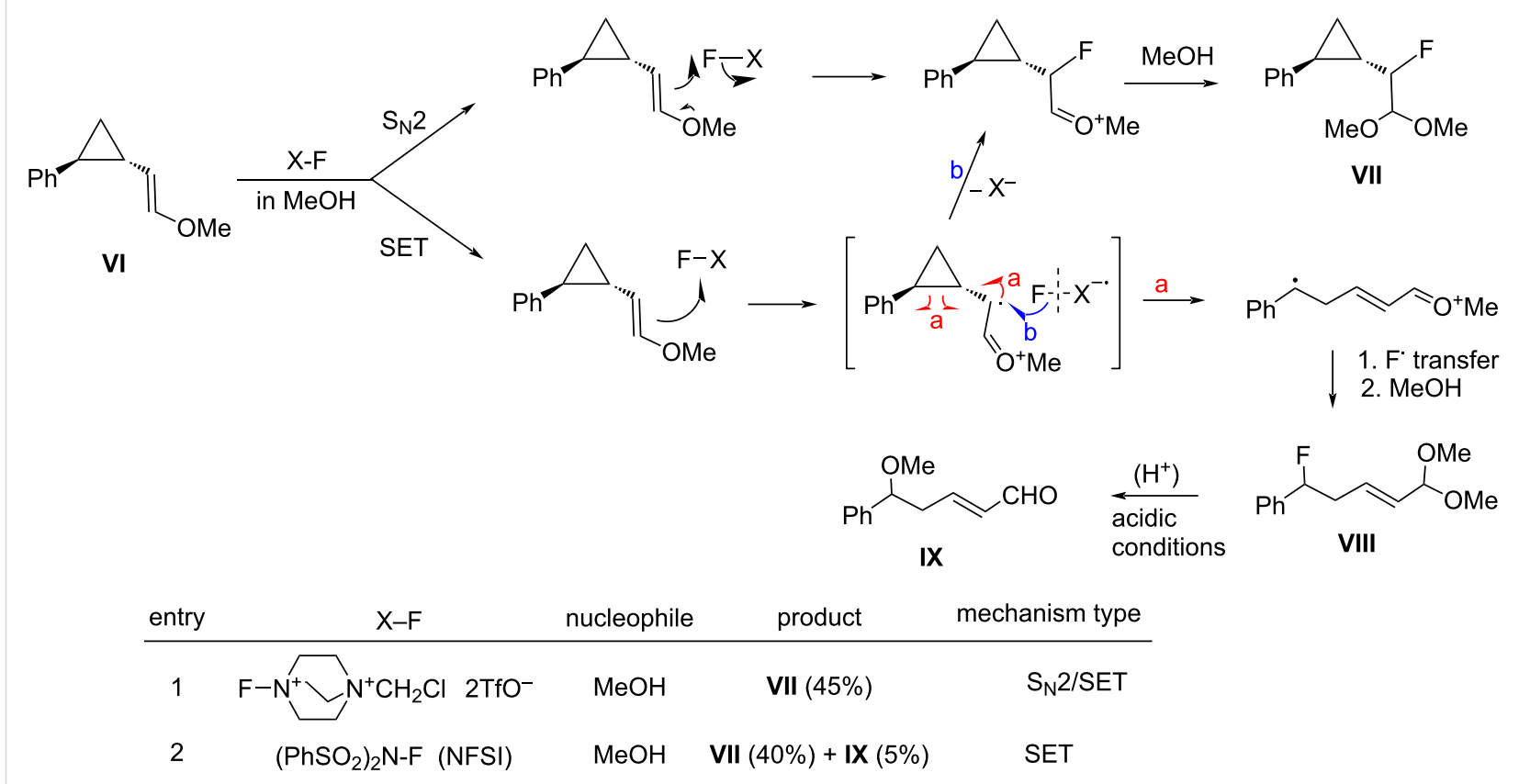


Selecfluor in $\mathrm{CH}_{3} \mathrm{CN}$ and an ionic liquid supported the conventional polar mechanism $\left(\mathrm{S}_{\mathrm{N}} 2\right)$ [151]. However, in 2006, Stavber et al. made similar competition studies and proposed a SET process as the dominant mechanism that explained the higher reactivity of durene viz-à-viz mesitylene towards Selectfluor in aq $\mathrm{CH}_{3} \mathrm{CN}$ [152]. In 2009, Shubin et al. performed competitive studies of mesitylene and durene with NFSI under solvent-free reaction conditions and reported that the reaction rate ratio $\left(k_{\text {Mes }} / k_{\text {Dur }}\right)$ followed a polar mechanism [153].

Since 2015, many papers supporting either SET or $\mathrm{S}_{\mathrm{N}} 2$ mechanisms have appeared, including those reported by C. Liu et al. (SET) in 2015 [154], Chen et al. $\left(S_{N} 2\right)$ in 2016 [155], Tang et al. (SET) in 2016 [156], F. Liu et al. (SET) in 2016 [157] and 2017 [158], Mayr et al. $\left(S_{\mathrm{N}} 2\right)$ in 2018 [137], Hodgson et al. $\left(\mathrm{S}_{\mathrm{N}} 2\right)$ in 2018 [138], Li et al. (SET) in 2018 [159], Shi et al. (SET) in 2018 [160], Li et al. (SET) in 2019 [161], Mernyak et al. (SET) in 2019 [162], and Nelson et al. $\left(S_{N} 2\right)$ in 2019 [163].

TEMPO has been often used as a radical scavenger to explore the reaction mechanisms of $N$-F fluorinating agents but, in Nelson's paper [163] in 2019, it was revealed that Selectfluor reacted with TEMPO $(\mathbf{X})$ to form the oxoammonium salt XI (Scheme 104). This author concluded that the use of TEMPO as a radical trap in the reactions with Selectfluor was unreliable. This conclusion was subsequently confirmed by Borodkin et al. [164]. The latest review [165] by Hodgson and co-worker in 2021 discussed the reactivities and reaction mechanisms of electrophilic $N$-F fluorinating agents in detail.

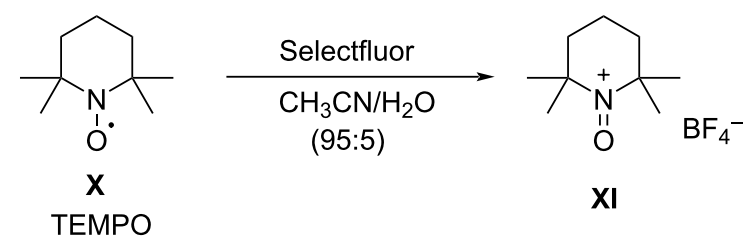

Scheme 104: Reaction of TEMPO with Selecfluor.

\section{Conclusion}

A historical timeline on the progress of $N$-F fluorinating reagents and their fluorinations has been described in this review. Table 1 shows a historical list of all the $N$-F reagents. The fluorination power and reaction mechanism of the $N-\mathrm{F}$ fluorinating agents have also been summarized briefly and from a historical perspective. The fluorination reactions described here for each $\mathrm{N}-\mathrm{F}$ fluorinating agent are those reported at the time. The synthetic applications of each $N$-F reagent since then are too numerous to be covered in this review. As many reviews on the reactions and applications of the $N$-F fluorinating agents have been published [39,133,142,165-181], readers are recommended to consult these reviews.

The seminal work of perfluoro- $N$-fluoropiperidine by Banks was reported in 1964 [16]. However, this compound could not be contemplated for two decades because of the very low yields in its production and fluorination reactions. At that time, $\mathrm{FClO}_{3}$ [10] and $O$-F reagents such as $\mathrm{CF}_{3} \mathrm{OF}$ and $\mathrm{CF}_{2}(\mathrm{OF})_{2}$ [11] were used as electrophilic fluorinating agents despite their inherent safety issues. The real attention on $\mathrm{N}$-F compounds started in the 1980's when the first report on a $N$-F fluorinating agent, $N$-fluoro-2-pyridone, was published by Purrington in 1983 [24]. The next year, Barnette reported $N$-fluoro- $N$-alkylarenesulfonamides that were easy-to-handle, stable crystalline compounds useful for the fluorination of carbanions [26]. Soon after (1986), Umemoto reported a series of $N$-fluoropyridinium triflates as easy-to-handle, reactive, and widely applicable reagents $[28,29]$.

Since then, many $N$-F fluorinating agents have been reported, one after another, as follows: powerful $\mathrm{N}$-fluorotrifluoromethanesulfonimide by DesMarteau in 1987 [45], mild $\mathrm{N}$-fluorosultams including first chiral $\mathrm{N}$-fluorosultams by Lang in 1988 [52] and 1989 [53], less reactive $N$-fluorolactams by Sathyamurthy in 1990 [55], moderate $N$-fluoro-o-benzenedisulfonimide (NFOBS) [57] and $N$-fluorobenzenesulfonimide (NFSI) [59] by Davis and Differding, respectively, in 1991, and powerful 1-chloromethyl-4-fluoro-1,4-diazoniabicyclo[2.2.2] octane bistetrafluoroborate (Selectfluor ${ }^{\mathrm{TM}}$ ) by Banks in 1992 [42]. Currently popular N-F fluorinating agents such as $N$-fluoropyridinium salts, NFSI, and Selectfluor were developed within a decade from the first Purrington's report (1983).

After this first rush, other notable $N$-F reagents were developed such as a series of zwitterionic $N$-fluoropyridinium salts by Umemoto in 1995 [76], another Selectfluor-type reagent, 1-fluoro-4-hydroxy-1,4-diazoniabicyclo[2.2.2]octane bistetrafluoroborate (NFTh/Accufluor ${ }^{\mathrm{TM}}$ ) by Poss and Shia in 1995 [78], a more powerful reagent, 1,4-difluoro-1,4-diazoniabicyclo[2.2.2] octane bistetrafluoroborate by Umemoto in 1996 [83], and a powerful and high fluorine-content reagent, $N, N$ 'difluoro-2,2'-bipyridinium bistetrafluoroborate (Synfluor ${ }^{\mathrm{TM}}$ ) by Umemoto in 1998 [86].

In 2000, practical chiral reagents, $N$-fluorinated chiral cinchona alkaloids were reported by Shibata and Takeuchi [95] and by Cahard [97]. In 2003, Cahard demonstrated that the chiral $N$-fluorocinchona alkaloids could be prepared quantitatively with not only Selectfluor but also with other powerful $N$-F fluorinating agents such as NFTh, NFSI, and N-fluoro-2,6- 
Table 1: Chronological list of the development of $N$-F fluorinating agents.

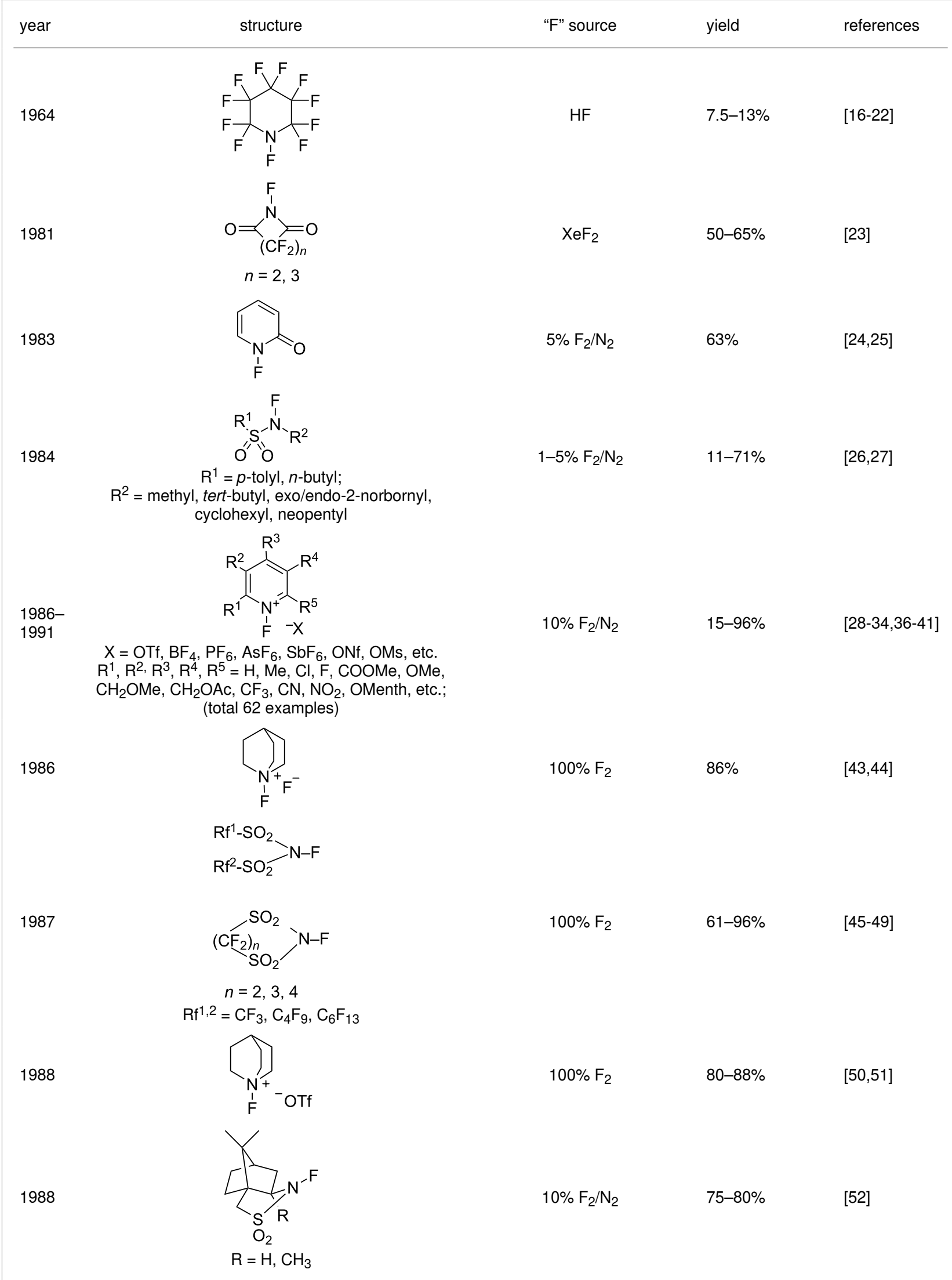


Table 1: Chronological list of the development of $N$-F fluorinating agents. (continued)

1989

1990

1990

1991

1991

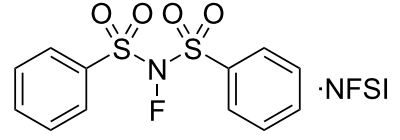

1991

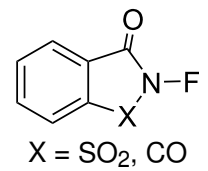

1992<smiles>[Y][N+]12CC[N+](F)(CC1)CC2</smiles>

$$
\mathrm{X}=\mathrm{OTf}, \mathrm{BF}_{4}
$$$$
\mathrm{R}=\mathrm{CH}_{3}, \mathrm{CH}_{2} \mathrm{Cl}, \mathrm{CH}_{2} \mathrm{CF}_{3}
$$

Selectfluor ${ }^{\mathrm{TM}}\left(\mathrm{R}=\mathrm{CH}_{2} \mathrm{Cl}, \mathrm{X}=\mathrm{BF}_{4}\right)$
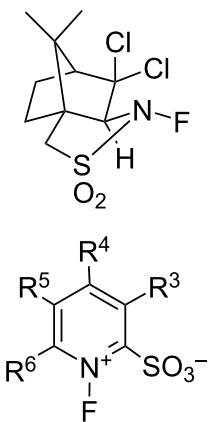

1995

1995

$R^{3}, R^{4}, R^{5}, R^{6}=H, C H_{3}, C F_{3}, C l, C_{2} H_{5}$, tert-butyl

$\mathrm{OH}$

$$
10 \% \mathrm{~F}_{2} / \mathrm{N}_{2}
$$

$74 \%$

$100 \% \mathrm{~F}_{2}$

$0.05 \%{ }^{18} \mathrm{~F}_{2} / \mathrm{Ne}$

$10 \% \mathrm{~F}_{2} / \mathrm{N}_{2}$

$10 \% \mathrm{~F}_{2} / \mathrm{N}_{2}$

$70 \%$

$\mathrm{Cs}^{+-} \mathrm{OSO}_{2} \mathrm{OF}$

$10 \% \mathrm{~F}_{2} / \mathrm{N}_{2}$

$10 \% \mathrm{~F}_{2} / \mathrm{N}_{2}$

$68 \%$

75]

$10 \% \mathrm{~F}_{2} / \mathrm{N}_{2}$

65-95\%

[76]
$[55,56]$

$[57,58]$

[59]

[60]

[42,61-74]<smiles>F[N+]12CC[N+]([18F])(CC1)CC2</smiles>

$10 \% \mathrm{~F}_{2} / \mathrm{N}_{2}$

$75 \%$

[78-80] 
Table 1: Chronological list of the development of $N$-F fluorinating agents. (continued)

1995

1996

1996<smiles></smiles>

$\mathrm{F}_{\mathrm{N}^{-}}-\mathrm{COCF}_{3}$<smiles>Fc1cc(F)c(F)nc1F</smiles>

$100 \% F_{2}$

$\left(X^{1}\right)^{-}\left(X^{2}\right)^{-}$

$5 \% \mathrm{~F}_{2} / \mathrm{N}_{2}$
$83 \%$

81]

$10 \% \mathrm{~F}_{2} / \mathrm{N}_{2}$

$62-82 \%$

[85]
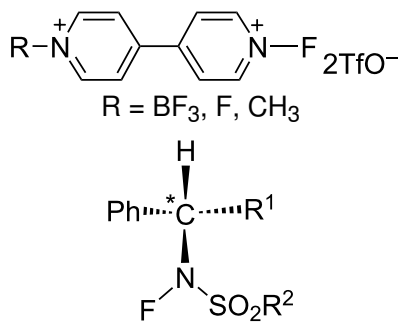

$\mathrm{R}^{1}=\mathrm{CH}_{3}, \mathrm{CH}_{2} \mathrm{OCOCH}$

$\mathrm{R}^{2}=\mathrm{CH}_{3}, p$-tolyl

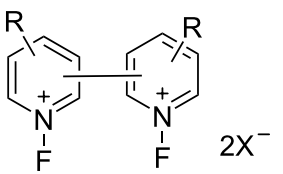

1998

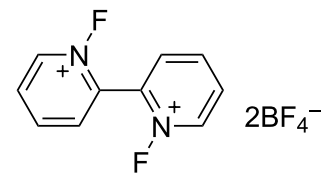

Synfluor $^{\mathrm{TM}}$

$\mathrm{X}=\mathrm{OTf}, \mathrm{BF}_{4}, \mathrm{PF}_{6}, \mathrm{SbF}_{6}$

bipyridyl = 2,2', 2,4', 3,3', 4,4'

$\mathrm{R}=\mathrm{H}, \mathrm{CH}_{3}, \mathrm{Cl}, \mathrm{CF}_{3}, \mathrm{Ph}, \mathrm{COOCH}_{3}$

1998
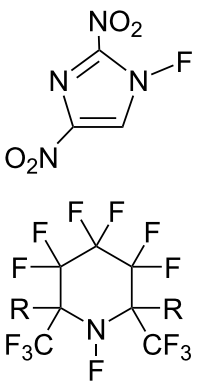

$\mathrm{R}=\mathrm{CH}_{3}, \mathrm{CF}_{3}$

\section{$10-20 \% \mathrm{~F}_{2} / \mathrm{N}_{2} \quad 64-97 \%$}

$5 \% \mathrm{~F}_{2} / \mathrm{N}_{2}$

[87,88]

$10 \% \mathrm{~F}_{2} / \mathrm{N}_{2}$

65-82\%

[89] 
Table 1: Chronological list of the development of $N$-F fluorinating agents. (continued)

1999<smiles>CCC1(C)C(=O)c2ccccc2S(=O)(=O)N1F</smiles>

1999<smiles>CC1(C2CCCCC2)c2ccccc2S(=O)(=O)N1F</smiles>

$(R)-(+)$

(S) $-(-)$<smiles>CC(C)(C)[C@]12Cc3ccc([N+](=O)[O-])cc3S(=O)(=O)N(F)[C@@H]1C2</smiles>

$(R),(S)$

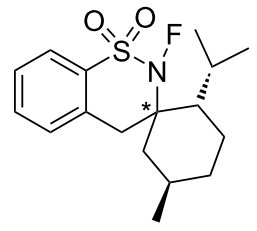

$(S, R, R),(S, S, R)$

2000

$\mathrm{FClO}_{3}$

$44-81 \%$

[94]

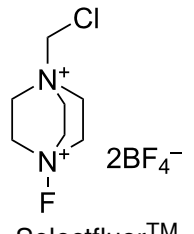

prepared in situ

$[95,96]$
[90]

[91]

$66-83 \% \quad$ [93]<smiles></smiles><smiles>CCC1C[N+]2(F)CCC1C2[C@H](OC(F)(F)F)c1ccnc2ccc(OC)cc12</smiles>

2000

Selectfluor $^{\mathrm{TM}}$

$84 \%$

$[97,98]$

Selectfluor (F-TEDA-BF 4 )

F-TEDA-OTf

NFTh

$100 \%$

[99]

2003

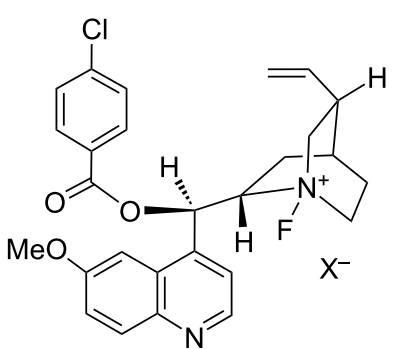

$\mathrm{X}=\mathrm{BF}_{4}, \mathrm{OTf}, \mathrm{N}\left(\mathrm{SO}_{2} \mathrm{Ph}\right)_{2}$ 
Table 1: Chronological list of the development of $N-\mathrm{F}$ fluorinating agents. (continued)

2003

2011

2012

2013

2013

2013

2016

2016

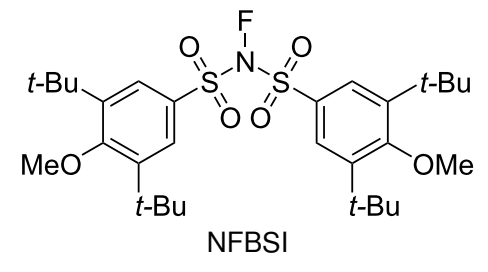
$10 \% \mathrm{~F}_{2} / \mathrm{N}_{2}$

$10 \% \mathrm{~F}_{2} / \mathrm{N}_{2}$

$20.9-89.4 \%$

[103-105]

$\mathrm{XeF}_{2}$

$29-51 \%$

[106]

$10 \% \mathrm{~F}_{2} / \mathrm{N}_{2}$ or<smiles>F[n+]1c(Cl)c(Cl)c(Cl)c(Cl)c1Cl</smiles>

$0.2 \% \mathrm{~F}_{2} / \mathrm{N}_{2}$

$27-67 \%$

[108]

$\mathrm{R}^{1}=\mathrm{H}, \mathrm{CF}_{3}$;

$\mathrm{R}^{2}=\mathrm{H}, \mathrm{CH}_{3}$

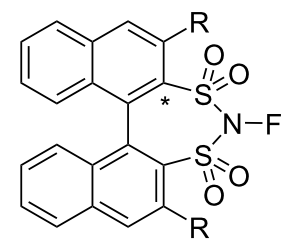

$(R), \mathrm{R}=\mathrm{H}$;

$(S), \mathrm{R}=3,5-\left(\mathrm{CF}_{3}\right)_{2} \mathrm{C}_{6} \mathrm{H}_{3}$

$$
\underset{\mathrm{Me}-\mathrm{NFSI}}{\mathrm{SO}_{2} \mathrm{CH}_{3}}
$$

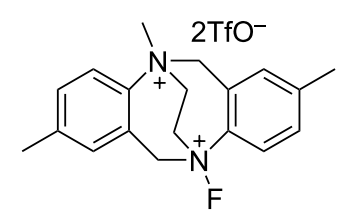

$>95 \%$

[107]

[102]

100]

$57 \%$

$$
\text { [102] }
$$

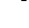


Table 1: Chronological list of the development of $N-\mathrm{F}$ fluorinating agents. (continued)

2018

2018<smiles>CN1CC[N+](F)(CC#N)CC1[O+]</smiles>

Os,
$20 \% \mathrm{~F}_{2} / \mathrm{N}_{2}$<smiles>O=S(=O)(c1ccccc1)N(F)S(=O)(=O)c1ccccc1</smiles>

NFSI
$[114]$

$20-93 \%$
$\mathrm{Ar}^{1}=\mathrm{C}_{6} \mathrm{H}_{5}, 4-\mathrm{Cl}-\mathrm{C}_{6} \mathrm{H}_{4}, 2,4,6-$ triMe- $\mathrm{C}_{6} \mathrm{H}_{2}$, etc.;

$\mathrm{Ar}^{2}=4-\mathrm{CF}_{3}-\mathrm{C}_{6} \mathrm{H}_{4}, 3-\mathrm{CF}_{3}-\mathrm{C}_{6} \mathrm{H}_{4}, 3,5-\mathrm{diCF}_{3} \mathrm{C}_{6} \mathrm{H}_{3}$ dichloropyridinium tetrafluoroborate [99]. After a break of a decade, in 2013, chiral dicationic DABCO-based $N$-F reagents 36-5 and chiral $N$-fluorobinaphthyldisulfonimides 37-2 were reported by Gouverneur [107] and by Shibata, Ma, and Cahard [108], respectively. In 2016, Shibata reported $N$-fluoromethanesulfonimide (Me-NFSI) as a high atom-economy reagent [111] and Gouverneur and Cvingroš reported a novel $N$-F reagent 39-3 derived from the ethylene-bridged Tröger base [113]. More recently, Zipse and Renaud in 2018, disclosed $N$-fluoro$\mathrm{N}$-aryl-arenesulfonamides (NFAS) as radical fluorinating agents [115].

A very large number of $N$-F fluorinating agents have been developed so far and a considerable number of easy-to-handle $N$-F reagents have been commercialized. In particular, Selectfluor, NFSI, and $N$-fluoropyridinium salt derivatives are produced in factories on a large scale. This has greatly contributed to the remarkable advancement of organofluorine chemistry. Before the appearance of $N$-F reagents, electrophilic fluorinating agents were thought dangerous and difficult to handle and special techniques were required. Chemists avoided them. Now, practicing chemists use them without any problem. The $N$-F reagents have brought such a dramatic change that many chemists nowadays may not realize the magnitude of this change and the contributions of the pioneers.

For practitioners in the field, high thermal stability and nonhygroscopicity of reagents are key factors for easy handling and a long shelf life. Many $N$-F reagents satisfy this requirement, however, there are limitations as the fluorinating power increases. $N$-Fluoropentachloropyridinium triflate $(\mathbf{5 - 4 v})$ and tetrafluoroborate $(\mathbf{5 - 4 w})$ rank as the most powerful of the nonhygroscopic and thermally stable $N$-F agents. However, the more powerful $N$-fluoro-2,4,6-trichloro-1,3,5-triazinium tetrafluoroborate (31-2) is moisture-sensitive and not easy-tohandle. $N, N^{\prime}$-Difluoro-1,4-diazoniabicyclo[2.2.2]octane bistetrafluoroborate (22-1d) ranks top in the easy-to-handle 1,4- diazoniabicyclo[2.2.] ]octane salt series. Salt 22-1d is more powerful than Selectfluor. Unfortunately, synthetic chemists have had little chance to use it because it has not been commercialized due to patent issues despite its simple one-pot process using cheap materials. However, since all the patents have now expired, it is expected that $\mathbf{2 2 - 1 d}$ may soon be commercialized.

It is now rare for researchers and laboratories to use molecular fluorine $\left(\mathrm{F}_{2}\right)$ in universities and institutes, because of strict safety regulations, although $20 \%$ or $10 \% \mathrm{~F}_{2}$ diluted with $\mathrm{N}_{2}$ can be handled without significant problems. As a result, currently reported fluorination reactions have been limited to the use of a few commercially available and inexpensive $N$-F reagents such as Selectfluor and NFSI. As mentioned in this review, there are many other useful $N$-F fluorinating agents and the plentiful supply will satisfy the strong demand for fluorinations. That said, there is still room for improvement or refinement. The authors think that further research and development on $N-\mathrm{F}$ fluorinating reagents is needed for the advancement of synthetic fluorine chemistry but, for this to happen, it would be highly desirable to develop a safe and convenient $F_{2}$ generator.

\section{Funding}

We are grateful to the National Institutes of Health (R01GM121660) for financial support.

\section{ORCID ${ }^{\circledR}$ iDs}

Teruo Umemoto - https://orcid.org/0000-0002-8718-8127

Gerald B. Hammond - https://orcid.org/0000-0002-9814-5536

\section{References}

1. Ojima, I., Ed. Fluorine in Medicinal Chemistry and Chemical Biology; John Wiley \& Sons, Ltd: Chichester, United Kingdom, 2009. doi:10.1002/9781444312096 See for a selected book.

2. Jeschke, P. ChemBioChem 2004, 5, 570-589. doi:10.1002/cbic. 200300833 
3. Berger, R.; Resnati, G.; Metrangolo, P.; Weber, E.; Hulliger, J. Chem. Soc. Rev. 2011, 40, 3496-3508. doi:10.1039/c0cs00221f

4. Inoue, M.; Sumii, Y.; Shibata, N. ACS Omega 2020, 5, 10633-10640. doi:10.1021/acsomega.0c00830

5. Mei, H.; Remete, A. M.; Zou, Y.; Moriwaki, H.; Fustero, S.; Kiss, L.; Soloshonok, V. A.; Han, J. Chin. Chem. Lett. 2020, 31, 2401-2413. doi:10.1016/j.cclet.2020.03.050

6. Ogawa, Y.; Tokunaga, E.; Kobayashi, O.; Hirai, K.; Shibata, N. iScience 2020, 23, 101467. doi:10.1016/j.isci.2020.101467

7. Uneyama, K., Ed. Organofluorine Chemistry; Blackwell Publishing: Oxford, United Kingdom, 2006. doi:10.1002/9780470988589

8. Ramachandran, P. V. Future Med. Chem. 2009, 1, 771-772. doi: $10.4155 /$ fmc.09.67

9. Harper, D. B.; O'Hagan, D. Nat. Prod. Rep. 1994, 11, 123-133. doi:10.1039/np9941100123

10. Schlosser, M.; Heinz, G. Chem. Ber. 1969, 102, 1944-1953. doi:10.1002/cber.19691020620

11. Barton, D. H. R. Pure Appl. Chem. 1977, 49, 1241-1249. doi:10.1351/pac197749091241

12. Appelman, E. H.; Basile, L. J.; Thompson, R. C. J. Am. Chem. Soc. 1979, 101, 3384-3385. doi:10.1021/ja00506a046

13. Rozen, S.; Lerman, O. J. Am. Chem. Soc. 1979, 101, 2782-2784. doi:10.1021/ja00504a073

14. Rozen, S.; Lerman, O.; Kol, M.; Hebel, D. J. Org. Chem. 1985, 50, 4753-4758. doi:10.1021/jo00224a019

15. Filler, R. Isr. J. Chem. 1978, 17, 71-79. doi:10.1002/ijch.197800010

16. Banks, R. E.; Williamson, G. E. Chem. Ind. (London) 1964, 1864-1865.

17. Banks, R. E.; Cheng, W. M.; Haszeldine, R. N. J. Chem. Soc. 1962, 3407-3416. doi:10.1039/jr9620003407

18. Banks, R. E.; Ginsberg, A. E.; Haszeldine, R. N. J. Chem. Soc. 1961, 1740-1743. doi:10.1039/jr9610001740

19. Banks, R. E.; Haszeldine, R. N.; Hatton, R. Tetrahedron Lett. 1967, 8, 3993-3996. doi:10.1016/s0040-4039(01)89722-7

20. Polishchuk, V. R.; German, L. S. Tetrahedron Lett. 1972, 13, 5169-5172. doi:10.1016/s0040-4039(01)85198-4

21. Banks, R. E.; Tsiliopoulos, E. J. Fluorine Chem. 1986, 34, 281-285. doi:10.1016/s0022-1139(00)85081-2

22. Banks, R. E.; Murtagh, V.; Tsiliopoulos, E. J. Fluorine Chem. 1991, 52, 389-401. doi:10.1016/s0022-1139(00)80353-x

23. Yagupols'kii, Y. L.; Savina, T. I. J. Org. Chem. USSR 1981, 17, 1180-1181.

24. Purrington, S. T.; Jones, W. A. J. Org. Chem. 1983, 48, 761-762. doi:10.1021/j000153a037

25. Purrington, S. T.; Jones, W. A. J. Fluorine Chem. 1984, 26, 43-46. doi:10.1016/s0022-1139(00)85117-9

26. Barnette, W. E. J. Am. Chem. Soc. 1984, 106, 452-454. doi:10.1021/ja00314a050

27. Lee, S. H.; Schwartz, J. J. Am. Chem. Soc. 1986, 108, 2445-2447. doi:10.1021/ja00269a052

28. Umemoto, T.; Tomita, K. Tetrahedron Lett. 1986, 27, 3271-3274. doi:10.1016/s0040-4039(00)84772-3

29. Umemoto, T.; Kawada, K.; Tomita, K. Tetrahedron Lett. 1986, 27 , 4465-4468. doi:10.1016/s0040-4039(00)84980-1

30. Umemoto, T.; Tomizawa, G. Bull. Chem. Soc. Jpn. 1986, 59, 3625-3629. doi:10.1246/bcsj.59.3625

31. Umemoto, T.; Tomita, K.; Kawada, K. Org. Synth. 1990, 69, 129-140. doi:10.15227/orgsyn.069.0129
32. Umemoto, T.; Fukami, S.; Tomizawa, G.; Harasawa, K.; Kawada, K.; Tomita, K. J. Am. Chem. Soc. 1990, 112, 8563-8575. doi:10.1021/ja00179a047

33. Umemoto, T.; Harasawa, K.; Tomizawa, G.; Kawada, K.; Tomita, K. Bull. Chem. Soc. Jpn. 1991, 64, 1081-1092. doi:10.1246/bcsj.64.1081

34. Umemoto, T.; Harasawa, K.; Tomizawa, G.; Kawada, K.; Tomita, K. J. Fluorine Chem. 1991, 53, 369-377. doi:10.1016/s0022-1139(00)80960-4

35. Meinert, H. Z. Chem. 1965, 5, 64. doi:10.1002/zfch.19650050208

36. Umemoto, T.; Tomita, K. N-Fluoropyridinium salt-containing polymer. Jpn. Kokai Tokkyo Koho S63-295610, Dec 2, 1988.

37. Nukui, K.; Kamiya, K. Production method of $N$-fluoropyridinium salts. Jpn. Patent 3038065, May 8, 2000.

38. Fukami, S.; Nukui, K.; Kawada, K. Production method of $\mathrm{N}$-fluoropyridinium tetrafluoroborate. Jpn. Kokai Tokkyo Koho H09-255657, Sept 30, 1997.

39. Kawada, K. N-Fluoropyridinium Salt Fluorination for Preparing Aryl Fluorides. In Fluorination; Hu, J.; Umemoto, T., Eds.; Springer: Singapore, 2020. doi:10.1007/978-981-10-1855-8_40-2

40. Naruta, Y.; Tani, F.; Maruyama, K. Tetrahedron Lett. 1992, 33, 1069-1072. doi:10.1016/s0040-4039(00)91863-x

41. Poss, A. J.; Van der Puy, M.; Nalewajek, D.; Shia, G. A.; Wagner, W. J.; Frenette, R. L. J. Org. Chem. 1991, 56, 5962-5964. doi:10.1021/jo00020a051

42. Banks, R. E.; Mohialdin-Khaffaf, S. N.; Lal, G. S.; Sharif, I.; Syvret, R. G. J. Chem. Soc., Chem. Commun. 1992, 595-596. doi:10.1039/c39920000595

43. Banks, R. E.; Du Boisson, R. A.; Tsiliopoulos, E. J. Fluorine Chem. 1986, 32, 461-466. doi:10.1016/s0022-1139(00)81953-3

44. Banks, R. E.; Du Boisson, R. A.; Morton, W. D.; Tsiliopoulos, E. J. Chem. Soc., Perkin Trans. 1 1988, 2805-2811. doi:10.1039/p19880002805

45. Singh, S.; DesMarteau, D. D.; Zuberi, S. S.; Witz, M.; Huang, H.-N. J. Am. Chem. Soc. 1987, 109, 7194-7196. doi:10.1021/ja00257a051

46. Resnati, G.; DesMarteau, D. D. J. Org. Chem. 1991, 56, 4925-4929. doi:10.1021/jo00016a022

47. Xu, Z.-Q.; DesMarteau, D. D.; Gotoh, Y. J. Chem. Soc., Chem. Commun. 1991, 179-181. doi:10.1039/c39910000179

48. DesMarteau, D. D.; Xu, Z.-Q.; Witz, M. J. Org. Chem. 1992, 57, 629-635. doi:10.1021/jo00028a042

49. Pennington, W. T.; Resnati, G.; DesMarteau, D. D. J. Org. Chem. 1992, 57, 1536-1539. doi:10.1021/jo00031a038

50. Banks, R. E.; Sharif, I. J. Fluorine Chem. 1988, 41, 297-300. doi:10.1016/s0022-1139(00)81553-5

51. Banks, R. E.; Sharif, I. J. Fluorine Chem. 1991, 55, 207-214. doi:10.1016/s0022-1139(00)80123-2

52. Differding, E.; Lang, R. W. Tetrahedron Lett. 1988, 29, 6087-6090. doi:10.1016/s0040-4039(00)82271-6

53. Differding, E.; Lang, R. W. Helv. Chim. Acta 1989, 72, 1248-1252. doi:10.1002/hlca.19890720609

54. Banks, R. E.; Khazaei, A. J. Fluorine Chem. 1990, 46, 297-305. doi:10.1016/s0022-1139(00)80997-5

55. Satyamurthy, N.; Bida, G. T.; Phelps, M. E.; Barrio, J. R. J. Org. Chem. 1990, 55, 3373-3374. doi:10.1021/jo00297a071

56. Grakauskas, V.; Baum, K. J. Org. Chem. 1970, 35, 1545-1549. doi:10.1021/jo00830a061

57. Davis, F. A.; Han, W. Tetrahedron Lett. 1991, 32, 1631-1634. doi:10.1016/s0040-4039(00)74290-0 
58. Davis, F. A.; Han, W.; Murphy, C. K. J. Org. Chem. 1995, 60, 4730-4737. doi:10.1021/jo00120a014

59. Differding, E.; Ofner, H. Synlett 1991, 187-189. doi:10.1055/s-1991-20673

60. Gakh, A. A.; Romaniko, S. V.; Ugrak, B. I.; Fainzilberg, A. A. Tetrahedron 1991, 47, 7447-7458. doi:10.1016/s0040-4020(01)89746-5

61. Banks, R. E.; Lawrence, N. J.; Popplewell, A. L. J. Chem. Soc., Chem. Commun. 1994, 343-344. doi:10.1039/c39940000343

62. Abdul-Ghani, M.; Banks, E. R.; Besheesh, M. K.; Sharif, I.; Syvret, R. G. J. Fluorine Chem. 1995, 73, 255-257. doi:10.1016/0022-1139(94)03225-o

63. Banks, R. E.; Besheesh, M. K.; Mohialdin-Khaffaf, S. N.; Sharif, I. J. Chem. Soc., Perkin Trans. 1 1996, 2069-2076. doi:10.1039/p19960002069

64. Banks, R. E.; Besheesh, M. K.; Mohialdin-Khaffaf, S. N.; Sharif, I. J. Fluorine Chem. 1996, 78, 43-50. doi:10.1016/0022-1139(96)03395-7

65. Lal, G. S. J. Org. Chem. 1993, 58, 2791-2796. doi:10.1021/jo00062a023

66. Stavber, S.; Sotler, T.; Zupan, M. Tetrahedron Lett. 1994, 35 , 1105-1108. doi:10.1016/s0040-4039(00)79977-1

67. Lal, G. S. Synth. Commun. 1995, 25, 725-737. doi:10.1080/00397919508011410

68. Brown, D. S.; Marples, B. A.; Smith, P.; Walton, L. Tetrahedron 1995, 51, 3587-3606. doi:10.1016/0040-4020(95)00075-j

69. Lal, G. S.; Pastore, W.; Pesaresi, R. J. Org. Chem. 1995, 60, 7340-7342. doi:10.1021/jo00127a046

70. Zupan, M.; Iskra, J.; Stavber, S. J. Org. Chem. 1995, 60, 259-260. doi:10.1021/jo00106a045

71. Brunavs, M.; Dell, C. P.; Owton, W. M. J. Fluorine Chem. 1994, 68, 201-203. doi:10.1016/0022-1139(93)03042-k

72. Matthews, D. P.; Miller, S. C.; Jarvi, E. T.; Sabol, J. S.; McCarthy, J. R. Tetrahedron Lett. 1993, 34, 3057-3060. doi:10.1016/s0040-4039(00)93378-1

73. Hodson, H. F.; Madge, D. J.; Slawin, A. N. Z.; Widdowson, D. A.; Williams, D. J. Tetrahedron 1994, 50, 1899-1906. doi:10.1016/s0040-4020(01)80862-0

74. McClinton, M. A.; Sik, V. J. Chem. Soc., Perkin Trans. 11992 , 1891-1895. doi:10.1039/p19920001891

75. Davis, F. A.; Zhou, P.; Murphy, C. K. Tetrahedron Lett. 1993, 34 , 3971-3974. doi:10.1016/s0040-4039(00)60592-0

76. Umemoto, T.; Tomizawa, G. J. Org. Chem. 1995, 60, 6563-6570. doi:10.1021/jo00125a049

77. MEC Reagents: Fluorinating agents and Perfluoroalkylating agents; Daikin Chemical Sales company Brochure, 1997.

78. Poss, A. J.; Shia, G.

1-Substituted-4-fluoro-1,4-diazoniabicyclo[2.2.2]octane salts and their application as fluorinating agents. U.S. Patent US5,459,267, Oct 17, 1995.

79. Stavber, S.; Zupan, M. Tetrahedron Lett. 1996, 37, 3591-3594. doi:10.1016/0040-4039(96)00630-2

80. Poss, A. J.; Shia, G. A. Tetrahedron Lett. 1999, 40, 2673-2676. doi:10.1016/s0040-4039(99)00303-2

81. Cabrera, I.; Appel, W. K. Tetrahedron 1995, 51, 10205-10208. doi:10.1016/0040-4020(95)00597-2

82. Banks, R. E.; Besheesh, M. K.; Tsiliopoulos, E. J. Fluorine Chem. 1996, 78, 39-42. doi:10.1016/0022-1139(95)03380-7
83. Umemoto, T.; Nagayoshi, M. Bull. Chem. Soc. Jpn. 1996, 69, 2287-2295. doi:10.1246/bcsj.69.2287

84. Banks, R. E.; Besheesh, M. K. J. Fluorine Chem. 1995, 74, 165-166. doi:10.1016/0022-1139(95)03295-o

85. Banks, R. E.; Besheesh, M. K.; Mohialdin-Khaffaf, S. N.; Sharif, I. J. Fluorine Chem. 1997, 81, 157-161. doi:10.1016/s0022-1139(96)03521-x

86. Umemoto, T.; Nagayoshi, M.; Adachi, K.; Tomizawa, G. J. Org. Chem. 1998, 63, 3379-3385. doi:10.1021/j0972338q

87. Laali, K. K.; Tanaka, M.; Forohar, F.; Cheng, M.; Fetzer, J. C. J. Fluorine Chem. 1998, 91, 185-190. doi:10.1016/s0022-1139(98)00224-3

88. Forohar, F.; Damavarapu, R.; Jayasuriya, K.; Kwok, T. J. 13th Winter Fluorine Conference; St. Petersburg, Florida, USA, 1997; p 39.

89. Banks, R. E.; Besheesh, M. K.; Lawrence, N. J.; Tovell, D. J. J. Fluorine Chem. 1999, 97, 79-84. doi:10.1016/s0022-1139(99)00032-9

90. Takeuchi, Y.; Liu, Z.; Suzuki, E.; Shibata, N.; Kirk, K. L. J. Fluorine Chem. 1999, 97, 65-67. doi:10.1016/s0022-1139(99)00028-7

91. Takeuchi, Y.; Suzuki, T.; Satoh, A.; Shiragami, T.; Shibata, N. J. Org. Chem. 1999, 64, 5708-5711. doi:10.1021/j09904011

92. Takeuchi, Y.; Satoh, A.; Suzuki, T.; Kameda, A.; Dohrin, M.; Satoh, T.; Koizumi, T.; Kirk, K. L. Chem. Pharm. Bull. 1997, 45, 1085-1088. doi:10.1248/cpb.45.1085

93. Shibata, N.; Liu, Z.; Takeuchi, Y. Chem. Pharm. Bull. 2000, 48, 1954-1958. doi:10.1248/cpb.48.1954

94. Liu, Z.; Shibata, N.; Takeuchi, Y. J. Org. Chem. 2000, 65, 7583-7587. doi:10.1021/j00055584

95. Shibata, N.; Suzuki, E.; Takeuchi, Y. J. Am. Chem. Soc. 2000, 122, 10728-10729. doi:10.1021/ja002732x

96. Shibata, N.; Suzuki, E.; Asahi, T.; Shiro, M. J. Am. Chem. Soc. 2001, 123, 7001-7009. doi:10.1021/ja010789t

97. Cahard, D.; Audouard, C.; Plaquevent, J.-C.; Roques, N. Org. Lett. 2000, 2, 3699-3701. doi:10.1021/ol006610l

98. Cahard, D.; Audouard, C.; Plaquevent, J.-C.; Toupet, L.; Roques, N. Tetrahedron Lett. 2001, 42, 1867-1869. doi:10.1016/s0040-4039(01)00017-x

99. Baudequin, C.; Loubassou, J.-F.; Plaquevent, J.-C.; Cahard, D. J. Fluorine Chem. 2003, 122, 189-193. doi:10.1016/s0022-1139(03)00085-x

100.Banks, R. E.; Besheesh, M. K.; Fraenk, W.; Klapötke, T. M. J. Fluorine Chem. 2003, 124, 229-232. doi:10.1016/j.jfluchem.2003.08.010

101.Schleyer, P. v. R.; Buzek, P.; Klapötke, T. M.; Tornieporth-Oetting, I. C.; Broschag, M.; Pickardt, J. Inorg. Chem. 1993, 32, 1523-1524. doi:10.1021/ic00060a033

102. Yasui, H.; Yamamoto, T.; Ishimaru, T.; Fukuzumi, T.; Tokunaga, E.; Akikazu, K.; Shiro, M.; Shibata, N. J. Fluorine Chem. 2011, 132, 222-225. doi:10.1016/j.jluchem.2011.01.005

103.Chen, G.; Chen, F.; Zhang, Y.; Yang, X.; Yuan, X.; Wu, F.; Yang, X. J. Fluorine Chem. 2012, 133, 155-159. doi:10.1016/j.jfluchem.2011.10.012

104.Zhang, Y.; Yang, X.-J.; Xie, T.; Chen, G.-L.; Zhu, W.-H.; Zhang, X.-Q.; Yang, X.-Y.; Wu, X.-Y.; He, X.-P.; He, H.-M. Tetrahedron 2013, 69, 4933-4937. doi:10.1016/j.tet.2013.04.037

105.Wang, F.; Li, J.; Hu, Q.; Yang, X.; Wu, X.-Y.; He, H. Eur. J. Org. Chem. 2014, 3607-3613. doi:10.1002/ejoc.201402072 
106. Shunatona, H. P.; Früh, N.; Wang, Y.-M.; Rauniyar, V.; Toste, F. D. Angew. Chem., Int. Ed. 2013, 52, 7724-7727. doi:10.1002/anie.201302002

107. Wolstenhulme, J. R.; Rosenqvist, J.; Lozano, O.; llupeju, J.; Wurz, N.; Engle, K. M.; Pidgeon, G. W.; Moore, P. R.; Sandford, G.; Gouverneur, V. Angew. Chem., Int. Ed. 2013, 52, 9796-9800. doi:10.1002/anie.201304845

108.Zhu, C.-L.; Maeno, M.; Zhang, F.-G.; Shigehiro, T.; Kagawa, T.; Kawada, K.; Shibata, N.; Ma, J.-A.; Cahard, D. Eur. J. Org. Chem. 2013, 6501-6505. doi:10.1002/ejoc.201300956

109. Ratjen, L.; García-García, P.; Lay, F.; Beck, M. E.; List, B. Angew. Chem., Int. Ed. 2011, 50, 754-758. doi:10.1002/anie.201005954

110. Treskow, M.; Neudörfl, J.; Giernoth, R. Eur. J. Org. Chem. 2009, 3693-3697. doi:10.1002/ejoc.200900548

111.Fukushi, K.; Suzuki, S.; Kamo, T.; Tokunaga, E.; Sumii, Y.; Kagawa, T.; Kawada, K.; Shibata, N. Green Chem. 2016, 18 , 1864-1868. doi:10.1039/c5gc02612a

112.Bohlmann, R. N-Fluorosulfonimides, process for their production, as well as their use as fluorinating agents. WO Patent WO94/24098, Oct 27, 1994.

113.Pereira, R.; Wolstenhulme, J.; Sandford, G.; Claridge, T. D. W.; Gouverneur, V.; Cvengroš, J. Chem. Commun. 2016, 52, 1606-1609. doi:10.1039/c5cc08375c

114.Chen, C.; Luo, Y.; Fu, L.; Chen, P.; Lan, Y.; Liu, G. J. Am. Chem. Soc. 2018, 140, 1207-1210. doi:10.1021/jacs.7b11470

115. Meyer, D.; Jangra, H.; Walther, F.; Zipse, H.; Renaud, P. Nat. Commun. 2018, 9, 4888. doi:10.1038/s41467-018-07196-9

116. Hachisuka, H.; Kitano, M. J. Fluorine Chem. 1991, 54, 205. doi:10.1016/s0022-1139(00)83715-x

117. Kitano, M.; Hachisuka, H.; Umemoto, T. 16th National Meeting on Fluorine Chemistry, Oct 21, 1991; Nagoya, Japan; pp 101-102.

118. Sudlow, K.; Woolf, A. A. J. Fluorine Chem. 1994, 66, 9-11. doi:10.1016/0022-1139(93)02929-9

119.Solkan, V. N.; Fainzil'berg, A. A. Russ. J. Org. Chem. 1994, 30, 1200.

120. Fainzil'berg, A. A.; Faustov, V. I. Russ. J. Org. Chem. 2001, 37, 755-756. doi:10.1023/a:1012436925944

121. Gilicinski, A. G.; Pez, G. P.; Syvret, R. G.; Lal, G. S. J. Fluorine Chem. 1992, 59, 157-162. doi:10.1016/s0022-1139(00)80214-6

122.Differding, E.; Bersier, P. M. Tetrahedron 1992, 48, 1595-1604. doi:10.1016/s0040-4020(01)88718-4

123. Oliver, E. W.; Evans, D. H. J. Electroanal. Chem. 1999, 474, 1-8. doi:10.1016/s0022-0728(99)00296-x

124. Adachi, K.; Takahashi, I.; Harada, M.; Umemoto, T. J. Fluorine Chem. 2016, 183, 100-111. doi:10.1016/j.jfluchem.2015.09.013

125. Toullec, P. Y.; Devillers, I.; Frantz, R.; Togni, A. Helv. Chim. Acta 2004, 87, 2706-2711. doi:10.1002/hlca.200490240

126.Xue, X.-S.; Wang, Y.; Li, M.; Cheng, J.-P. J. Org. Chem. 2016, 81, 4280-4289. doi:10.1021/acs.joc.6b00683

127.Li, M.; Xue, X.-S.; Cheng, J.-P. Acc. Chem. Res. 2020, 53, 182-197. doi:10.1021/acs.accounts.9b00393

128. Christe, K. O.; Dixon, D. A. J. Am. Chem. Soc. 1992, 114, 2978-2985. doi:10.1021/ja00034a033

129. Rueda-Becerril, M.; Chatalova Sazepin, C.; Leung, J. C. T.; Okbinoglu, T.; Kennepohl, P.; Paquin, J.-F.; Sammis, G. M. J. Am. Chem. Soc. 2012, 134, 4026-4029. doi:10.1021/ja211679v

130.Sibi, M. P.; Landais, Y. Angew. Chem., Int. Ed. 2013, 52, 3570-3572. doi:10.1002/anie.201209583

131.Shigehisa, H.; Aoki, T.; Yamaguchi, S.; Shimizu, N.; Hiroya, K. J. Am. Chem. Soc. 2013, 135, 10306-10309. doi:10.1021/ja405219f
132. Shigehisa, H.; Nishi, E.; Fujisawa, M.; Hiroya, K. Org. Lett. 2013, 15, 5158-5161. doi:10.1021/ol402696h

133. Chatalova-Sazepin, C.; Hemelaere, R.; Paquin, J.-F.; Sammis, G. M. Synthesis 2015, 47, 2554-2569. doi:10.1055/s-0034-1378824

134. Champagne, P. A.; Desroches, J.; Hamel, J.-D.; Vandamme, M.; Paquin, J.-F. Chem. Rev. 2015, 115, 9073-9174. doi:10.1021/cr500706a

135.Szpera, R.; Moseley, D. F. J.; Smith, L. B.; Sterling, A. J.; Gouverneur, V. Angew. Chem., Int. Ed. 2019, 58, 14824-14848. doi:10.1002/anie.201814457

136. Yang, J.-D.; Wang, Y.; Xue, X.-S.; Cheng, J.-P. J. Org. Chem. 2017, 82, 4129-4135. doi:10.1021/acs.joc.7b00036

137. Timofeeva, D. S.; Ofial, A. R.; Mayr, H. J. Am. Chem. Soc. 2018, 140 , 11474-11486. doi:10.1021/jacs.8b07147

138. Rozatian, N.; Ashworth, I. W.; Sandford, G.; Hodgson, D. R. W. Chem. Sci. 2018, 9, 8692-8702. doi:10.1039/c8sc03596b

139. Rozatian, N.; Beeby, A.; Ashworth, I. W.; Sandford, G.; Hodgson, D. R. W. Chem. Sci. 2019, 10, 10318-10330. doi:10.1039/c9sc04185k

140. Rozatian, N.; Harsanyi, A.; Murray, B. J.; Hampton, A. S.; Chin, E. J.; Cook, A. S.; Hodgson, D. R. W.; Sandford, G. Chem. - Eur. J. 2020, 26, 12027-12035. doi:10.1002/chem.202001120

141.Du, X.; Zhang, H.; Yao, Y.; Lu, Y.; Wang, A.; Wang, Y.; Li, Z. Theor. Chem. Acc. 2019, 138, No. 28. doi:10.1007/s00214-019-2417-2

142. Lal, G. S.; Pez, G. P.; Syvret, R. G. Chem. Rev. 1996, 96, 1737-1756 doi:10.1021/cr941145p

143. Lee, K. Y.; Kochi, J. K. J. Chem. Soc., Perkin Trans. 2 1992, 1011-1017. doi:10.1039/p29920001011

144.Bockman, T. M.; Lee, K. Y.; Kochi, J. K. J. Chem. Soc., Perkin Trans. 2 1992, 1581-1594. doi:10.1039/p29920001581

145. Differding, E.; Rüegg, G. M. Tetrahedron Lett. 1991, 32, 3815-3818. doi:10.1016/s0040-4039(00)79383-x

146. Differring, E.; Wehrli, M. Tetrahedron Lett. 1991, 32, 3819-3822. doi:10.1016/s0040-4039(00)79384-1

147.Zupan, M.; Škulj, P.; Stavber, S. Chem. Lett. 1998, 27, 641-642. doi:10.1246/cl.1998.641

148. Vincent, S. P.; Burkart, M. D.; Tsai, C.-Y.; Zhang, Z.; Wong, C.-H. J. Org. Chem. 1999, 64, 5264-5279. doi:10.1021/jo990686h

149. Nyffeler, P. T.; Durón, S. G.; Burkart, M. D.; Vincent, S. P.; Wong, C.-H. Angew. Chem., Int. Ed. 2005, 44, 192-212. doi:10.1002/anie.200400648

150. Piana, S.; Devillers, I.; Togni, A.; Rothlisberger, U. Angew. Chem., Int. Ed. 2002, 41, 979-982. doi:10.1002/1521-3773(20020315)41:6<979::aid-anie979>3.0.co;2-e

151. Laali, K. K.; Borodkin, G. I. J. Chem. Soc., Perkin Trans. 2 2002, 953-957. doi:10.1039/b111725d

152. Kralj, P.; Zupan, M.; Stavber, S. J. Org. Chem. 2006, 71, 3880-3888. doi:10.1021/jo060213s

153. Andreev, R. V.; Borodkin, G. I.; Shubin, V. G. Russ. J. Org. Chem. 2009, 45, 1468-1473. doi:10.1134/s107042800910008x

154.Geng, C.; Du, L.; Liu, F.; Zhu, R.; Liu, C. RSC Adv. 2015, 5, 33385-33391. doi:10.1039/c4ra15202f

155.Chen, Q.; Zeng, J.; Yan, X.; Huang, Y.; Wen, C.; Liu, X.; Zhang, K. J. Org. Chem. 2016, 81, 10043-10048. doi:10.1021/acs.joc.6b01932

156. Li, C.-T.; Yuan, X.; Tang, Z.-Y. Tetrahedron Lett. 2016, 57, 5624-5627. doi:10.1016/j.tetlet.2016.11.003

157.Wu, S.-W.; Liu, F. Org. Lett. 2016, 18, 3642-3645. doi:10.1021/acs.orglett.6b01691 
158.Wu, S.-W.; Liu, J.-L.; Liu, F. Chem. Commun. 2017, 53, 12321-12324. doi:10.1039/c7cc07165e

159.Zhang, Y.; Wen, C.; Li, J. Org. Biomol. Chem. 2018, 16, 1912-1920. doi:10.1039/c7ob03059b

160.Fan, X.; Wang, Q.; Wei, Y.; Shi, M. Chem. Commun. 2018, 54, 10503-10506. doi:10.1039/c8cc05634j

161.Zhou, J.; Fang, Y.; Wang, F.; Li, J. Org. Biomol. Chem. 2019, 17, 4470-4474. doi:10.1039/c9ob00467j

162.Jójárt, R.; Traj, P.; Kovács, É.; Horváth, Á.; Schneider, G.; Szécsi, M.; Pál, A.; Paragi, G.; Mernyák, E. Molecules 2019, 24, 1783. doi:10.3390/molecules24091783

163. Wood, S. H.; Etridge, S.; Kennedy, A. R.; Percy, J. M.; Nelson, D. J. Chem. - Eur. J. 2019, 25, 5574-5585. doi:10.1002/chem.201900029

164.Borodkin, G. I.; Elanov, I. R.; Gatilov, Y. V.; Shubin, V. G. J. Fluorine Chem. 2019, 228, 109412. doi:10.1016/j.jfluchem.2019.109412

165. Rozatian, N.; Hodgson, D. R. W. Chem. Commun. 2021, 57, 683-712. doi:10.1039/d0cc06339h

166. Furin, G. G. In Methods of Organic Chemistry (Houben-Weyl), Organo-fluorine Compounds Vol E10a; Baasner, B.; Hagemann, H.; Tatlow, J. C., Eds.; Thieme: Stuttgart, New York, 1999; pp 432-499.

167.Banks, R. E. J. Fluorine Chem. 1998, 87, 1-17. doi:10.1016/s0022-1139(97)00127-9

168. Singh, R. P.; Shreeve, J. M. Acc. Chem. Res. 2004, 37, 31-44. doi:10.1021/ar030043v

169. Kiselyov, A. S. Chem. Soc. Rev. 2005, 34, 1031-1037. doi:10.1039/b509217p

170.Umemoto, T. N-Fluoropyridinium Salts, Synthesis and Fluorination Chemistry. In Advances in Organic Synthesis; Laali, K. K., Ed.; Bentham Science Publishers Ltd.: Netherlands, 2006; Vol. 2, pp 159-181. doi:10.2174/978160805198410602010159

171. Umemoto, T. Preparation, Reactivity, and Applications of N-Fluoropyridinium Salts. In Fluorinated Heterocycles; Gakh, A. A.; Kirk, K. L., Eds.; ACS Symposium Series, Vol. 1003; American Chemical Society: Washington, DC, USA, 2009; pp 37-58. doi:10.1021/bk-2009-1003.ch003

172.Baudoux, J.; Cahard, D. Electrophilic Fluorination with N-F Reagents. In Organic Reactions; Denmark, S. E., Ed.; John Wiley \& Sons, 2008; pp 347-672. doi:10.1002/0471264180.or069.02

173.de Azambuja, F.; Altman, R. A. NFSI and Its Analogs Fluorination for Preparing Alkenyl Fluorides. In Fluorination; Hu, J.; Umemoto, T., Eds.; Springer: Singapore, 2018. doi:10.1007/978-981-10-1855-8_20-1

174. Yan, H.; Zhu, C. NFSI Radical Fluorination for Preparing Alkyl Fluorides. In Fluorination; Hu, J.; Umemoto, T., Eds.; Springer: Singapore, 2018. doi:10.1007/978-981-10-1855-8_1-1

175.Guyon, H.; Cahard, D. Selectfluor and Its Analogs Electrophilic Fluorination for Preparing Alkyl Fluorides. In Fluorination; Hu, J.; Umemoto, T., Eds.; Springer: Singapore, 2018. doi:10.1007/978-981-10-1855-8_8-1

176. de Azambuja, F.; Altman, R. A. SelectFluor and Its Analogs Fluorination for Preparing Alkenyl Fluorides. In Fluorination; Hu, J.; Umemoto, T., Eds.; Springer: Singapore, 2018. doi:10.1007/978-981-10-1855-8_19-1

177. Yan, H.; Zhu, C. SelectFluor Radical Fluorination for Preparing Alkyl Fluorides. In Fluorination; Hu, J.; Umemoto, T., Eds.; Springer: Singapore, 2018. doi:10.1007/978-981-10-1855-8_2-1
178. Chen, C.; Chen, P.; Liu, G.

$N, N^{\prime}$-Difluoro-1,4-Diazoniabicyclo[2.2.2]octane Salt Electrophilic Fluorination. In Fluorination; Hu, J.; Umemoto, T., Eds.; Springer: Singapore, 2018. doi:10.1007/978-981-10-1855-8_47-1

179. Kawada, K. N-Fluoropyridinium Salt Electrophilic Fluorination for Preparing Alkyl Fluorides. In Fluorination; Hu, J.; Umemoto, T., Eds.; Springer: Singapore, 2018. doi:10.1007/978-981-10-1855-8_21-2

180. Kawada, K. N-Fluoropyridinium Salt Radical Fluorination for Preparing Alkyl Fluorides. In Fluorination; Hu, J.; Umemoto, T., Eds.; Springer: Singapore, 2018. doi:10.1007/978-981-10-1855-8_41-1

181.Wang, G.; Ma, J.-A. NFSI and Its Analogs Electrophilic Fluorination for Preparing Alkyl Fluorides. In Fluorination; Hu, J.; Umemoto, T., Eds.; Springer: Singapore, 2018. doi:10.1007/978-981-10-1855-8_6-1

\section{License and Terms}

This is an Open Access article under the terms of the Creative Commons Attribution License (https://creativecommons.org/licenses/by/4.0). Please note that the reuse, redistribution and reproduction in particular requires that the author(s) and source are credited and that individual graphics may be subject to special legal provisions.

The license is subject to the Beilstein Journal of Organic Chemistry terms and conditions: (https://www.beilstein-journals.org/bjoc/terms)

The definitive version of this article is the electronic one which can be found at: https://doi.org/10.3762/bjoc.17.123 